Aus der Abteilung Humangenetik

(Prof. Dr. med. W. Engel)

im Zentrum Hygiene und Humangenetik

der Medizinischen Fakultät der Universität Göttingen

\title{
Molekulare Charakterisierung von ZFYVE27 und Identifizierung von Deletionen in SPG4
}

\author{
INAUGURAL-DISSERTATION
}

zur Erlangung des Doktorgrades

der Medizinischen Fakultät

der Georg-August-Universität zu Göttingen

vorgelegt von

Philip Lars Krawen

aus Bremerhaven

Göttingen 2009 
Dekan: Prof. Dr. med. C. Frömmel

I. Berichterstatter: PD Dr. rer. nat. J. Neesen

II. Berichterstatter/in: PD Dr. med. Schmidt

III. Berichterstatter/in: PD Dr. med, Dr. rer. nat. Crozier

Tag der mündlichen Prüfung: 05.05.2010 
1. Einleitung 3

1.1 Die hereditären spastischen Paraplegien 3

$\begin{array}{lll}1.2 & \text { Klinisches Bild }\end{array}$

1.3 Genetik der HSP 4

$\begin{array}{lll}1.4 & \text { ZFYVE27 } & 7\end{array}$

$\begin{array}{lll}1.5 & \text { Ziele dieser Arbeit } & 7\end{array}$

2. Material und Methoden 8

$\begin{array}{llr}2.1 & \text { Material } & 8\end{array}$

$\begin{array}{llr}2.1 .1 & \text { Bakterienstämme } & 8\end{array}$

$\begin{array}{lll}\text { 2.1.2 Oligonukleotide } & 8\end{array}$

2.1.2.1 ZFYVE27-Primer 8

$\begin{array}{lll}\text { 2.1.2.2 SPG4-Primer } & 10\end{array}$

$\begin{array}{lll}2.1 .3 & \text { Antikörper } & 11\end{array}$

$\begin{array}{lll}2.1 .4 & \text { Vektoren } & 11\end{array}$

$\begin{array}{lll}2.1 .5 & \text { Chemikalien } & 11\end{array}$

$\begin{array}{lll}\text { 2.1.6 Gebrauchswaren } & 13\end{array}$

$\begin{array}{lll}2.1 .7 & \text { Geräte } & 14\end{array}$

$\begin{array}{lll}\text { 2.1.8 Gebrauchsfertige Reaktionssysteme } & 14\end{array}$

$\begin{array}{lll}\text { 2.1.9 Puffer und Lösungen } & 15\end{array}$

$\begin{array}{lll}2.1 .10 & \text { Kulturmedien } & 16\end{array}$

$\begin{array}{lll}2.1 .11 & \text { Sterilisation } & 17\end{array}$

$\begin{array}{lll}2.1 .12 & \text { Datenbanken } & 17\end{array}$

$\begin{array}{lll}2.1 .13 & \text { Patientenproben } & 17\end{array}$ 
$\begin{array}{llr}2.2 & \text { Methoden } & 18\end{array}$

$\begin{array}{ll}\text { 2.2.1 Lagerung und Vermehrung von E. coli } & 18\end{array}$

$\begin{array}{ll}\text { 2.2.2 Konzentrationsbestimmung } & 18\end{array}$

2.2.2.1 Konzentrationsbestimmung von genomischer DNA mit dem FL-800 Mikroplate Fluoreszenz Reader

2.2.2.2 Konzentrationsbestimmung von genomischer DNA mit dem Eppendorf BioPhotometer

$\begin{array}{ll}\text { 2.2.3 Nukleinsäurepräparation } & 19\end{array}$

2.2.3.1 Isolierung von RNA aus Blut mit dem PAXGene Blood RNA Kit 19

2.2.3.2 Isolierung von RNA aus EDTA-Blutproben nach abgeändertem Protokoll des Purescript Kits von Gentra

2.2.3.3 Isolierung von Plasmid-DNA aus E. coli im analytischen Maßstab (Methode nach Birnboim und Doly 1979)

2.2.3.4 Isolierung von Plasmid-DNA aus E. coli im präparativen Maßstab 21

2.2.3.5 Isolierung von DNA-Fragmenten aus Agarosegelen 22

2.2.3.6 Aufreinigung von PCR-Produkten über Millipore-Säulen 23

$\begin{array}{lll}\text { 2.2.3.7 Ethanolfällung } & 23\end{array}$

2.2.4 Enzymatische Modifikation von Nukleinsäuren 23

2.2.4.1 Restriktionsenzymatische Spaltung 23

$\begin{array}{ll}\text { 2.2.4.2 Ligation von DNA-Fragmenten } & 24\end{array}$

2.2.5 Radioaktive Markierung von Nukleinsäuren 24

2.2.6 Methoden der Polymerase-Kettenreaktion 25

2.2.6.1 PCR an Plasmid-DNA 25

2.2.6.2 PCR an genomischer DNA 26

$\begin{array}{lll}2.2 .6 .3 & \text { RT-PCR } & 26\end{array}$

$\begin{array}{ll}2.2 .6 .4 \text { „Nested“-PCR } & 27\end{array}$

2.2.6.5 „Long Range”-PCR 28

$\begin{array}{lll}2.2 .6 .6 & \text { Sequenzanalyse } & 28\end{array}$

2.2.7 Standard-Agarosegelelektrophorese 29

$\begin{array}{lll}2.2 .8 & \text { Zellkulturtechniken } & 30\end{array}$ 
$\begin{array}{lll}\text { 2.2.8.1 Kultivierung von HeLa-Zellen } & 30\end{array}$

2.2.8.2 Transfektion von HeLa-Zellen 30

2.2.8.3 Analyse von Fusionsproteinen $\quad 31$

2.2.8.4 Immunfluoreszenzfärbung von HeLa-Zellen 32

2.2.9 Southernblot 32

2.2.10 Hybridisierung mit radioaktiv markierten Sonden 32

2.2.11 Deletionsdetektion mittels quantitativer Real-Time-PCR 33

$\begin{array}{ll}\text { 3. } & \text { Ergebnisse }\end{array}$

$\begin{array}{lll}3.1 & \text { Sequenzierung von ZFYVE27 } & 38\end{array}$

3.1.1 Identifizierung der Exon/Intron-Grenzen und Amplifikation der Exons 38

3.1.2 Sequenzveränderungen im ZFYVE27-Gen 39

3.2 Expression des ZFYVE27-Gens 41

3.2.1 Analyse der Expression des ZFYVE27-Gens auf RNA-Ebene beim Menschen $\quad 42$

3.2.2 Klonierung der menschlichen ZFYVE27-cDNA 44

3.2.3 Analyse der Expression des Zfyve27-Gens auf RNA-Ebene

$\begin{array}{lll}3.3 & \text { Co-Immunlokalisation } & 49\end{array}$

3.3.1 Immunfluoreszenz-Analyse von ZFYVE27 in HeLa-Zellen 49

3.3.2 Generierung von ZFYVE27-cDNA(c.572G>T) 53

3.3.3 Immunfluoreszenz-Analyse von ZFYVE27(p.G191V) in HeLa-
Zellen

3.4 Deletionssuche im SPG4-Gen mit Hilfe der Real-Time-PCR 56

3.4.1 Ergebnisse der Real-Time-PCR-Untersuchung 56

3.4.2 “Long-Range”-PCR 59

$\begin{array}{lll}3.4 .3 & \text { RT-PCR } & 60\end{array}$

$\begin{array}{lll}3.4 .4 & \text { Southernblot } & 61\end{array}$ 
$\begin{array}{ll}\text { 4. Diskussion } & 63\end{array}$

$\begin{array}{lll}\text { 4.1 } & \text { Problemstellung } & 63\end{array}$

$\begin{array}{lll}4.2 & \text { ZFYVE27 }\end{array}$

$\begin{array}{lll}\text { 4.2.1 } & \text { FYVE-Finger-Proteinfamilie } & 64\end{array}$

$\begin{array}{lll}\text { 4.2.1.1 EEA1 } & 67\end{array}$

$\begin{array}{lll}\text { 4.2.1.2 PIKfyve / Fablp } & 68\end{array}$

$\begin{array}{lll}\text { 4.2.1.3 Hrs/Vps27p } & 68\end{array}$

4.2.1.4 Frabin, Fgd1-3 / YOTB 69

$\begin{array}{lll}\text { 4.2.1.5 SARA / Endofin } & 69\end{array}$

$\begin{array}{ll}\text { 4.2.2 Eigenschaften von ZFYVE27 } & 70\end{array}$

4.2.2.1 Expression in Homo sapiens und Mus musculus 70

4.2.2.2 Intrazelluläre Lokalisation 71

4.2.2.3 Struktureller Aufbau und Funktion 72

$\begin{array}{lll}\text { 4.2.3 Mutationsanalyse von AD-HSP-Patienten } & 74\end{array}$

$\begin{array}{lll}\text { 4.3 Deletionen in SPG4 } & 79\end{array}$

5. Zusammenfassung 82

6. Literaturverzeichnis 83

$\begin{array}{ll}\text { 7. Anhang } & 91\end{array}$

7.1 cDNA, kodierende Sequenz und Aminosäuresequenz der
menschlichen ZFYVE27-Spleißvarianten

$\begin{array}{lll}\text { 7.1.1 Transcript Variante } 1 & 91\end{array}$

$\begin{array}{lll}\text { 7.1.2 Transcript Variante 2 } & 93\end{array}$

$\begin{array}{lll}\text { 7.1.3 Transcript Variante } 3 & 95\end{array}$

$\begin{array}{lll}\text { 7.1.4 Transcript Variante } 4 & 97\end{array}$

7.2 cDNA, kodierende Sequenz und Aminosäuresequenz von 99

7.3 Ergebnisse der Real-Time-PCR-Messungen 102 


\section{Abkürzungen}

\begin{tabular}{|c|c|}
\hline A & Ampere \\
\hline $\mathrm{Abb}$ & Abbildung \\
\hline $\mathrm{AD}$ & autosomal-dominant \\
\hline AR & autosomal-rezessiv \\
\hline BLAST & engl.: basic local alignment search tool \\
\hline $\mathrm{Bp}$ & Basenpaare \\
\hline${ }^{\circ} \mathrm{C}$ & Grad Celsius \\
\hline cDNA & komplementäre DNA \\
\hline $\mathrm{cm}$ & Zentimeter \\
\hline DEPC & Diethylenpyrocarbonat \\
\hline DNA & Desoxyribonukleinsäure \\
\hline EDTA & Ethylendiamintetraessigsäure \\
\hline et al. & et alii \\
\hline $\mathrm{EtOH}$ & Ethanol \\
\hline g & Gramm \\
\hline $\mathrm{kb}$ & Kilobasenpaare \\
\hline $\mathrm{kDa}$ & Kilodalton \\
\hline KHSP & komplizierte hereditäre spastische Paraplegie \\
\hline 1 & Liter \\
\hline$\mu \mathrm{mol}$ & Mikromol \\
\hline $\mathrm{m}$ & Meter, Milli $\left(10^{-3}\right)$ \\
\hline M & Molar \\
\hline$\mu$ & Mikro $\left(10^{-6}\right)$ \\
\hline $\mathrm{mM}$ & Millimol \\
\hline mRNA & messenger Ribonukleinsäure \\
\hline $\mathrm{NaCl}$ & Natrium-Chlorid \\
\hline NCBI & engl.: National Center for Biotechnology Information \\
\hline PBS & Phosphatgepufferte Salzlösung \\
\hline PCR & Polymerase-Kettenreaktion \\
\hline PHSP & reine hereditäre spastische Paraplegie \\
\hline PI3P & Phosphoinositol-3-Phosphat \\
\hline PI5P & Phosphoinositol-5-Phosphat \\
\hline
\end{tabular}




$\begin{array}{ll}\text { RNA } & \text { Ribonukleinsäure } \\ \text { T } & \text { Temperatur } \\ \text { Upm } & \text { Umdrehungen pro Minute } \\ \text { UTR } & \text { Untranslatierte Region } \\ \text { V } & \text { Volt } \\ \text { Vol } & \text { Volumen } \\ \text { XC } & \text { X-chromosomal }\end{array}$




\section{Einleitung}

\subsection{Die hereditären spastischen Paraplegien}

Die hereditären spastischen Paraplegien (HSP) sind eine klinisch und genetisch heterogene Gruppe erblicher neurodegenerativer Erkrankungen, welche durch eine progrediente spastische Paraparese und Hyperreflexie der unteren Extremitäten gekennzeichnet sind (Behan und Maia 1974). Die ersten Beschreibungen der Erkrankung wurden 1880 und 1893 vom Neurologen Adolf von Strümpell verfasst (Reid 1997), welcher in zwei Familien jeweils mehrere Mitglieder mit progredienter spastischer Paraparese und gesteigerten Muskeleigenreflexen ohne weitere neurologische Symptome gefunden hatte. Im Jahre 1898 stellte Lorrain in seiner Doktorarbeit drei weitere Fälle mit Symptomen der HSP dar, wobei hierbei zum ersten Mal ein Patient mit einer komplizierten Form beschrieben wurde (Bruyn und Scheltens 1991). Die Strümpell-Lorrainsche Erkrankung gilt heute als Synonym für die hereditäre spastische Paraplegie. Aufgrund der vielfältigen Symptome und der teilweise uneinheitlichen diagnostischen Kriterien schwankt die Prävalenz epidemiologischer Studien zu dem Thema zwischen 14/100000 (Skre 1974) und 0,9/100000 (Werdelin 1986) Einwohnern. Beide Geschlechter sind gleich häufig betroffen und können in jedem Alter erkranken, wobei jedoch zwei Häufigkeitsgipfel auszumachen sind: Der erste findet sich vor dem sechsten Lebensjahr, der zweite zwischen dem zweiten und vierten Lebensjahrzehnt. Auf pathologischer Ebene findet sich bei HSP-Erkrankten eine Degeneration der Pyramidenbahnen und der Hinterstränge. Besonders die langen Axone zeigen eine von kaudal aufsteigende Schädigung, während die neuronalen Zellkörper länger erhalten bleiben können (Fink et al. 1996). Da bisher noch keine kausale Therapie existiert, können HSP-Patienten momentan nur symptomatisch mit Physiotherapie und medikamentöser Einstellung der Spastik behandelt werden. Zusätzlich ist eine Versorgung der Patienten mit Hilfsmitteln wichtig, damit sie im Alltag besser zurechtkommen. 


\subsection{Klinisches Bild}

Klinisch werden innerhalb der Gruppe der hereditären spastischen Paraplegien eine unkomplizierte, reine Form und eine komplizierte Form unterschieden. Bei der unkomplizierten Form kommt es typischerweise an den Beinen $\mathrm{zu}$ gesteigerten Muskeleigenreflexen und einer spastischen Tonuserhöhung. Diese tritt vor allem bei Flexion der Hüft-, Knie- und Sprunggelenke auf. Weiterhin finden sich an den Beinen häufig positive Pyramidenbahnzeichen, und es kann zu Muskelschwächen und Paresen kommen. Hierbei sind der M. iliopsoas und der M. tibialis am häufigsten betroffen. Die Störungen führen in vielen Fällen zu einem zirkumduzierenden Gangbild und können bis zur kompletten Immobilisierung fortschreiten. Neben den motorischen Auffälligkeiten kann es bei der reinen Form auch zu einer Störung der Pallästhesie und zu einer Urge-Inkontinenz kommen. Die komplizierte Form kann mit zusätzlichen neurologischen Symptomen wie Demenz, Epilepsie, Ataxie, Sehschwäche, Taubheit, Ichthyosis und mentaler Retardierung einhergehen.

\subsection{Genetik der HSP}

Nach genetischen Gesichtspunkten kann die HSP in autosomal-dominante, autosomal-rezessive und X-chromosomale Formen eingeteilt werden. Der größte Anteil mit 70 bis 80 Prozent der Erkrankungen wird autosomal-dominant vererbt, in 20 Prozent der Fälle liegt ein autosomal-rezessiver Erbgang vor, und in einzelnen Fällen ist eine X-chromosomale Vererbung gegeben. Über Kopplungsanalysen konnten bereits 41 Genloci, die mit der Entstehung der HSP assoziiert sind, identifiziert werden (Salinas et al. 2008). Die meisten der entsprechenden Genprodukte sind aber noch unbekannt. Tabelle 1 gibt eine Übersicht über die HSP-Loci. 


\begin{tabular}{|c|c|c|c|c|}
\hline & Locus & Vererbung & Genprodukt & Phänotyp \\
\hline SPG1 & $\mathrm{Xq} 28$ & $\mathrm{XC}$ & L1-Cam & KHSP, Hydrozephalus \\
\hline SPG2 & $\mathrm{Xq} 22$ & $\mathrm{XC}$ & PLP1 & PHSP, KHSP \\
\hline SPG3A & $14 \mathrm{q} 11-\mathrm{q} 21$ & $\mathrm{AD}$ & Atlastin & PHSP \\
\hline SPG4 & $2 \mathrm{p} 21-22$ & $\mathrm{AD}$ & Spastin & PHSP, KHSP \\
\hline SPG5 & $8 p 12-q 13$ & AR & CYP7B1 & PHSP \\
\hline SPG6 & $15 q 11.1$ & $\mathrm{AD}$ & NIPA1 & PHSP \\
\hline SPG7 & $16 \mathrm{q} 24.3$ & $\mathrm{AR}$ & Paraplegin & PHSP, KHSP \\
\hline SPG8 & $8 \mathrm{q} 23-24$ & $\mathrm{AD}$ & Strumpellin & PHSP \\
\hline SPG9 & $10 \mathrm{q} 23.3-24.1$ & $\mathrm{AD}$ & - & KHSP \\
\hline SPG10 & $12 q 13$ & $\mathrm{AD}$ & KIF5A & PHSP \\
\hline SPG11 & $15 q 13-15$ & AR & Spatacsin & PHSP, KHSP \\
\hline SPG12 & $19 q 13$ & $\mathrm{AD}$ & - & PHSP \\
\hline SPG13 & $2 q 33.1$ & $\mathrm{AD}$ & HSP60 & PHSP \\
\hline SPG14 & $3 \mathrm{q} 27-28$ & $\mathrm{AR}$ & - & KHSP \\
\hline SPG15 & $14 \mathrm{q} 22-24$ & $\mathrm{AD}$ & Spastizin & KHSP, Kjellin-Syndrom \\
\hline SPG16 & Xq11.2 & $\mathrm{XC}$ & - & PHSP, KHSP \\
\hline SPG17 & $11 q 12-14$ & $\mathrm{AD}$ & BSCL2 & KHSP, Silver-Syndrom \\
\hline SPG19 & $9 \mathrm{q} 33-34$ & $\mathrm{AD}$ & - & PHSP \\
\hline SPG20 & $13 q 22.31$ & $\mathrm{AR}$ & Spartin & KHSP, Troyer-Syndrom \\
\hline SPG21 & $15 q 22.31$ & AR & Maspardin & KHSP \\
\hline SPG23 & $1 \mathrm{q} 24-32$ & AR & - & KHSP \\
\hline SPG24 & $13 q 14$ & $\mathrm{AR}$ & - & PHSP \\
\hline SPG25 & $6 \mathrm{q} 23.3-24.1$ & $\mathrm{AR}$ & - & PHSP \\
\hline SPG26 & 12p11.1-q14 & $\mathrm{AR}$ & - & KHSP \\
\hline SPG27 & $10 \mathrm{q} 22.1-\mathrm{q} 24.1$ & $\mathrm{AR}$ & - & KHSP \\
\hline SPG28 & $14 \mathrm{q} 21.3-\mathrm{q} 22.3$ & AR & - & PHSP \\
\hline SPG29 & $1 \mathrm{p} 31-\mathrm{p} 21$ & $\mathrm{AD}$ & - & KHSP \\
\hline SPG30 & $2 q 37$ & $\mathrm{AR}$ & - & PHSP \\
\hline SPG31 & $2 \mathrm{p} 12$ & $\mathrm{AD}$ & REEP1 & PHSP \\
\hline SPG32 & $14 q 12-q 21$ & $\mathrm{AR}$ & - & KHSP \\
\hline SPG35 & $16 q 21-q 23$ & AR & - & KHSP \\
\hline SPG36 & $12 q 23-q 24$ & $\mathrm{AD}$ & - & - \\
\hline SPG37 & $8 \mathrm{p} 21.1-\mathrm{q} 13.3$ & $\mathrm{AD}$ & - & - \\
\hline SPG38 & $4 \mathrm{p} 16-\mathrm{p} 15$ & $\mathrm{AD}$ & - & KHSP, Silver-Syndrom \\
\hline SPG39 & 19p13 & AR & NTE & KHSP \\
\hline \multicolumn{5}{|c|}{ Tabelle 1: bekannte Genloci der HSP } \\
\hline \multicolumn{3}{|c|}{ AD: autosomal-dominant } & \multicolumn{2}{|c|}{ PHSP: Pure HSP } \\
\hline \multicolumn{3}{|c|}{ AR: autosomal-rezessiv } & \multicolumn{2}{|c|}{ KHSP: komplizierte HSP } \\
\hline \multicolumn{5}{|c|}{ XC: X-chromosomal } \\
\hline
\end{tabular}


1999 konnten Hazan et al. das dem SPG4-Locus entsprechende Gen identifizieren und Mutationen in diesem Gen bei Patienten mit autosomal-dominantem Erbgang der Erkrankung nachweisen. Seitdem wurden über 100 verschiedene Mutationen im SPG4-Gen gefunden, wobei diese Mutationen für ca. 40 Prozent der AD-HSPFälle verantwortlich sind.

SPG4 besteht aus 17 Exons und kodiert für Spastin, welches zur Familie der AAA-Proteine gehört. Die Proteine dieser Gruppe sind an einer Vielzahl von zellulären Funktionen beteiligt, darunter auch an der Bildung von Peroxisomen und an intrazellulären Transportvorgängen. Neben Spastin konnten u. a. die Genprodukte Atlastin (SPG3A), NIPA1 (SPG6), KIF5A (SPG10), HSP60 (SPG13), BSCL2 (SPG17) und REEP1 (SPG31) den für die AD-HSP verantwortlichen Loci zugeordnet werden.

Trotz der in den letzten Jahren bei der Identifizierung verantwortlicher Gene erzielten Fortschritte bleibt die Ursache der HSP-Erkrankung in ungefähr 50\% der untersuchten Fälle noch immer ungeklärt. In unserer Arbeitsgruppe wurde mit Hilfe der Yeast-Two-Hybrid-Methode, in der weiteren Arbeit mit Y2H abgekürzt, nach Interaktionspartnern von Spastin gesucht. Es wurden hierbei 5 putative Interaktionspartner identifiziert, welche mit der genomischen Position bekannter Genloci der HSP übereinstimmen. Die gefundenen Gene Reticulon1, Reticulon3, CRELD, COPS5 und ZFYVE27 könnten durch eine Wechselwirkung die Funktion von Spastin beeinflussen und so an der Entstehung der HSP beteiligt sein (Mannan et al. 2006) Das dem AD-HSP-Locus SPG9 entsprechende ZFYVE27 sollte aus diesem Grund in dieser Arbeit untersucht werden. 


\section{$1.4 \quad$ ZFYVE27}

Das ZFYVE27-Gen liegt an Position 10q24.2 des menschlichen Genoms und damit im Bereich des AD-HSP-Locus SPG9 (10q23.3-q24.2) (Lo Nigro et al. 2000). Es codiert für ein bisher unbekanntes, hypothetisches Protein mit einem Molekulargewicht von $42 \mathrm{kDA}$. Es besteht aus 13 Exons, die sich über einen genomischen Bereich von ungefähr $27 \mathrm{~kb}$ erstrecken. Im C-terminalen Bereich besitzt es eine putative Phosphoinositol-bindende Domäne, welche auch als FYVE-Domäne bezeichnet wird. Diese Bezeichnung setzt sich aus den Anfangsbuchstaben der vier Proteine Fab1p, YOTB, Vps27p und EEA1 zusammen, bei denen diese Domäne zuerst entdeckt wurde. Moleküle, welche diese strukterell einem Zink-Finger entsprechende Domäne enthalten, sind unter anderem an Membrantransportvorgängen und Signaltransduktionsvorgängen beteiligt (Stenmark et al. 2002).

\subsection{Ziele dieser Arbeit}

- $\quad$ Nachweis der Interaktion zwischen ZFYVE27 und SPG4

- Untersuchungen zur Expression von ZFYVE27 in humanen und murinen Geweben

- Untersuchung der intrazellulären Verteilung von ZFYVE27 in HeLa-Zellen

- Analyse des ZFYVE27-Gens in HSP-Patienten

- Identifizierung von putativen Deletionen im SPG4-Gen mit Hilfe der RealTime-PCR bei HSP-Patienten. 


\section{Material und Methoden}

\subsection{Material}

\subsubsection{Bakterienstämme}

Zur Vermehrung von Plasmiden wurden kompetente Zellen vom Stamm E. coli K12 DH5a (Methode nach Hanahan 1985) von der Firma Invitrogen GmbH, Karlsruhe verwendet. Genotyp: [ $\mathrm{F}^{-}$, end A1, hsdR 17, $\left(\mathrm{r}_{\kappa}{ }^{-} \mathrm{m}_{\kappa}{ }^{-}\right), \operatorname{supE44}$, thi1, recA1, gyrA (Nal), relA1, $\Delta$ (lacZYA-argF)U169, $\phi 80$ lacZAM15].

\subsubsection{Oligonukleotide}

Die Oligonukleotide wurden in einer Konzentration von $100 \mathrm{pmol} / \mu \mathrm{l}$ bei $-20^{\circ} \mathrm{C}$ gelagert. Die folgenden Primer wurden durch die Firmen Eurogentec (Köln) und Qiagen (Hilden) synthetisiert:

\subsubsection{ZFYVE27-Primer}

\begin{tabular}{|c|c|}
\hline Name & $\begin{array}{c}\text { Sequenz } \\
5\end{array}-3$, \\
\hline FL-1-F & GCA GGC GCA CTG CTG GCA AGG GTG CTT G \\
\hline FL-1-R & GGA GCC CGT GAG GCT GGA CAG GGA AGG CCA T \\
\hline FL-2-F & GCT CAC AGG TTT ACT GTT GGC ACC ACC TG \\
\hline FL-2-R & GGA CAG CCC AGC CAC TGC CTA ATG GTC \\
\hline FL-3-F & GAC CAT CCC TAG CCA ACT GTA CCT GCA AG \\
\hline FL-3-R & GCT CTT CCC CTG AGG TAA GAG GGG CAG AG \\
\hline FL-4-F & GAG CGG CTC TTG TCA GTT TAT TAA TGT GC \\
\hline FL-4-R & CAG CAA ACT GAT GAT TAG CTG TAG AGA C \\
\hline
\end{tabular}




\begin{tabular}{|c|c|}
\hline FL-5-F & GCT CAG AGT TAG GAG GGT GAC TCT TTC \\
\hline FL-5-R & GGC CTG GGA AAT AGC AGG AAC TAC AAC AGA \\
\hline FL-6-F & GCC ATT TCG TGG TGT TTT GGG TAG CCT GG \\
\hline FL-6-R & GGC ACT CTT TCA ACC AGT GAG TTC TAG C \\
\hline FL-7-F & GGC TGA ACC GGC TGC TGC CAC ACC TCG T \\
\hline FL-7-R & CCC ACA GTT CTG AGA CTC TGC CCC TGT GG \\
\hline FL-8/9-F & CTG GCC TTG CTC CCT GGC TCA CTG TGT CC \\
\hline FL-8/9-R & GGA GGA AAC GTT CCC GTA GGC CTG ACT AC \\
\hline FL-10-F & CGG GCA GGC TAG CAA GCT GGG CAG GGA G \\
\hline FL-10-R & CAG CTC CAG AAT CCA GCT GGA GAG AGT \\
\hline FL-A-F & CCG TCT GTG CTG CCT GGT CTC CCC TCC CCA \\
\hline FL-A-R & TAG GGT GGG GCT GCA TCC AGG TGT TCT TCC \\
\hline FL-B-R & GAG GAA CAA GCA GTG GGC GTC TGG GTG GGC \\
\hline FL-B-R & GCC TAA TAT GAT GTC GAG CAC ACA AAG CTA G \\
\hline FL-C-F & CTT GGT CTT CCA AAG TGT TAG GAT TAC AAG \\
\hline FLJ-ORF-F & ATG CAG ACA TCA GAA CGT GAG GGG AGT GGG \\
\hline FLJ-ORF-R & CTT GCT CAA GGT CTG GTT ACA CGA GGC AC \\
\hline FL-Nested-F & ACC CTG CCG CCT CCC TCA CGG AGC CAG CGG \\
\hline FL-Nested-R & ACT TGC TCA AGG TCT GGT TAC ACG AGG CAC \\
\hline FLJ-RT Ex4-R & AAG AAC TCC ACA TCC CCA GAA AGA GCG TGC \\
\hline FLJ-RT Ex6-F & CTC ACA CCG GGC AGC GTG GAG GAG GCT GAG \\
\hline FLJ-RT Ex8-R & GAG AAG GTG GCC GAG CAG CCC GTG CAG TTC \\
\hline FL-M-RT F1 & GAC CGC TCC GGG GCT TGG TGG CCC TTC TGT \\
\hline FL-M-RT F2 & TCG GGA CCT GAG TGG GCC GGA GGC GAG CCC \\
\hline FL-M-RT F3 & GGA TGC AGG GGA CGG TGT TCG ATA CTT GCT \\
\hline FLJ-M-RT-R1 & CCC CGG CAC ACC TCC TGA AGG TTA GCC CAG T \\
\hline FLJ-M-RT-R2 & TTT GCT CAG GGT CTG ATT GCT GGA GGC GCA C \\
\hline FLJ-M-RT-R3 & ACA GGC CTC AGA GGC CCA GAG TTG GGA CAG \\
\hline FLJ Ex-Sonde R F F AAC AGT GTG AAG TAG AAA CTG AGT & \\
\hline
\end{tabular}




\subsubsection{SPG4-Primer}

\begin{tabular}{|c|c|}
\hline Name & $\begin{array}{c}\text { Sequenz } \\
5^{\prime}-3^{\prime}\end{array}$ \\
\hline SPG4- RNA F & GTG GCT CGA GAA CTT CAA CCT TCT \\
\hline SPG4 RNA F2 & CAG TGA GAG CTG TGA ATG AAT TCT CC \\
\hline SPG4 RNA R2 & GCC GAT GAC GTT CAT TGA AGA TCT TG \\
\hline SPG4_RNA_F3 & GTG AAT GAA TTC TCC GGG TGG ACG AGG GA \\
\hline SPG4_RNA_R3 & CCA GTA AAC TAA GGG CAA ATA TCT \\
\hline SPG4-RNA- F4 & CAA GTC ACA AAC GGC AGT CTA TAA TGA CA \\
\hline SPG4-RNA-R4 & AGA AGG TTG AAG TTC TCG AGC CAC \\
\hline SPG4-RNA-R5 & AGT ACT GTC ATT ATA GAC GTC CGT TTG TG \\
\hline SPG4 Taq Ex1-F & GTC CGA GTC TTC CAC AAA CAG \\
\hline SPG4 Taq Ex1-R & CCC CCT AGT TAC CTT TCT CAT C \\
\hline SPG4 EX 2 R1 & GTA ACA GAG GAA AGA CCC TGT CTC \\
\hline SPG4 Taq Ex2-R & GGT AAC AGA GGA AAG ACC CTG TCT CAA \\
\hline SPG4 EX3 F1 & GTA TAA AGA CTG TGA CTC CCC ATG \\
\hline SPG4 EX3 R1 & CAC ACA TT CCA ATA CAT CCC ACA TC \\
\hline SPG4 Taq Ex4-F II & AGA AGA TGC AAC CAG TTT TGC CAT TTT C \\
\hline SPG4 Taq Ex4-R & TTA ACC TAA ACC CAC CTG ACT GGA \\
\hline SPG4 EX 5 F1 N & CAC CCC TAT GAA GAT CCT GGT AC \\
\hline SPG4 Taq Ex5-R & ATT AAA GTT ACT GTC CCA GAA TAC C \\
\hline SPG4 Taq Ex8-F II & TTG TTC ACA GGG CTT AGA GCT CCT GCC A \\
\hline SPG4 Taq Ex8-R II & ACT CAA ATT TGA AGA GAA CCC TTA CCA G \\
\hline SPG4 Taq Ex9-F & AAA CTC TTG GCC TCA AGT GAT \\
\hline SPG4 EX 9 R1 & CTG ATG TTT AAG CCA GCC AGT TTA CGG \\
\hline SPG4 EX 10-12 F1 & GGG ACG GTT AGT AGT ACT CTC CCC \\
\hline SPG4 EX 10R & GAT AGT CTT TAA GCT TGC CCT TCT TT \\
\hline SPG4 EX 13 F1 & CAG ATT CAA GAA GAC AGA TCT AC \\
\hline SPG4 Taq Ex13-R & AAA ATT CAA ACA CAG ATA CAT ACC TCC TCA \\
\hline SPG4 EX 14 F1 & GGG TAA CAG CAC AAG ACC CTG TC \\
\hline SPG4 EX 14 R1 & CGT CTT GCA AAG GAC ATA GCC AGT G \\
\hline SPG4 Taq Ex15-F & TGC TGT TTC TTC CTT CCC TTC C \\
\hline SPG4 Taq Ex15-R & TGC AGT GAA CTA TGA TTG TGC C \\
\hline SPG4 Taq Ex16-F & GCC CTT CAA CAA TTT CAA CTG CAA A \\
\hline SPG4 Taq Ex16-R & AAA AAA AAA ACC ACA CAC ACA CAC ATT C \\
\hline SPG4 Taq Ex17-F II & CTA GAT GAG AAA TAT TCG ATT ATC TGA \\
\hline SPG4 Taq Ex17-R & GTC TGT TTT CTG GTT CAT CTT \\
\hline
\end{tabular}




\subsubsection{Antikörper}

Monoklonal anti-EEA1

Monoklonal anti-E2-tag

Polyklonal anti-c-Myc
BD Biosciences Clontech, Heidelberg

Abcam, Cambridge

Dunn Labortechnik GmbH, Asbach

\subsubsection{Vektoren}

Klonierungen von PCR-Produkten wurden mit dem Plasmid pGem ${ }^{\circledR}-$ Teasy-Kit

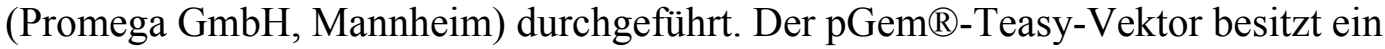
Ampicillinresistenz-Gen und bietet durch das lac-Operon die Möglichkeit einer Blau-Weiß-Selektion auf IPTG/ X- $\beta$ Gal-Medium.

pGem ${ }^{\circledR}$-Teasy

pEGFP-C1

pQM-Ntag/A
Promega GmbH, Mannheim

BD Biosciences Clontech, Heidelberg

Abcam, Cambridge

\subsubsection{Chemikalien}

Nicht gesondert aufgeführte Chemikalien wurden von der Firma Merck (Darmstadt) in p.A.-Qualität bezogen.

$\left[\alpha-{ }^{32} \mathrm{P}\right] \mathrm{dCTP}$

$1 \mathrm{~kb}$ DNA ladder

Agar

Agarose

Ampuwa

Ampicillin

Blocking Reagenz

Bromphenolblau

BSA (Faktor V)
Amersham Pharmacia Biotech GmbH, Freiburg

Invitrogen $\mathrm{GmbH}$, Karlsruhe

Fluka-Sigma-Aldrich GmbH, Taufkirchen

PEQLAB Biotechnologie GmbH, Erlangen

Fresenius AG, Bad Homburg

Sigma-Aldrich Chemie GmbH, Taufkirchen

Carl Roth GmbH \& Co., Karlsruhe

Sigma-Aldrich Chemie GmbH, Taufkirchen

Biomol, Hamburg 
Buffer AE Elution Buffer

QIAGEN GmbH, Hilden

Buffer EL Erythrocyte Lysis Buffer QIAGEN GmbH, Hilden

Chloroform

DEPC

DMEM

DMSO

dNTP

DPBS

DTT

EDTA

Essigsäure

Ethanol

Ethidiumbromid

FKS

Formamid

Glycerin

HotStarTaq $^{\text {TM }}$

IPTG

Isopropanol

Kaliumacetat

Kanamycin

Lachsspermien-DNA

Methanol

MOPS

Phenol

Phosphorsäure

Proteinase K

Rapid-hyb buffer

Restriktionsendonukleasen

RNase A

RNase freies Wasser

RNase Inhibitor

SDS
Sigma-Aldrich Chemie GmbH, Taufkirchen

Carl Roth GmbH \& Co., Karlsruhe

Gibco/BRL, Karlsruhe

Sigma-Aldrich Chemie GmbH, Taufkirchen

Invitrogen $\mathrm{GmbH}$, Karlsruhe

PAN Biotech GmbH

Biomol GmbH, Hamburg

ICN Biomedicals GmbH, Eschwege

Carl Roth GmbH \& Co., Karlsruhe

Carl Roth GmbH \& Co., Karlsruhe

Carl Roth GmbH \& Co., Karlsruhe

Gibco/BRL, Karlsruhe

Carl Roth GmbH \& Co., Karlsruhe

ICN Biomedicals GmbH, Eschwege

QIAGEN GmbH, Hilden

Biomol GmbH, Hamburg

Carl Roth GmbH \& Co., Karlsruhe

Carl Roth GmbH \& Co., Karlsruhe

Sigma-Aldrich Chemie GmbH, Taufkirchen

Sigma-Aldrich Chemie GmbH, Taufkirchen

Carl Roth GmbH \& Co., Karlsruhe

Sigma-Aldrich Chemie GmbH, Taufkirchen

Biomol GmbH, Hamburg

Fluka-Sigma-Aldrich GmbH, Taufkirchen

Boehringer Mannheim GmbH, Mannheim

Amersham Pharmacia Biotech $\mathrm{GmbH}$,

Freiburg

Invitrogen $\mathrm{GmbH}$, Karlsruhe

Gibco/BRL, Karlsruhe

QIAGEN GmbH, Hilden

QIAGEN GmbH, Hilden

ICN Biomedicals GmbH, Eschwege 


$\begin{array}{ll}\text { SYBR Green Mix } & \text { Abgene, Hamburg } \\ \text { SYBR Green Mix } & \text { QIAGEN GmbH, Hilden } \\ \text { T4-DNA-Ligase } & \text { Invitrogen GmbH, Karlsruhe } \\ \text { Triton X-100 } & \text { Serva, Heidelberg } \\ \text { Taq-DNA-Polymerase } & \text { Amersham Pharmacia Biotech GmbH, } \\ & \text { Freiburg } \\ \text { TRI Reagent }{ }^{-R N A / D N A / P r o t e i n ~} & \text { Molecular Research Center Inc., Cincinnati } \\ \text { Tris } & \text { Carl Roth GmbH \& Co., Karlsruhe } \\ \text { X- } \beta \text { Gal } & \text { Biomol GmbH, Hamburg }\end{array}$

\subsubsection{Gebrauchswaren}

Nicht gesondert aufgeführte Gebrauchswaren stammten von den Firmen Krannich GmbH \& Co. KG (Göttingen) und Schütt Labortechnik GmbH (Göttingen).

Blottingpapier GB001-004 Schleicher \& Schüll GmbH, Dassel

Centrisart I-Zentrifugationsröhrchen Sartorius AG, Göttingen

Hybond $^{\mathrm{TM}}$-XL-Nitrocellulosemembran Amersham Pharmacia Biotech $\mathrm{GmbH}$, Freiburg

$\operatorname{MicroSpin}^{\mathrm{TM}} \mathrm{S}-200 \mathrm{H}$

Montage ${ }^{\mathrm{P} P C R}$ filter devices

Nunclon ${ }^{\circledR}$ delta Surface

Plastikwaren

Quarz-Küvette

Reaktionsgefäße

Röntgenfilm Hyperfilm ${ }^{\mathrm{TM}}$ MP

Sterilfilter

Zellkulturflaschen
Amersham Pharmacia Biotech GmbH, Freiburg

Millipore GmbH, Schwalbach

NUNC®, Roskilde

Greiner, Solingen und Falkon, Heidelberg

Hellma, Mühlheim

Eppendorf, Hamburg

Amersham Pharmacia Biotech GmbH, Freiburg

Sartorius AG, Göttingen

Greiner, Nürtingen 


\subsubsection{Geräte}

Entwicklungsgerät Gevamatic110U Agfa Gevaert, München

Kühlzentrifuge, 5417R

Eppendorf, Hamburg

Magnetrührer

Schütt Labortechnik, Göttingen

Megafuge1.0 R

Heraeus GmbH, Hanau

Mikroskop BX60

Olympus, München

Tischzentrifuge 5415C

Eppendorf, Hamburg

Thermocycler Perkin Elmer

Applied Biosystems, Weiterstadt

Thermocycler Primus

MWG-Biotech, Ebersberg

Transilluminator, UVT-28M

Herolab GmbH, Wiesloch

TurboBlotter ${ }^{\mathrm{TM}}$

Schleicher \& Schüll GmbH, Dassel

Mischer

Bender \& Hobein AG, Zürich

Waagen

Sartorius, Göttingen

\subsubsection{Gebrauchsfertige Reaktionssysteme}

Hexalabel $^{\mathrm{TM}}$ DNA Labeling Kit

MBI Fermentas GmbH, St. Leon-Rot

Lipofectamin $2000^{\mathrm{TM}}$ Transfection Reagenz Invitrogen $\mathrm{GmbH}$, Karlsruhe

pGEM®-T easy Vector System

Promega GmbH, Mannheim

PAXGene Blood RNA Kit

QIAGEN GmbH, Hilden

QIAEX® II Gel Extraction Kit

QIAGEN GmbH, Hilden

QIAGEN Plasmid Midi Kit

QIAGEN GmbH, Hilden

QIAGEN EndoFree Plasmid Maxi Kit

QIAGEN GmbH, Hilden

QIAprep ${ }^{\circledR}$ Spin miniprep Kit

QIAGEN GmbH, Hilden

ROCHE® One Step RT-PCR Kit

Boehringer GmbH, Mannheim

ROCHE® Expand Long Template PCR S. Boehringer GmbH, Mannheim

Taq DNA Polymerase

Amersham Biociences, Freiburg 


\subsubsection{Puffer und Lösungen}

Die verwendeten Puffer und Lösungen wurden, sofern nicht anders angegeben, je nach Bedarf mit deionisiertem Wasser $\left(\mathrm{dH}_{2} \mathrm{O}\right)$ oder Ampuwa (pyrogenfreies Wasser für molekularbiologisches Arbeiten) hergestellt.

Denaturierungslösung

$$
\begin{gathered}
0,5 \mathrm{M} \mathrm{NaOH} \\
1,5 \mathrm{M} \mathrm{NaCl} \\
\text { DEPC- } \mathrm{H}_{2} \mathrm{O} .
\end{gathered}
$$

dNTP-Mix

$10 \mathrm{mM}$ dATP

$10 \mathrm{mM} \mathrm{dCTP}$

$10 \mathrm{mM}$ dGTP

$10 \mathrm{mM}$ dTTP.

$10 \times$ MOPS-Puffer

$200 \mathrm{mM}$ MOPS

$50 \mathrm{mM}$ Na-Acetat

10 mM EDTA

in DEPC- $\mathrm{H}_{2} \mathrm{O}$.

Neutralisationslösung

0.5 M Tris/ $\mathrm{HCl} \mathrm{pH} 7,0$

$1,5 \mathrm{M} \mathrm{NaCl}$.

$10 \times$ PBS-Puffer

$1,3 \mathrm{M} \mathrm{NaCl}$

$70 \mathrm{mM} \mathrm{Na}_{2} \mathrm{HPO}_{4}$

$30 \mathrm{mM} \mathrm{NaH}_{2} \mathrm{PO}_{4}$

$\mathrm{pH} 7,4$.

$20 \times \mathrm{SSC}$

$3 \mathrm{M} \mathrm{NaCl}$

0,3 M Natriumcitrat

pH 7,0.

$5 \mathrm{x}$ TBE Puffer

$445 \mathrm{mM}$ Tris

445 mM Borsäure pH 8,0 
10 mM EDTA.

Upper Tris-Puffer

0,5 M Tris/ $\mathrm{HCl}, \mathrm{pH} 6,4$

$0,4 \%(\mathrm{w} / \mathrm{v})$ SDS.

\subsubsection{Kulturmedien}

LB-Medium

$1 \%(\mathrm{w} / \mathrm{v})$ Pepton

$0,5 \%(w / v)$ Hefe Extrakt

$0,5 \%(\mathrm{w} / \mathrm{v}) \mathrm{NaCl}$

$\mathrm{pH} 7,0$.

in $\mathrm{dH}_{2} \mathrm{O}$ angesetzt und autoklaviert

LB-Platten

$1,5 \%(w / v)$ Agar - Agar

in LB-Medium.

Ampicillin-Medium

$0,1 \mathrm{mg} / \mathrm{ml}$ Ampicillin

in LB-Medium.

Kanamycin-Medium

$25 \mathrm{mg} / \mathrm{ml}$ Kanamycin

in LB-Medium.

IPTG / X- $\beta$ Gal-Platten

$$
\begin{aligned}
& 1,5 \%(\mathrm{w} / \mathrm{v}) \text { Agar - Agar } \\
& 100 \mu \mathrm{M} \text { IPTG } \\
& 0,4 \%(\mathrm{w} / \mathrm{v}) \text { X-ßGal } \\
& \text { in Ampicillin-LB-Medium. }
\end{aligned}
$$

Festes LB-Medium enthielt einen Zusatz von 1,5\% (w/v) Agar. Nach dem Autoklavieren und Abkühlen auf ca. $60^{\circ} \mathrm{C}$ konnten den Medien Antibiotika und sonstige Zusätze aus sterilen Stammlösungen in den entsprechenden Konzentrationen zur selektiven Anzucht zugegeben werden. 


\subsubsection{Sterilisation}

Die Sterilisation von Lösungen erfolgte für 20 min bei $10^{5} \mathrm{~Pa} \quad \mathrm{im}$ Dampfdruckautoklaven (Webco, Bad Schwartau) oder durch Sterilfiltration (Sterilfilter mit Porengröße 0,2-0,45 $\mu \mathrm{m}$ ). Gebrauchswaren wurden entweder autoklaviert oder für $8-12$ Stunden bei $180^{\circ} \mathrm{C}$ hitzesterilisiert.

\subsubsection{Datenbanken}

Nukleotid- und Proteinsequenzen wurden mit der Sequenzdatenbank Genbank (http://www.ncbi.nlm.nih.gov) mit Hilfe des BLAST-Programms (Altschul et al. 1990) analysiert.

\subsubsection{Patientenproben}

Die untersuchten 93 DNA-Proben stammten aus einem Kollektiv von Patienten mit Verdacht auf eine autosomal-dominant vererbte spastische Spinalparalyse. Das Institut für Humangenetik Göttingen war mit der molekulargenetischen Untersuchung der DNA-Proben beauftragt worden. Im Rahmen einer differentialdiagnostischen Abklärung der Erkrankung waren zunächst die kodierenden Bereiche der Gene SPG3 und SPG4 durch eine Sequenzanalyse untersucht worden. Da hierbei keine Mutation detektiert werden konnte, wurde eine Deletionanalyse im SPG4-Gen sowie eine Sequenzanalyse der kodierenden Bereiche des ZFYVE27-Gens angeschlossen. 


\section{$2.2 \quad$ Methoden}

\subsubsection{Lagerung und Vermehrung von $E$. coli}

Die Langzeitlagerung eines Bakterienstammes erfolgte als Glycerin-Stock bei

- $80^{\circ} \mathrm{C}$. Es wurden $500 \mu \mathrm{l}$ einer Übernachtkultur mit $500 \mu 180 \%$ Glycerin vermischt und sofort eingefroren. Zusätzlich wurden die Bakterien auf Ampicillin-LB-Platten herangezogen und konnten dort für 4 Wochen bei $4^{\circ} \mathrm{C}$ gelagert werden. Zur Vermehrung wurde eine einzelne Kolonie eines Bakerienstammes bei $37^{\circ} \mathrm{C}$ über Nacht im LB-Medium angezogen. Dem Medium wurde entsprechend seiner plasmidkodierten Resistenz das entsprechende Antibiotikum zugesetzt. Kulturen von bis zu $5 \mathrm{ml}$ wurden in Glaskulturröhrchen inkubiert. Für größere Volumina wurden 250-ml-Erlenmeyerkolben verwendet, die ebenfalls bei $37^{\circ} \mathrm{C}$ in einem Schüttler über Nacht geschwenkt wurden.

\subsubsection{Konzentrationsbestimmung}

\subsubsection{Konzentrationsbestimmung von genomischer DNA mit dem FL800 Microplate Fluoreszenz Reader}

Zur genauen Bestimmung der Konzentration genomischer DNA wurden $2 \mu \mathrm{lder}$ Probe mit $18 \mu$ l AE-Puffer verdünnt. Die Probe wurde dann auf eine Nunclon ${ }^{\circledR}$ delta Surface-Platte pipettiert und $200 \mu 1$ der 1:1000 verdünnten PICO-Green Lösung hinzugefügt. Der FL800 Microplate Fluoreszenz Reader bestimmte die Emission (528 nm) nach Anregung durch Bestrahlung (485 nm). Die Errechnung der Probenkonzentration erfolgte dann im Vergleich mit standardisierten Lösungen der DNA des Phagen Lambda von vorgegebener Konzentration (200, $100,70,50,30,10,5$ und $1 \mathrm{ng} / \mu \mathrm{l})$.

AE-Puffer

$10 \mathrm{mM}$ Tris/ $\mathrm{HCl} \mathrm{pH} 9,0$

0,5 mM EDTA. 


\subsubsection{Konzentrationsbestimmung von genomischer DNA mit dem Eppendorf BioPhotometer}

Zur genauen Bestimmung der Konzentration von DNA-Lösungen wurden $2 \mu 1$ der Probe mit $398 \mu 1$ destilliertem Wasser verdünnt. Die Probe wurde dann in eine Küvette (Präzisions-Küvette aus Quarzglas SUPRASIL $®, 10 \mathrm{~mm}$ - Hellma) pipettiert und die Konzentration per Extinktionsmessung mit dem Photometer bei $260 \mathrm{~nm}$ bestimmt.

\subsubsection{Nukleinsäurepräparation}

\subsubsection{Isolierung von RNA aus Blut mit dem PAXGene Blood RNA Kit}

Die Gesamtblutproben wurden für $30 \mathrm{~min}$ bei 4000 x g pelletiert. Der Überstand wurde verworfen, $5 \mathrm{ml}$ DEPC-Wasser hinzugefügt und das Pellet vollständig resuspendiert. Die Probe wurde erneut für $30 \mathrm{~min}$ bei 4000 x g zentrifugiert, der Überstand wurde wieder verworfen. Das Pellet wurde in $360 \mu 1$ Resuspensierungspuffer (PAXGene BR1-Puffer) gelöst und die Lösung in ein RNA-Eppendorfcup überführt. $300 \mu 1$ Bindungspuffer (PAXGene BR2-Puffer) und $40 \mu \mathrm{l}$ Proteinase $\mathrm{K}$ wurden hinzugefügt. Die Probe wurde gründlich vermischt und dann unter ständigem Mischen für $10 \mathrm{~min}$ bei $55^{\circ} \mathrm{C}$ inkubiert. Danach wurde der Ansatz für 5 min mit 4000 x g zentrifugiert und der Überstand in ein neues RNA-Eppendorfcup überführt. Nach Zugabe von $350 \mu$ Ethanol wurde das Cup kurz zentrifugiert, der Überstand auf eine PAXGene Blood RNA Spin-Säule gegeben und diese für $1 \mathrm{~min}$ bei 10000 x g zentrifugiert. Die Säule wurde anschließend in ein neues RNA-Eppendorfcup gesteckt, einmal mit $700 \mu 1$ Waschpuffer 1 (PAXGene BR3-Puffer) und zweimal mit jeweils $500 \mu 1$ Waschpuffer 2 (PAXGene BR4-Puffer) gewaschen. Anschließend wurde die Säule in ein Elutions-Gefäß gesteckt und zweimal mit jeweils $40 \mu 1$ Elutionspuffer (PAXGene BR5-Puffer) gewaschen, um die RNA vom Filter zu lösen. 


\subsubsection{Isolierung von RNA aus EDTA-Blutproben nach abgeändertem Protokoll des Purescript Kits von Gentra}

Es wurde $1 \mathrm{ml}$ Blutprobe mit $2 \mathrm{ml}$ Erythrozyten-Lysis-Puffer vermischt und für eine Stunde auf Eis inkubiert. Nach Sedimentation der verbliebenen Blutzellen durch einminütige Zentrifugation bei 10000 x g wurde der Überstand verworfen und das Pellet in $600 \mu 1$ TRI Reagent gelöst. Der Ansatz wurde 5 min lang auf Eis inkubiert und anschließend, nach Zugabe von $100 \mu$ Chloroform, für 15 min bei 10000 x g zentrifugiert. Die obere wässrige Phase wurde in ein neues RNAEppendorfcup überführt. Es wurden $200 \mu$ I Isopropanol hinzugefügt. Der Ansatz wurde gut gemischt und für 10 min bei 10000 x g zentrifugiert. Anschließend wurde der Überstand verworfen und $200 \mu 170 \%$-Ethanol hinzugefügt. Nach 5 min Zentrifugation bei $10000 \mathrm{x} g$ wurde der Überstand erneut verworfen und das Pellet in 20-30 $\mu$ 1 DEPC-Wasser gelöst.

EL-Puffer $\quad \begin{aligned} & 10 \mathrm{mM} \mathrm{KHCO}_{3} \\ & 150 \mathrm{mM} \mathrm{NH}_{4} \mathrm{Cl} \\ & 0,1 \mathrm{mM} \mathrm{EDTA} \\ & \text { pH } 8,0 .\end{aligned}$

\subsubsection{Isolierung von Plasmid-DNA aus E. coli im analytischen Maßstab (Methode nach Birnboim und Doly 1979)}

Zur schnellen Präparation geringer Mengen von Plasmid-DNA für Restriktionsanalysen und Sequenzierungen wurden $5 \mathrm{ml}$ mit Antibiotika versetztes LB-Medium mit einer Bakterienkolonie angeimpft und über Nacht bei $37^{\circ} \mathrm{C}$ kultiviert. Diese Übernachtkultur wurde für $10 \mathrm{~min}$ mit $5500 \mathrm{x} \mathrm{g}$ bei Raumtemperatur sedimentiert. Das Pellet wurde in $200 \mu 1$ P1-Puffer resuspendiert und gemischt. Nach Zugabe von $200 \mu$ P2-Lösung wurde der Ansatz vorsichtig geschwenkt und 5 min bei RT inkubiert. Die Lyse wurde durch Zugabe von 200 $\mu 1$ Neutralisationslösung (P3) gestoppt und weitere 5 min bei RT inkubiert. Durch eine 20minütige Zentrifugation bei RT und 15000 x g wurden ausgefallene Proteine und genomische DNA vom plasmidhaltigen Überstand abgetrennt. Zur Fällung der DNA wurden $500 \mu 1$ kaltes Isopropanol hinzugegeben und 20 min bei 
$4^{\circ} \mathrm{C}$ und $15000 \mathrm{x}$ g zentrifugiert. Anschließend wurde die Plasmid-DNA mit 200 $\mu 1$ 70\%-Ethanol gewaschen, das Pellet nach dem Trocknen in $20 \mu 1$ Wasser gelöst und bei $-20^{\circ} \mathrm{C}$ gelagert.

P1-Puffer

P2-Lösung

P3-Lösung
$100 \mu \mathrm{g} / \mathrm{ml}$ RNase A

$50 \mathrm{mM}$ Tris/ $\mathrm{HCl} \mathrm{pH} 8,0$

10 mM EDTA.

$200 \mathrm{mM} \mathrm{NaOH}$

$1 \%(\mathrm{w} / \mathrm{v}) \mathrm{SDS}$.

2,55 M Kaliumacetat, $\mathrm{pH} 4,8$

\subsubsection{Isolierung von Plasmid-DNA aus E. coli im präparativen Maßstab}

Zur Präparation großer Mengen Plasmid-DNA wurde das „Midi-Kit" der Firma Qiagen aus Hilden eingesetzt. Die Methode beruht auf der alkalischen Lyse der Bakterienzellen mit anschließender Aufreinigung der Plasmid-DNA über eine Anionenaustauscher-Säule. Eine Bakterienkolonie wurde in $200 \mathrm{ml}$ LB-Medium mit dem entsprechenden Selektionsantibiotikum angeimpft und über Nacht unter Schütteln bei $37^{\circ} \mathrm{C}$ inkubiert. Die Zellen wurden für $20 \mathrm{~min}$ bei $5000 \mathrm{x}$ g und $4^{\circ} \mathrm{C}$ abzentrifugiert und das Pellet in $4 \mathrm{ml} \mathrm{P1-Puffer} \mathrm{vollständig} \mathrm{resuspendiert.} \mathrm{Durch}$ Zugabe von $4 \mathrm{ml}$ P2-Lösung wurden die Zellen lysiert. Das Zell-Lysat wurde 5 min bei Raumtemperatur inkubiert und durch Zugabe von $4 \mathrm{ml}$ P3-Lösung neutralisiert. Anschließend wurde die Probe für 20 min auf Eis inkubiert und dann für $20 \mathrm{~min}$ bei $10000 \mathrm{x} \mathrm{g}$ und $4^{\circ} \mathrm{C}$ zentrifugiert. Der plasmidhaltige Überstand wurde durch einen Filter auf eine mit QBT-Puffer äquilibrierte Anionenaustauscher-Säule geladen und diese 2-mal mit $10 \mathrm{ml}$ QC-Puffer gewaschen. Die Plasmid-DNA wurde mit $5 \mathrm{ml}$ QF-Puffer eluiert, durch Zugabe von $3,5 \mathrm{ml}$ Isopropanol gefällt und für $20 \mathrm{~min}$ bei $10000 \mathrm{x} \mathrm{g}$ und $4^{\circ} \mathrm{C}$

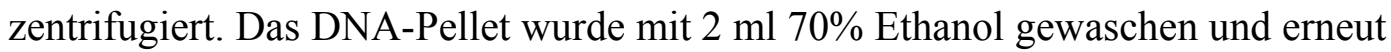
bei $10000 \mathrm{x} \mathrm{g}$ und $4^{\circ} \mathrm{C}$ für 10 min zentrifugiert. Nach dem Trocknen wurde das Pellet in $200 \mu 1$ Wasser aufgenommen. Die Lagerung der Plasmid-DNA erfolgte bei $-20^{\circ} \mathrm{C}$. 
QBT-Puffer

QC-Puffer

QF-Puffer
$750 \mathrm{mM} \mathrm{NaCl}$

50 mM MOPS, pH 7,0

$15 \%(\mathrm{v} / \mathrm{v})$ Ethanol

$0,15 \%(\mathrm{v} / \mathrm{v})$ Triton X-100.

$50 \mathrm{mM}$ MOPS, pH 7,0

$15 \%$ Ethanol.

$1.25 \mathrm{M} \mathrm{NaCl}$

50 mM MOPS, pH 8,2

$15 \%(v / v)$ Ethanol.

\subsubsection{Isolierung von DNA-Fragmenten aus Agarosegelen}

Die Isolierung von DNA-Fragmenten aus Agarosegelen (2.2.7, S. 29) für Klonierungsexperimente erfolgte mit dem QIAEX® II Gel Extraction Kit (Qiagen, Hilden). Die DNA wurde aus dem Agarosegel gelöst und an eine Silikatsuspension adsorbiert. Durch Absenken der Salzkonzentration wurde die DNA wieder eluiert. Nach der elektrophoretischen Auftrennung der DNA im Agarosegel wurde das $\mathrm{zu}$ isolierende DNA-Fragment mit einem Skalpell ausgeschnitten, in ein Reaktionsgefäß überführt und gewogen. Pro $100 \mathrm{mg}$ wurden $300 \mu \mathrm{l}$ QX1-Puffer eingesetzt. Zur Auflösung der Agarose und Bindung der DNA an die Silikatpartikel wurde der Ansatz für $10 \mathrm{~min}$ bei $50^{\circ} \mathrm{C}$ geschüttelt. Die Partikel mit der anhaftenden DNA wurden bei 10000 x g für 30 Sekunden abzentrifugiert und das Pellet in $500 \mu 1$ QX1-Puffer resuspendiert. Es folgten zwei Waschschritte mit $500 \mu$ l ethanolhaltigem PE-Puffer. Das Pellet wurde an der Luft getrocknet, in $20 \mu \mathrm{l}$ Wasser aufgenommen und die DNA für 5 min bei RT eluiert. Der Ansatz wurde bei 10000 x g für 30 Sekunden zentrifugiert und der Überstand mit der DNA in ein neues Reaktionsgefäß überführt. 


\subsubsection{Aufreinigung von PCR-Produkten über Millipore-Säulen}

Um PCR-Produkte von Salzen, Enzymen oder anderen Verunreinigungen zu befreien, wurden diese über eine Millipore-Säule aufgereinigt. Hierzu wurde der Ansatz mit der DNA auf die Membran der Säule gegeben und das Volumen mit $\mathrm{dH}_{2} \mathrm{O}$ auf $500 \mu \mathrm{l}$ aufgefüllt. Die Säule wurde für 30 Sekunden bei $10000 \mathrm{x} \mathrm{g}$ zentrifugiert. Anschließend wurde sie gewendet und die DNA in einer dem Ausgangsvolumen entsprechenden Menge $\mathrm{dH}_{2} \mathrm{O}$ eluiert.

\subsubsection{Ethanolfällung}

Durch die Ethanolfällung kann die DNA von Kontaminationen mit Proteinen, Salzen und freien Nukleotiden befreit werden. Die Präzipitation von DNA in wässriger Lösung erfolgte durch Zugabe von 0,1 Vol 3 M Natriumacetat ( $\mathrm{pH} 4,5)$ und 2,5 Vol reinem Ethanol und einer anschließenden Inkubation bei $-80^{\circ} \mathrm{C}$ für 20 min oder bei $-20^{\circ} \mathrm{C}$ für 2 Stunden. Das Gemisch wurde dann für 10 min bei 12000 x g zentrifugiert, der Überstand verworfen und das Pellet mit 2,5 Vol $70 \%$ (v/v) Ethanol gewaschen. Nach einem weiteren Zentrifugationsschritt wurde das Pellet in einer dem Ausgangsvolumen entsprechenden Menge $\mathrm{dH}_{2} \mathrm{O}$ gelöst.

\subsubsection{Enzymatische Modifikation von Nukleinsäuren}

\subsubsection{Restriktionsenzymatische Spaltung}

Restriktionsendonukleasen sind Enzyme, die DNA an sequenzspezifischen Stellen spalten können. Für eine Restriktion wurden 2-5 U pro $\mu \mathrm{g}$ DNA eingesetzt, wobei das Enzymvolumen $10 \%$ des Gesamtvolumens nicht überschreiten sollte. Restriktionen von genomischer DNA erfolgten über Nacht, die von Plasmid-DNA für 2 Stunden bei der für die Reaktion optimalen Temperatur. Die Restriktion wurde anschließend auf einem Agarosegel (2.2.7, S. 29) überprüft. 


\subsubsection{Ligation von DNA-Fragmenten}

Um PCR-Produkte in einen Vektor zu integrieren, wurde das pGem ${ }^{\circledR}$-TeasyVektorsystem verwendet. Der artifizielle 3'-Thymidinüberhang dieses Vektors ist komplementär zum 3'-Desoxyadenosin, das den PCR-Produkten durch die meisten Polymerasen angehängt wird. Dazu wurden in einem $10 \mu 1$ Reaktionsansatz $50 \mathrm{ng}$ des linearen Vektors mit dem Insert in 3-5 fachem molarem Überschuss, $5 \mathrm{U}$ T4-DNA-Ligase und $1 \mu \mathrm{l}$ des 10 x Ligationspuffers gemischt und über Nacht bei $4^{\circ} \mathrm{C}$ inkubiert.

\subsubsection{Radioaktive Markierung von Nukleinsäuren}

Die radioaktive Markierung von Nukleinsäuren mit $\left[\alpha-{ }^{32} \mathrm{P}\right]$ wurde nach dem Protokoll des Hexalabel ${ }^{\mathrm{TM}}$ DNA Labeling Kit durchgeführt. Das Verfahren beruht auf dem Prinzip des „random priming“ nach Feinberg und Vogelstein. Hierbei dienen Hexanukleotide einer Polymerase als Primer. Nach der Denaturierung der Nukleinsäuresonde binden die Hexanukleotide an der Nukleinsäure und bilden somit den Ausgangspunkt für die Nukleinsäuresynthese. Es wurden etwa 20-50 ng DNA und $10 \mu \mathrm{l}$ Hexanukleotidgemisch in $5 \mathrm{x}$ Puffer mit $\mathrm{dH}_{2} \mathrm{O}$ auf ein Volumen von $40 \mu \mathrm{l}$ gebracht. Anschließend wurde die DNA für $10 \mathrm{~min}$ im kochenden Wasserbad denaturiert und 2 min auf Eis abgekühlt. Hinzu kamen $3 \mu 1$ Mix C (dNTPs ohne dCTP), $4 \mu \mathrm{l}\left[\alpha_{-}{ }^{32} \mathrm{P}\right] \mathrm{dCTP}$ und $1 \mu \mathrm{l}$ Klenow-Fragment. Der Ansatz wurde nun für 10 min bei $37^{\circ} \mathrm{C}$ inkubiert. Nach Zugabe von $4 \mu \mathrm{dNTP}-\mathrm{Mix}$ wurde die Synthese für weitere $5 \mathrm{~min}$ fortgesetzt. Um die Reaktion zu beenden, wurden dem Ansatz $150 \mu \mathrm{l} \mathrm{dH}_{2} \mathrm{O}$ zugefügt. Das gesamte Reaktionsvolumen wurde auf eine vorbereitete MicroSpin ${ }^{\mathrm{TM}}$-Aufreinigungssäule aufgetragen und für $2 \mathrm{~min}$ bei $800 \mathrm{x}$ g zentrifugiert. Das Eluat wurde $10 \mathrm{~min}$ bei $95^{\circ} \mathrm{C}$ denaturiert, 3 min auf Eis abgekühlt und konnte anschließend direkt für eine Hybridisierung (2.2.10, S. 32) verwendet werden. 


\subsubsection{Methoden der Polymerase-Kettenreaktion}

Die PCR (Methode nach Saiki 1985) dient der Amplifikation kleinster Mengen genetischen Materials in vitro. Nach der Denaturierung der DNA binden sequenzspezifische synthetische Primer, an denen die hitzestabile Taq-Polymerase des Archaebakteriums Thermus aquaticus einen komplementären Strang bilden kann. Bei jedem Zyklus aus Denaturierung, Anlagerung und Verlängerung erfolgt eine Verdopplung der durch die Primer eingegrenzten Sequenz, sodass eine exponentielle Vervielfältigung des genetischen Materials erreicht wird.

\subsubsection{PCR an Plasmid-DNA}

Um DNA-Fragmente aus Plasmiden zu amplifizieren, wurden sequenzspezifische Primer verwendet. Dabei wurde nach folgendem Schema vorgegangen:

$\begin{array}{ll}5 \mathrm{ng} & \text { Plasmid-DNA } \\ 25 \mu \mathrm{l} & \text { Hotstart Taq-Polymerase Mix } \\ 10 \mathrm{pmol} & \text { Primer } \mathrm{f} \\ 10 \mathrm{pmol} & \text { Primer } \mathrm{r} \\ \text { ad } 50 \mu \mathrm{l} & \mathrm{dH}_{2} \mathrm{O} .\end{array}$

Nach 15 min initialer Denaturierung bei $96^{\circ} \mathrm{C}$ erfolgte die PolymeraseKettenreaktion mit 35 Zyklen im Thermocycler vom Model Primus (MWGBiotech AG) nach folgendem Programm:

$\begin{array}{lll}40 \text { Sekunden } & 94^{\circ} \mathrm{C} & \text { Denaturierung } \\ 50 \text { Sekunden } & 50-65^{\circ} \mathrm{C} & \text { Anlagerung } \\ 60-90 \text { Sekunden } & 72^{\circ} \mathrm{C} & \text { Verlängerung. }\end{array}$

Zum Abschluss des letzten Elongationsschrittes wurde die Reaktion für weitere 10 min bei $72^{\circ} \mathrm{C}$ fortgesetzt. Die Temperatur für eine optimale Anlagerung der Primer musste experimentell ermittelt werden. 


\subsubsection{PCR an genomischer DNA}

Zur Sequenzierung der exonischen Bereiche des ZFYVE27-Gens wurde vor der eigentlichen Sequenzanalyse (2.2.6.6, S. 28) eine PCR mit zwei Primern durchgeführt. Folgendes Reaktionsschema wurde verwendet:

$\begin{array}{ll}500 \mathrm{ng} & \text { genomische DNA } \\ 25 \mu \mathrm{l} & 25 \mu 1 \text { Hotstart Taq-Polymerase Mix } \\ 10 \mathrm{pmol} & \text { Primer A } \\ 10 \text { pmol } & \text { Primer B } \\ \text { ad } 50 \mu \mathrm{l} & \mathrm{dH}_{2} \mathrm{O} .\end{array}$

Nach 15 min initialer Denaturierung bei $96^{\circ} \mathrm{C}$ erfolgte die PolymeraseKettenreaktion mit 32 Zyklen im Thermocycler Perkin Elmer (Applied Biosystems) mit einer Anlagerungstemperatur von $60^{\circ} \mathrm{C}$.

\subsubsection{RT-PCR}

In der RT-PCR (Methode nach Kogan 1987) dient mRNA als Matrize für die reverse Transkriptase, die eine der RNA komplementäre cDNA bildet. In einer anschließenden PCR wird mit Hilfe von sequenzspezifischen Primern ein DNAFragment amplifiziert. Die RT-PCR wurde mit dem ROCHE® Titan OneStep RT-PCR Kit durchgeführt:

$\begin{array}{ll}1 \mu \mathrm{g} & \text { Gesamt-RNA } \\ 10 \mu \mathrm{l} & 5 \text { x ROCHE® Titan OneStep RT-PCR Puffer } \\ 10 \mathrm{pmol} & \text { Primer A } \\ 10 \mathrm{pmol} & \text { Primer B } \\ 1 \mu \mathrm{l} & \text { dNTP-Mix } \\ 1 \mu \mathrm{l} & \text { ROCHE® Titan OneStep RT-PCR DTT } \\ 1 \mu \mathrm{l} & \text { ROCHE® Titan OneStep RT-PCR Enzym- } \\ & \text { Mix } \\ \text { ad } 50 \mu \mathrm{l} & \text { DEPC } \mathrm{dH}_{2} \mathrm{O} \text { (RNAse frei). }\end{array}$


Die RT-PCR startete mit der reversen Transkription bei $50^{\circ} \mathrm{C}$ für $30 \mathrm{~min}$, wodurch ein einzelsträngiges cDNA-Molekül erhalten wurde. Es folgte die Aktivierung der Polymerase bei $94^{\circ} \mathrm{C}$ für 2 min. Für den Ablauf der Polymerase-Kettenreaktion wurden 35 Zyklen nach folgendem Programm durchgeführt:

$\begin{array}{lll}10 \text { Sekunden } & 94^{\circ} \mathrm{C} & \text { Denaturierung } \\ 30 \text { Sekunden } & 60^{\circ} \mathrm{C} & \text { Anlagerung } \\ 60 \text { Sekunden } & 68^{\circ} \mathrm{C} & \text { Verlängerung. }\end{array}$

Bei den letzten 25 Zyklen wurde bei jedem Zyklus der Verlängerungs-Schritt jeweils um 5 Sekunden erweitert, um den Wirkungsverlust der Polymerase auszugleichen. Um die Vervollständigung aller Fragmente zu gewährleisten, erfolgte der letzte Verlängerungsschritt für 10 min bei $68^{\circ} \mathrm{C}$.

\subsubsection{4 „Nested“-PCR}

Um mit einer sehr geringer Menge an genetischem Material eine ausreichende Amplifikation nach Polymerase-Kettenreaktion zu erhalten, kann man die Anzahl der Zyklen steigern, wodurch sich aber die Wahrscheinlichkeit für Fehlhybridisierungen erhöht. Soll die Spezifität der Amplifikation erhalten bleiben, wird in einem solchen Fall mit dem Produkt der ersten PCR eine zweite, verschachtelte PCR durchgeführt. Die Primer für diese so genannte „Nested“-PCR werden innerhalb des Fragments der ersten PCR gewählt.

$$
\begin{aligned}
& 5 \mu 1 \text { PCR Produkt } \\
& 0,5 \mu 110 \text { pmol Primer A } \\
& 0,5 \mu 110 \text { pmol Primer B } \\
& 25 \mu 1 \text { Hotstart Taq-Polymerase Mix } \\
& \text { ad } 50 \mu 1 \mathrm{dH}_{2} \mathrm{O} .
\end{aligned}
$$

Nach 15 min initialer Denaturierung der Nukleinsäuren und Enzymaktivierung bei $96^{\circ} \mathrm{C}$ erfolgte die Polymerase-Kettenreaktion mit 20-30 Zyklen im Thermocycler Primus (MWG-Biotech AG). 


\subsubsection{5 „Long Range“-PCR}

Bei der „Long Range“-PCR wurde das ROCHE® Expand Long Template PCR System verwendet. Es wurde eine PCR an genomischer DNA durchgeführt, wobei Bereiche von 5 bis $10 \mathrm{~kb}$ amplifiziert wurden.

$\begin{array}{ll}500 \mathrm{ng} & \text { genomische DNA } \\ 0,75 \mu \mathrm{l} & \text { ROCHE® Enzym Mix } \\ 10 \mathrm{pmol} & \text { Primer A } \\ 10 \mathrm{pmol} & \text { Primer B } \\ 5 \mu \mathrm{l} & \text { ROCHE® 10x PCR-Puffer 2 } \\ 7 \mu \mathrm{l} & \text { dNTP-Mix } \\ \text { ad } 50 \mu \mathrm{l} & \mathrm{dH}_{2} \mathrm{O} .\end{array}$

Nach 2 min initialer Denaturierung bei $94^{\circ} \mathrm{C}$ erfolgte die PolymeraseKettenreaktion mit 32 Zyklen im Thermocycler Perkin Elmer (Applied Biosystems).

$\begin{array}{lll}\text { 15 Sekunden } & 94^{\circ} \mathrm{C} & \text { Denaturierung } \\ 30 \text { Sekunden } & 62,5^{\circ} \mathrm{C} & \text { Anlagerung } \\ 5-10 \text { min } & 68^{\circ} \mathrm{C} & \text { Verlängerung. }\end{array}$

Um die Vervollständigung aller Fragmente zu gewährleisten, erfolgte der letzte Verlängerungsschritt für $7 \mathrm{~min}$ bei $68^{\circ} \mathrm{C}$.

\subsubsection{Sequenzanalyse}

Die Sequenzierung wurde nach dem Kettenabbruchverfahren (Methode nach Sanger 1977) durchgeführt. Wie bei einer PCR bindet ein sequenzspezifischer Primer an die denaturierte DNA, sodass eine DNA-Polymerase einen komplementären Nukleinsäurestrang generieren kann. Im Unterschied zur PCR werden jedoch nicht nur dNTPs (Desoxynukleosidtriphosphate) verwendet, sondern auch vier unterschiedliche ddNTPs (Didesoxynukleosidtriphosphate), die mit unterschiedlichen Fluoreszenzfarbstoffen markiert sind. Werden die ddNTP`s 
eingebaut, kommt es zu einem Abbruch in der Strangsynthese. Dies führt zu unterschiedlich großen DNA-Fragmenten. Nach einer elektrophoretischen Auftrennung können durch Fluorographie die Positionen des Kettenabbruches sichtbar gemacht werden, wodurch auf die Sequenz geschlossen werden kann.

Um eine Sequenzanalyse durchzuführen, wurden $1 \mu \mathrm{g}$ DNA, 10 pmol eines Primers und $4 \mu \mathrm{l}$ DYEnamic ET-Terminator-Mix mit $\mathrm{dH}_{2} \mathrm{O}$ auf ein Reaktionsvolumen von $10 \mu 1$ verdünnt. Die Reaktion erfolgte nach 40 Sekunden Denaturierung bei $95^{\circ} \mathrm{C}$ mit 25 Zyklen in einem Thermocycler vom Typ Primus (MWG-Biotech AG):

$\begin{array}{lll}20 \text { Sekunden } & 95^{\circ} \mathrm{C} & \text { Denaturierung } \\ 15 \text { Sekunden } & 50^{\circ} \mathrm{C} & \text { Anlagerung } \\ 60 \text { Sekunden } & 60^{\circ} \mathrm{C} & \text { Verlängerung. }\end{array}$

Die DNA-Fragmente wurden in einer Sephadex-Säule aufgereinigt und über einen automatischen Sequenzierer vom Modell MegaBace1000 (Amersham Bioscience, Freiburg) ausgewertet. Im Fall, dass eine Veränderung in der Sequenz gefunden wurde, wurde der entsprechende Bereich erneut amplifiziert und ein zweites Mal sequenziert, um auszuschließen, dass der Basenaustausch durch einen Fehler in der PCR entstanden war.

\subsubsection{Standard-Agarosegelelektrophorese}

Um die Nukleinsäuren elektrophoretisch aufzutrennen, wurden Agarosegele in einer horizontalen Kammer verwendet. Je nach Größe der aufzutrennenden Fragmente wurden Gele mit 0,6-1,5 \% (w/v) Agaroseanteil verwendet. $100 \mathrm{ml} \mathrm{0,5}$ x TBE Puffer wurden mit der Agarose in einer Mikrowelle aufgekocht, mit $10 \mu 1$ Ethidiumbromid (5 $\mathrm{mg} / \mathrm{ml})$ gemischt und im Gelträger ausgehärtet. Die Gelkammer wurde mit 0,5 x TBE Puffer gefüllt und der Gelträger eingesetzt. Die DNA-Proben wurden mit 1/3 Vol Probenpuffer versetzt und in die Geltaschen an der Kathode aufgetragen. Die Elektrophorese erfolgte bei einer konstanten Spannung von $80 \mathrm{~V}$ bis eine klare Auftrennung der Fragmente zu sehen war. Eine Abschätzung der Fragmentgrößen erfolgte durch den Vergleich mit dem 
Längenstandard. Die Kontrolle der Auftrennung und die fotografische Dokumentation der mit Ethidiumbromid gefärbten Gele erfolgten mittels UVAnregung auf einem Transilluminator.

Probenpuffer

$$
\begin{aligned}
& 70 \%(\mathrm{v} / \mathrm{v}) \text { Glycerin } \\
& 0,01 \%(\mathrm{w} / \mathrm{v}) \text { Bromphenolblau } \\
& 0,01 \%(\mathrm{w} / \mathrm{v}) \text { Xylencyanol FF. }
\end{aligned}
$$

\subsubsection{Zellkulturtechniken}

\subsubsection{Kultivierung von HeLa-Zellen}

Für die Transfektionen wurden kultivierte HeLa-Zellen verwendet. Die gesamten Arbeiten mit Zellkulturen wurden in einer Umluft-Sterilbank der Firma Heraeus mit sterilen Glas- oder Plastikpipetten durchgeführt. Bei HeLa-Zellen handelt es sich um etablierte Zervix-Karzinom-Zellen, die in Gewebekulturflaschen mit 10 ml Zellkulturmedium (2.1.10, S. 16) und $5 \% \mathrm{CO}_{2}-$ Begasung bei feuchter Atmosphäre im $37^{\circ} \mathrm{C}$ warmen Brutschrank kultiviert wurden. In der Regel wurden die proliferierenden Zellen alle 3 Tage geteilt und in neue Kulturflaschen überführt. Dazu wurden nach Entnahme des verbrauchten Mediums die auf dem Boden der Flasche haftenden Zellen mit 10 ml PBS gewaschen und anschließend mit 1,5 ml Trypsin/EDTA - Gemisch abgelöst. Jeweils $2 \mathrm{ml}$ dieser Zellsuspension wurden dann in neue Kulturflaschen überführt und mit $10 \mathrm{ml}$ Medium aufgefüllt, sowie nach vorsichtigem Schwenken zur Verteilung in der Flasche im Brutschrank unter obigen Bedingungen kultiviert.

\subsubsection{Transfektion von HeLa-Zellen}

Als Transfektion wird das Einbringen von Fremd-DNA in Zellkulturzellen bezeichnet. Hierzu wurde die Methode der Lipofektion gewählt. Dabei werden die Plasmide mittels Liposomen in die Zielzelle gebracht. Vorteil dieser auch als transiente Transfektion bezeichneten Methode, bei der die Plasmid-DNA nicht in das Genom integriert wird, ist ein Vorliegen dieser in hoher Kopienzahl, was zu 
einer hohen Proteinexpression führt. Die vorgesehenen Zellen wurden wie in 2.2.8.1 beschrieben solange kultiviert, bis sie eine konfluente, zusammenhängende Schicht von etwa $80 \%$ der Fläche der Kulturflasche gebildet hatten. Für die folgende Transfektion wurde Lipofectamin 2000 TransfectionReagenz von Invitrogen benutzt. Es wurden zwei Ansätze vorbereitet: Der erste enthielt $10 \mu$ Lipofectamin und wurde mit OptiMEM-1 Medium auf $100 \mu 1$ Gesamtvolumen aufgefüllt. Der zweite enthielt $3 \mu \mathrm{g}$ Plasmid-DNA und wurde ebenfalls mit OptiMEM-1 auf $100 \mu 1$ aufgefüllt. Nach separater Inkubation beider Ansätze für 5 min bei RT wurden diese zügig in einem der Reaktionsgefäße vermischt und noch einmal für 20 min bei RT inkubiert. Während dieser Phase wurden die in DMEM kultivierten HeLa-Zellen mit $10 \mathrm{ml}$ PBS gewaschen und nach Entfernung des PBS mit $1 \mathrm{ml}$ OptiMEM-1 Medium bedeckt. Nach Ablauf der 20minütigen Inkubationsphase wurde das Transfektionsgemisch Tropfen für Tropfen auf die Zellen in den Flaschen gegeben. Es folgte eine Inkubationsphase bei $37^{\circ} \mathrm{C}$ im Brutschrank von $3-4$ Std.. Nach dieser Zeit wurde das Transfektionsgemisch in der Kulturflasche gegen DMEM Medium, das FKS und Antibiotika enthielt, ausgetauscht. Im Anschluss an eine erneute Inkubation im Brutschrank bei $37^{\circ} \mathrm{C}$ für $24-48 \mathrm{Std}$. konnten die transfizierten Zellen zur Isolierung der exprimierten Proteine herangezogen werden.

\subsubsection{Analyse von Fusionsproteinen}

Zuvor mit Fusionsproteinen transfizierte Zellen wurden für $48 \mathrm{Std}$. bei $37^{\circ} \mathrm{C}$ kultiviert. Statt Zellkulturflaschen wurden Vierkammerobjektträger verwendet. Nach 10 min Fixierung auf dem Objektträger mittels Methanol wurden diese für 5 min in PBT inkubiert und nach Beträufeln mit DAPI, welches an DNA bindet und somit den Zellkern fluoreszieren lässt, enthaltendem Vectashield Mounting ${ }^{\circledR}$ Medium mit einem Deckgläschen abgedeckt. Die Ergebnisse der Transfektion konnten dann unter dem Mikroskop mit UV-Licht (Olympus BX60) sichtbar gemacht und über eine angeschlossene Digitalkamera mit entsprechender bildbearbeitender Software (SIS) archiviert werden. 


\subsubsection{Immunfluoreszenzfärbung von HeLa-Zellen}

Die über Nacht auf Vierkammerobjekträgern gewachsenen Zellen wurden für 10 min bei RT durch eine eiskalte Methanol/Acetonmischung (Verhältnis 1:1) fixiert. Nach einmaligem Waschen in PBS wurden unspezifische Bindungsstellen durch Inkubation in Blocking-Lösung abgedeckt. Anschließend wurde der erste in PBS dilutierte Antikörper über Nacht bei $4^{\circ} \mathrm{C}$ in einer feuchten Kammer hinzugefügt. Nach 4 x Waschen mit PBS/0.2 \% Tween-20 konnte mit dem zweiten Antikörper für 1 Stunde bei RT inkubiert werden. Nach 3 x Waschen mit PBS/0.2 \% Tween20 wurde ein Tropfen DAPI enthaltendes Mounting Medium auf die Objektträger gegeben und mit einem Deckgläschen abgedeckt. Analog zur Analyse von Fusionsproteinen konnten die Ergebnisse mit einem Olympus BX60 Mikroskop sichtbar gemacht und über digitale Bildverarbeitung archiviert werden.

\begin{tabular}{lll} 
Blocking-Lösung: & \multicolumn{2}{l}{ PBS mit } \\
& $5 \%$ & Ziegen-Serum \\
$3 \%$ & BSA \\
$1 \times$ & Roti-Block-Lösung.
\end{tabular}

\subsubsection{Southernblot}

Um DNA aus einem Agarosegel auf eine Nitrocellulosemembran zu transferieren, wurde ein Southernblot durchgeführt (Methode nach Southern 1975). Das Agarosegel wurde 2 × $20 \mathrm{~min}$ in Denaturierungslösung und anschließend 2 × 20 min in Neutralisationlösung geschwenkt. Der Transfer auf die Hybond ${ }^{\mathrm{TM}}-\mathrm{C}$ Nitrocellulosemembran erfolgte über Nacht in einem TurboBlotter ${ }^{\mathrm{TM}}$ gemäß Herstellerangaben mit 20 x SSC als Transferflüssigkeit. Zur kovalenten Fixierung der DNA wurde die Membran dann 2 Stunden bei $80^{\circ} \mathrm{C}$ inkubiert. 


\subsubsection{Hybridisierung mit radioaktiv markierten Sonden}

Um spezifische mRNAs oder DNA-Fragmente auf einer Membran nachweisen zu können, wurde eine Hybridisierung mit einer radioaktiv markierten Sonde (2.2.5, S. 24) durchgeführt. Der Filter wurde zunächst kurz in 2 x SSC äquilibriert. Dann wurde er so in ein mit 2 x SSC gefülltes Hybridisierungsgefäß gegeben, dass die Nukleinsäure-behaftete Seite nach innen zeigte. Die Lösung wurde vorsichtig abgegossen, so dass sich der Filter luftblasenfrei an die Innenseite des Gefäßes legte. Zur Verminderung unspezifischer Bindungen der Sonde wurden dann $10 \mathrm{ml}$ auf $65^{\circ} \mathrm{C}$ erwärmter „Rapid-hyb buffer“ sowie $200 \mu l$ denaturierte Lachsspermien-DNA $(10 \mu \mathrm{g} / \mu \mathrm{l})$ zugegeben. Die Membran wurde für mindestens 4 Stunden bei $65^{\circ} \mathrm{C}$ prähybridisiert. Anschließend wurde die denaturierte, radioaktiv markierte Sonde hinzugefügt und über Nacht bei $65^{\circ} \mathrm{C}$ inkubiert. Nach der Hybridisierung wurde die Membran in Waschlösung I bei $65^{\circ} \mathrm{C} 2$ x $10 \mathrm{~min}$ im Wasserbad geschwenkt und anschließend in Waschlösung II solange inkubiert, bis die Hintergrundaktivität ausreichend gesenkt war. Die Membran wurde getrocknet, eingeschweißt und mit einem Röntgenfilm in eine Autoradiographiekassette eingelegt. Der Film wurde dann bei $-80^{\circ} \mathrm{C}$ je nach Aktivität 3 Tage bis 4 Wochen exponiert und anschließend entwickelt.

Waschlösung I

$0,2 \%(\mathrm{w} / \mathrm{v}) \mathrm{SDS}$ in $2 \times$ SSC.

Waschlösung II

$$
\begin{aligned}
& 0,2 \%(\mathrm{w} / \mathrm{v}) \mathrm{SDS} \\
& \text { in } 0,2 \times \mathrm{SSC} .
\end{aligned}
$$

\subsubsection{Deletionsdetektion mittels quantitativer Real-Time-PCR}

Die Detektion eines deletierten Bereichs im SPG4-Gen wurde durch die Quantifizierung des Testamplikons relativ zu einem Referenzamplikon mittels quantitativer Real-Time-PCR ermöglicht (Boehm et al. 2004). Zur Detektion wurde der SYBR-Green-I-Farbstoff (Abb. 1) verwendet. Dieser Farbstoff ist in einem optimierten Verhältnis im „2 x QuantiTect SYBR Green PCR Master Mix“ 
(Qiagen, Hilden) enthalten. Er bindet alle doppelsträngigen DNA-Moleküle und emittiert während des Bindungsvorgangs ein Fluoreszenzsignal. Aufgrund dessen ist es möglich, verschiedene Zielbereiche zu quantifizieren und dabei auf den Einsatz von sequenz-spezifischen Fluoreszenz-Sonden $\mathrm{zu}$ verzichten. Das Exzitationsmaximum des Farbstoffs liegt bei 494 nm, das Emissionsmaximum liegt bei $521 \mathrm{~nm}$.

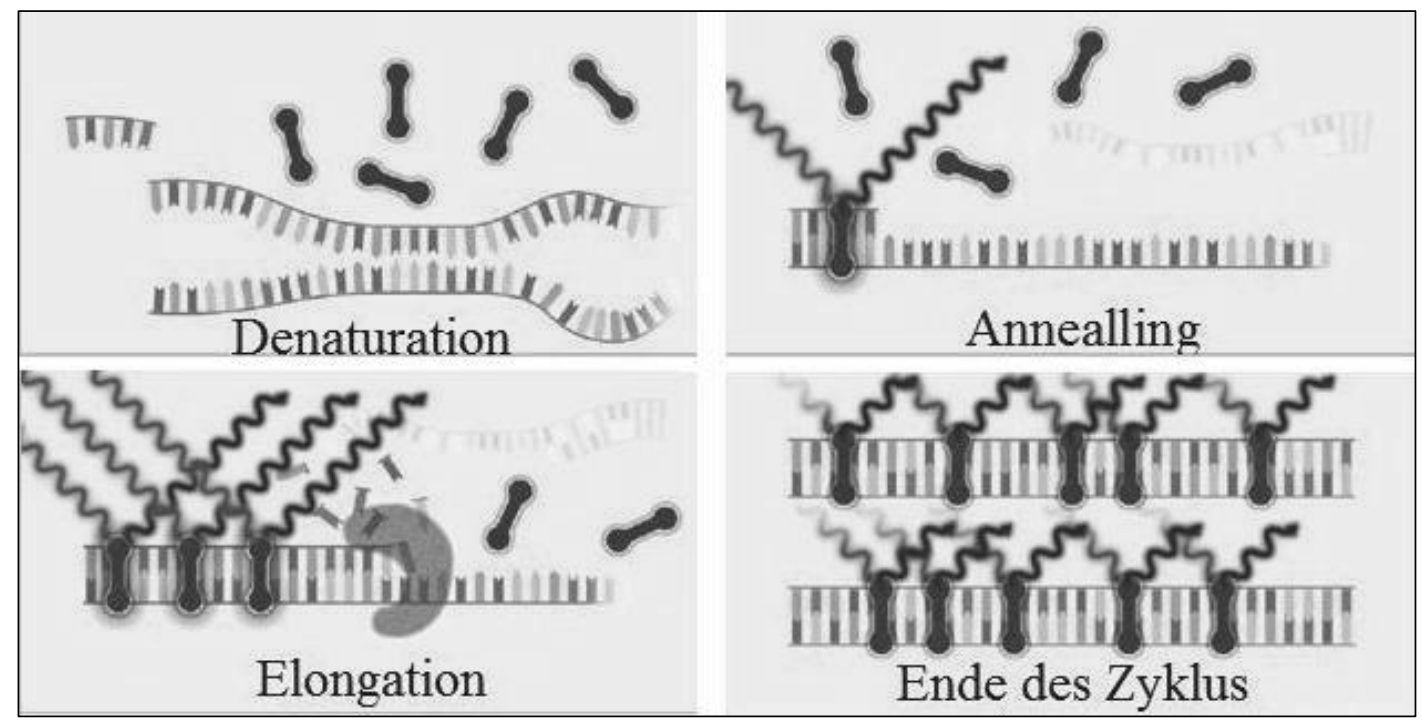

Abbildung 1: Wirkungsweise des SYBR-Green-I-Farbstoffs.

Beim Denaturierungsschritt ist es für den SYBR-Green-I-Farbstoffs unmöglich, sich an die DNA anzulagern, da die DNA einzelsträngig ist. Beim Annealingsvorgang lagern sich die Primer an die einzelsträngige DNA an und bilden somit kurze, doppelsträngige Bereiche. An ihnen können wenige SYBR-Green-I-Farbstoff-Moleküle binden. Je weiter die Elongation voranschreitet, desto länger wird der doppelsträngige Bereich, und entsprechend mehr SYBR-Green-IFarbstoffmoleküle können sich anlagern und Fluoreszenz emittieren.

Eine 384-Proben-Hochdurchsatz-Analyse wurde mit dem ABI Prism 7900 Sequence Detection System auf weißen 384-Loch-Platten für eine 3fache Verstärkung der Fluoreszenzsignale durchgeführt. Dieses System arbeitet mit einem Temperatur-Cycler und einem Laser, der $\mathrm{zu}$ jedem der 384 Reaktionsansätze gelenkt wird und diese anregt. Die Fluoreszenz-Emission jeder Probe, die durch Interkalation des SYBR Green I Fluoreszenz-Farbstoffes an doppelsträngige DNA entsteht, wird mittels einer ladungsempfindlichen Vorrichtung gebündelt und gemessen. Die Daten wurden mit Hilfe der SequenzDetektionssystem-Software (SDS Version 2.1, PE Applied Biosystems) quantifiziert und ausgewertet. 
Die Reaktions-Ansätze enthielten 0,25 pMol eines jeden Oligonukleotids und $5 \mu 1$ 2x QuantiTect ${ }^{\mathrm{TM}} \mathrm{SYBR}^{\circledR}$ Green PCR Master Mix (Qiagen, Hilden). Letzterer enthält die HotStarTaq ${ }^{\mathrm{TM}}$ DNA-Polymerase in einem optimierten Puffer, dNTP Mix (mit dUTP-Additiv), den SYBR Green-I-Fluoreszenz-Farbstoff und ROX Farbstoff als passive Referenz.

Um das Auftreten von unspezifischen Produkten auszuschließen, wurde nach Abschluß der Amplifikation routinemäßig eine Schmelzkurvenanalyse durchgeführt. Dabei wurde kontinuierlich die Fluoreszenz (F) bei steigender Temperatur ( T) gemessen und die Steigung dF/dT (1. Ableitung) errechnet. Diese wurde gegen die Temperatur aufgetragen und damit die Maxima bei den primerspezifischen Schmelztemperaturen aufgezeigt. Zusätzliche Maxima verrieten unspezifische Produkte, z.B. Primer-Dimere.

\begin{tabular}{|c|c|c|}
\hline $50^{\circ} \mathrm{C}$ & $2 \min$ & \\
\hline $95^{\circ} \mathrm{C}$ & $15 \mathrm{~min}$ & \\
\hline $94{ }^{\circ} \mathrm{C}$ & $15 \mathrm{sec}$ & \\
\hline $60{ }^{\circ} \mathrm{C}$ & $30 \mathrm{sec}$ & 40 Zyklen \\
\hline $72{ }^{\circ} \mathrm{C}$ & $1 \mathrm{~min}$ & \\
\hline $94{ }^{\circ} \mathrm{C}$ & $30 \mathrm{sec}$ & \\
\hline $60{ }^{\circ} \mathrm{C}$ & $30 \mathrm{sec}$ & \\
\hline $60^{\circ} \mathrm{C}-95^{\circ} \mathrm{C}$ & $2^{\circ} \mathrm{C} / \mathrm{min}$. & \\
\hline
\end{tabular}

Die Kontroll-DNA wurde zur Erstellung einer Standard-Kurve genutzt. Die Anzahl an Zyklen, bei der die Menge des amplifizierten Zielbereichs einen bestimmten Schwellenwert erreicht, ist der sog. Wert $C_{t}$. Dieser $C_{t}$-Wert korreliert mit der Anzahl der Kopien zum Startpunkt. Eine höhere oder niedrigere StartKopiezahl resultiert in einem signifikant früheren oder späteren Anstieg der Fluoreszenz-Emission (Abb. 2). 

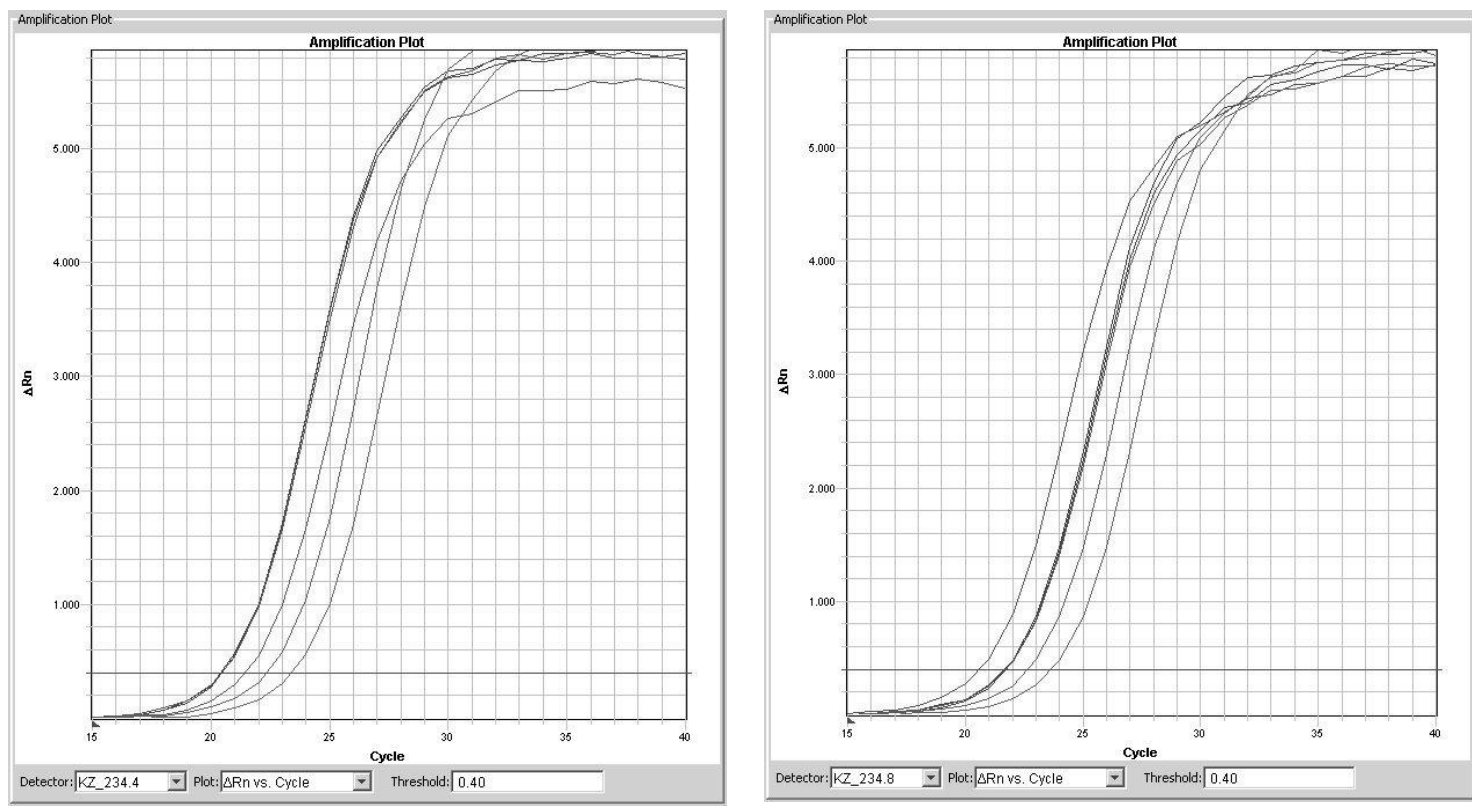

Abbildung 2: lineare Darstellung der Standardkurven

Mit Konzentrationen: 5,0 ng/ $\mu 1,2,5 \mathrm{ng} / \mu 1,1,25 \mathrm{ng} / \mu 1$ und 0,625 ng/ $\mu 1$. Die probenspezifische Kurve (fett) rechts zeigt einen im Vergleich zu links signifikant späteren Anstieg und damit eine (in diesem Fall) um die Hälfte verminderte Konzentration an.

Die absolute Quantifizierung des Zielamplikons in unbekannten Proben wird ermöglicht durch die Messung des $\mathrm{C}_{\mathrm{t}}$-Wertes und durch lineare Interpolation in der entsprechenden halblogarithmischen Darstellung $\left(\mathrm{c}_{\mathrm{t}} / \log \left(\mathrm{c}_{0}\right)\right)$ (Abb. 3).

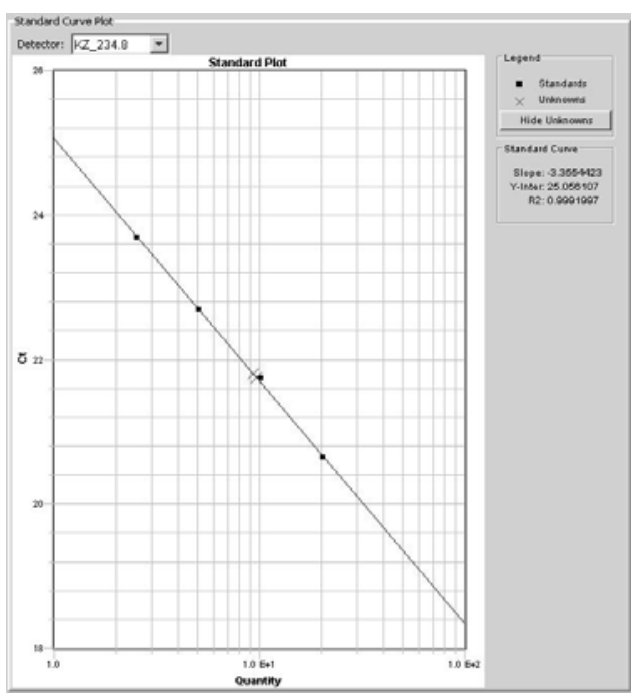

Abbildung 3: Halblogarithmische Darstellung: Standardkurve.

Aufgetragen ist der $\mathrm{C}_{t}$-Wert gegen die logarithmische Konzentration der DNA $\left(\mathrm{c}_{\mathrm{t}} / \log \left(\mathrm{c}_{\mathrm{o}}\right)\right)$ Die halblogarithmische Darstellung ermöglicht die absolute Quantifizierung des Zielamplikons durch lineare Interpolation. Die vier schwarzen Punkte stellen die Konzentrationen der Referenz-DNA in den Konzentrationen $20 \mathrm{ng} / \mu \mathrm{l}, 10 \mathrm{ng} / \mu \mathrm{l}, 5 \mathrm{ng} / \mu \mathrm{l}$ und 2,5 ng/ $/ 1$ dar. Die dünne schwarze Linie kennzeichnet die aus den Standardkonzentrationen interpolierte, logarithmierte Konzentration. 
Die absoluten Daten wurden exportiert, in Excel importiert und gegen das homozygote Referenz-Amplikon durch Berechnung des Verhältnisses $\mathrm{c}_{\text {Testamplikon }} / \mathrm{c}_{\text {Referenzamplikon }}$ normalisiert. Durch diese Methode werden die Menge und die Qualität genomischer DNA für jede Probe normalisiert (Boehm et al. 2004). 


\section{Ergebnisse}

Die hereditäre spastische Paraplegie ist eine Erbkrankheit, die durch eine progressive Parese und Spastik der unteren Extremität charakterisiert ist. Sie wird autosomal-dominant, autosomal-rezessiv oder X-chromosomal rezessiv vererbt. Der größte Anteil mit circa 70 bis $80 \%$ der Fälle folgt dabei dem autosomaldominanten Erbgang. Bei 40 bis 50\% der Patienten mit autosomal-dominantem Erbgang wird die Erkrankung durch Mutationen im SPG4- und SPG3-Gen verursacht, so dass in mehr als der Hälfte der Fälle Mutationen in anderen Genen als Ursache der Erkrankung angenommen werden können. In vorhergehenden Arbeiten war das ZFYVE27-Gen als möglicher Interaktionspartner des SPG4Gens identifiziert worden. Zudem schien der chromosomale Locus des Gens dem AD-HSP-Locus SPG9 zu entsprechen (Lo Nigro et al. 2000). Daher wurde das ZFYVE27-Gen als ein Kandidatengen für die HSP angesehen. Im Rahmen dieser Arbeit wurden die DNA-Proben von 43 HSP-Patienten mit autosomaldominantem Erbgang, bei denen Mutationen in den Genen SPG3 und SPG4 ausgeschlossen worden waren, auf Mutationen im ZFYVE27-Gen untersucht.

\subsection{Sequenzierung von ZFYVE27}

\subsubsection{Identifizierung der Exon/Intron-Grenzen und Amplifikation der Exons}

Die als Interaktionspartner von SPG4 identifizierte 2746 bp große cDNA von ZFYVE27 (Genbank Nummer AK097945) wurde mit Hilfe des NCBI-Programms http://www.ncbi.nlm.hih.gov für Homologievergleiche auf genomischer Ebene verwendet, um die Lage der Exons und die Übergänge von exonischen und intronischen Bereichen zu bestimmen. Es wurde festgestellt, dass sich das ZFYVE27-Gen aus dreizehn Exons zusammensetzt. Das ATG-Start-Codon ist im zweiten und das TGA-Stop-Codon im letzten Exon lokalisiert. Zur Amplifikation wurden spezifische, die Exons flankierende Primer generiert, so dass bei der 
anschließenden Sequenzierung auch die Analyse der Exon/Intron-Grenzen möglich war. Diese Primer wurden sowohl für die Amplifikation (2.2.6.2, S. 25), als auch für die Sequenzierung (2.2.6.6, S. 28) der amplifizierten Fragmente verwendet.

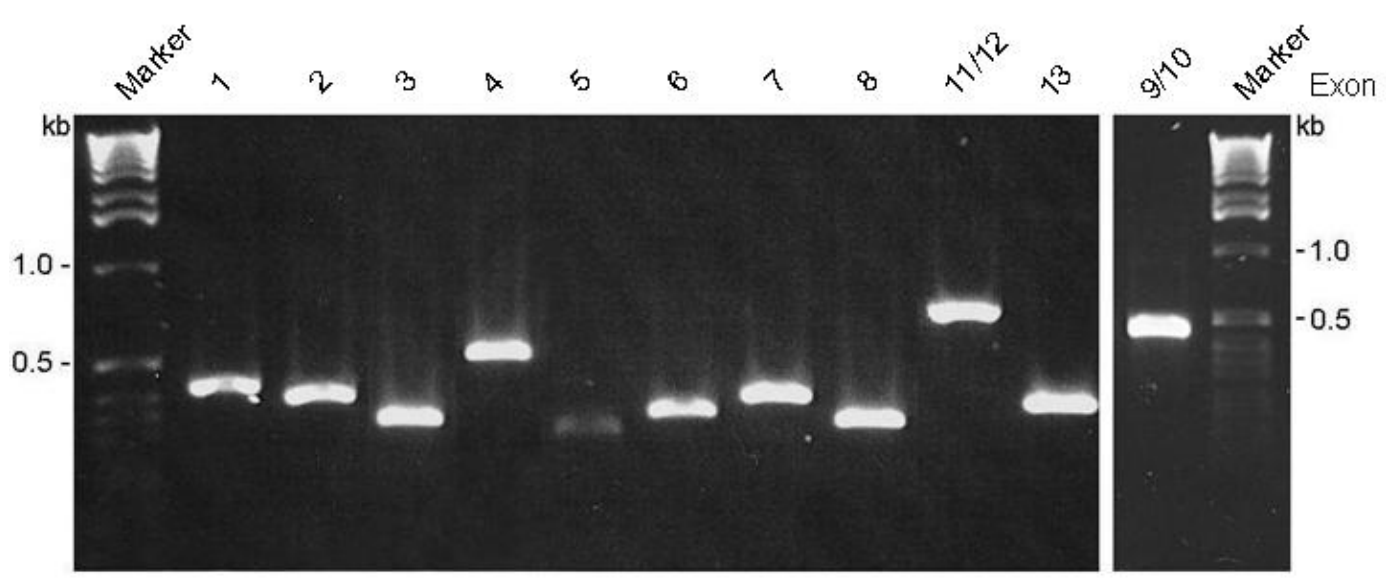

Abbildung 4: PCR-Produkte der 13 Exons von ZFYVE27

Agarosegel mit den Amplifikaten der exonischen Bereiche des ZFYVE27-Gens. Die Exons 9 und 10, als auch die Exons 11 und 12 wurden gemeinsam amplifiziert, da sie auf genomischer Ebene durch kleine Introns getrennt sind. Entsprechend der Beschriftung über den Spuren wurden neben dem Größenstandard (Marker) links und rechts aussen die Proben aufgetragen. Die Ziffern bezeichnen die amplifizierten Fragmente der Exons 1-13.

\subsubsection{Sequenzveränderungen im ZFYVE27-Gen}

Bei der Sequenzierung (2.2.6.6, S. 28) der exonischen Bereiche des ZFYVE27Gens von 43 HSP-Patienten konnten bei 4 Patienten insgesamt 5 Veränderungen auf genomischer Ebene nachgewiesen werden. Die gefundenen Veränderungen betreffen sowohl nicht-translatierte Bereiche (5'UTR-187T $>$ A, 5'UTR-117C $>$ T), als auch kodierende Sequenzen (c.127C $>$ T, c.572G $>$ T) und intronische Regionen (IVS+57T $>$ C). Die Nummerierungen beziehen sich auf Variante 4 der ZFYVE27cDNA. Die Veränderungen c. $127 \mathrm{C}>\mathrm{T}$ und c.572G $>\mathrm{T}$ wurden bei demselben Patienten nachgewiesen. Der Basenaustausch von Guanin durch Thymidin an Position 572 der kodierenden Sequenz von ZFYVE27 bewirkt einen Austausch der Aminosäure Glycin durch Valin (p.G191V). 


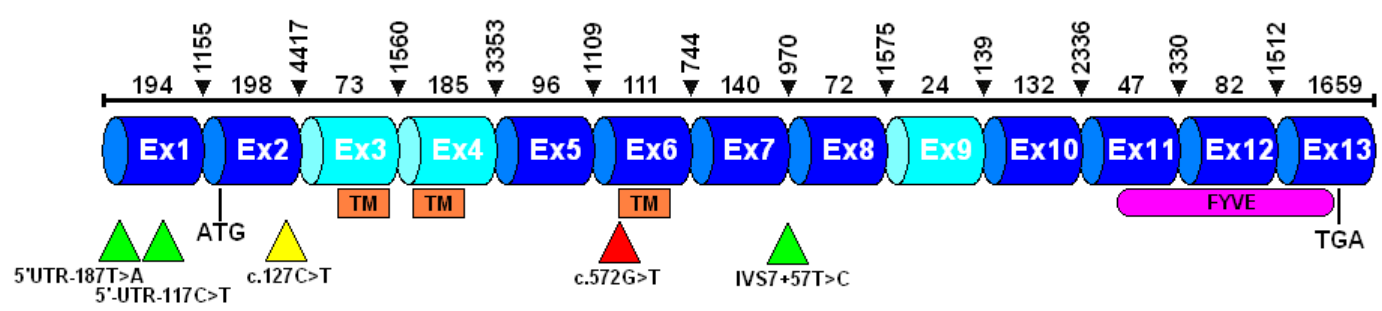

\section{Abbildung 5: Genomische Struktur des ZFYVE27-Gens}

Die Abbildung zeigt den Aufbau des ZFYVE27-Gens. Die Exons sind jeweils mit Ex1 bis Ex13 beschriftet. Dunkelblau dargestellte Exons finden sich in allen bisher analysierten Transkripten, wohingegen hellblaue Bereiche nur in einzelnen Transkripten auftreten. Die Größe der Exons und Introns ist in Basenpaaren über dem jeweiligen Bereich angegeben. Unter der cDNA befinden sich in orange drei Transmembrandomänen und die FYVE-Dömäne in pink. Weiterhin sind 5 Veränderungen und ihre ungefähre Lage in Form von Dreiecken dargestellt. Die grünen Markierungen stellen Veränderungen dar, welche in untranslatierten Bereichen der cDNA bzw. im Intron liegen. Die gelbe Markierung stellt eine Veränderung dar, welche im translatierten Bereich der cDNA liegt, aber keinen Aminosäurenaustausch bewirkt. Die rote Markierung entspricht der Veränderung, die einen Aminosäurenaustausch bewirkt. Die Lokalisation der Veränderungen ist unter den Dreiecken angegeben.

Um auszuschließen, dass die Veränderung c.572G $>\mathrm{T}$ ein Polymorphismus ist, wurde das Exon 6 von 50 DNA-Kontrollproben sequenziert. In keiner von diesen und auch in keiner weiteren der 43 Patientenproben konnte diese Veränderung nachgewiesen werden.

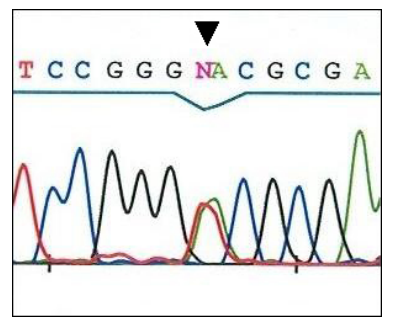

Abbildung 6: 5‘UTR-187T $>$ A

Darstellung des Sequenzausschnitts mit der Veränderung $5^{\circ}$ UTR187T $>$ A, die im 5'-untranslatierten-Bereich an Position -187 der cDNA liegt. Das schwarze Dreieck markiert die übereinander gelagerten Signale, welche durch den heterozygoten Austausch von Adenosin durch Thymidin entsteht.

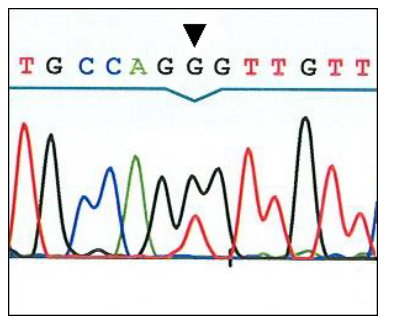

Abbildung 7: 5‘UTR-117C $>$ T

Ausschnitt aus der Sequenz des ersten Exons. Das schwarze Dreieck ist über dem Basenaustausch 5'UTR-117C $>\mathrm{T}$ positioniert, der im 5'untranslatierten-Bereich an Position -117 der cDNA liegt. 


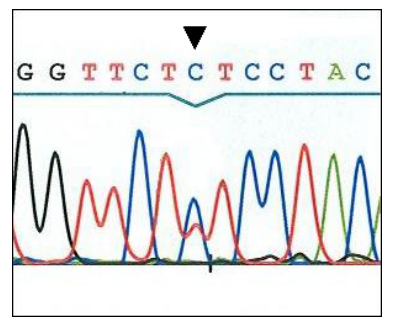

Abbildung 8: c.127C $>\mathrm{T}$,

Der dargestellte Abschnitt der DNA-Sequenz enthält die Veränderung c. $127 \mathrm{C}>\mathrm{T}$. Der Basenaustausch im zweiten Exon ist durch das schwarze Dreieck markiert.

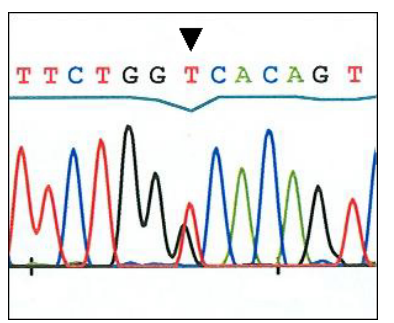

\section{Abbildung 9: c.572G $>$ T}

Grafische Darstellung des Ausschnitts der Sequenz, der die putative Mutation c.572G>T enthält. Das schwarze Dreieck ist über der im Exon 6 liegendnen Veränderung positioniert.

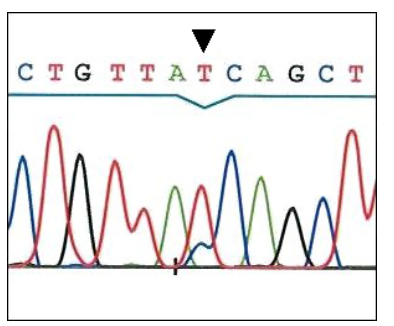

\section{Abbildung 10: IVS+57T $>C$}

Darstellung des intronischen DNA-Abschnitts zwischen Exon 7 und 8, welcher den heterozygoten Austausch von Thymidin durch Cytosin enthält (IVS7+57T $>$ C). Das schwarze Dreieck markiert den Basenaustausch.

\subsection{Expression des ZFYVE27-Gens}

$\mathrm{Zu}$ Beginn dieser Arbeit lagen keine detaillierten Informationen über die Expression des ZFYVE27-Gens vor, deswegen wurde im Rahmen dieser Arbeit sowohl die Gesamt-RNA aus verschiedenen menschlichen und murinen Geweben als auch aus verschiedenen Zellinien mit Hilfe der RT-PCR (2.2.6.3, S. 26) auf eine Expression des ZFYVE27-Gens hin untersucht.

Zunächst wurde das NCBI-Programm http://www.ncbi.nlm.hih.gov verwendet, um mögliche Transkriptvarianten des ZFYVE27-Gens zu identifizieren. Die Sequenz von ZFYVE27 wurde mit dem menschlichen Genom und der vorliegenden EST-Datenbank verglichen. Hierdurch konnten vier putative Spleißvarianten identifiziert werden. 


Variante 1

\section{Abbildung 11: putative Spleißvarianten von ZFYVE27}

Die unterschiedlichen Spleißvarianten der ZFYVE27-cDNAs sind in der schematischen Darstellung mit Variante 1 bis Variante 4 bezeichnet. Über jeder Variante ist jeweils die Länge der cDNA und der kodierenden Sequenz (CDS) in Basenpaaren (bp) und die Anzahl der Exons angegeben. Die Exons sind jeweils mit Ex1 bis Ex13 beschriftet. Die dunkelblauen Exons sind in jeder Spleißvariante vorhanden. Die drei hellblauen finden sich nur in einzelnen Varianten. Das Exon 8X unterscheidet sich von Exon 8 durch 15 Basen, die an seinem Anfang zusätzlich vorhanden sind.

\subsubsection{Analyse der Expression des ZFYVE27-Gens auf RNA-Ebene beim Menschen}

Im nächsten Schritt sollte überprüft werden, in welchen Geweben des Menschen die einzelnen Transkriptvarianten des ZFYVE27-Gens exprimiert werden. Hierzu wurden RT-PCR-Analysen (2.2.6.3, S. 26) mit RNA aus Gehirn, Herz, Niere, Nebenniere, Trachea, Testis und Leber durchgeführt. Zuerst wurden die Primer FLJ-Nested-F und FLJ-Nested-R verwendet, die den kodierenden Bereich der ZFYVE27-cDNA flankieren. Die Reaktionen mit diesem Primerpaar lieferten nicht genügend Produkt, so dass das Experiment mit den Primern FLJ-ORF-F und FLJ-RT Ex-4-R, die nur den Bereich der Exons 2 bis 6 eingrenzen, wiederholt wurde. Die Lage dieser Primer im zweiten und sechsten Exon könnte bei Vorliegen der Variante 1 von ZFYVE27 zu einem 401 bp großen Produkt und bei Expression der Varianten 2, 3 und 4 zu einem 663 bp großen Amplifikat führen (s. Abb. 9). 

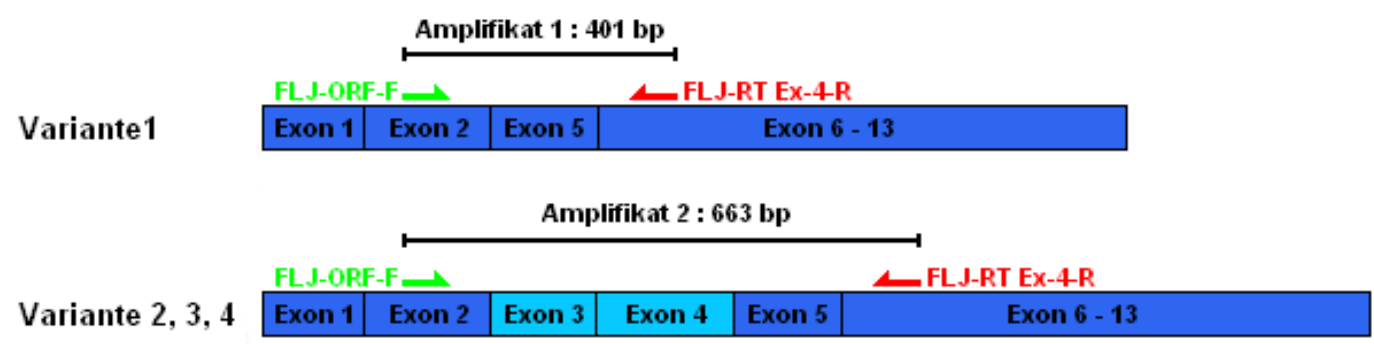

\section{Abbildung 12: Parameter der RT-PCR Exon 2-6}

Schematische Darstellung der bei der RT-PCR verwendeten Primer im Bezug zur ZFYVE27cDNA. Der „,forward“-Primer FLJ-ORF-F ist grün und der „reverse“-Primer FLJ-RT-4-R rot über der blauen cDNA dargestellt.

Als Kontrolle wurde jeweils eine zusätzliche Reaktion ohne RNA mitgeführt, um durch Kontaminationen entstandene Produkte ausschließen zu können. Diese Kontrolle wurde als „0-Kontrolle“ bezeichnet.

Die gelelektrophoretische Auftrennung (2.2.7.1, S. 29) der Produkte und ihre Darstellung mit Hilfe von Ethidiumbromid unter UV-Licht-Anregung zeigten bei der RT-PCR mit RNA aus dem Gehirn eine deutliche, ungefähr 400 bp große, Bande. In den anderen Proben ließen sich spezifische Produkte nicht eindeutig nachweisen. Eine schwache, ungefähr 600-700 bp große Bande konnte in den RT-PCRs mit RNA aus Nebenniere und Testis dargestellt werden. In den Geweben Herz, Niere, Trachea und Leber konnte kein Produkt nachgewiesen werden. Auf eine GAPDH-Kontrolle in den gleichen Reaktionsansätzen wurde aufgrund der ähnlichen Größe der entstehenden Produkte verzichtet.

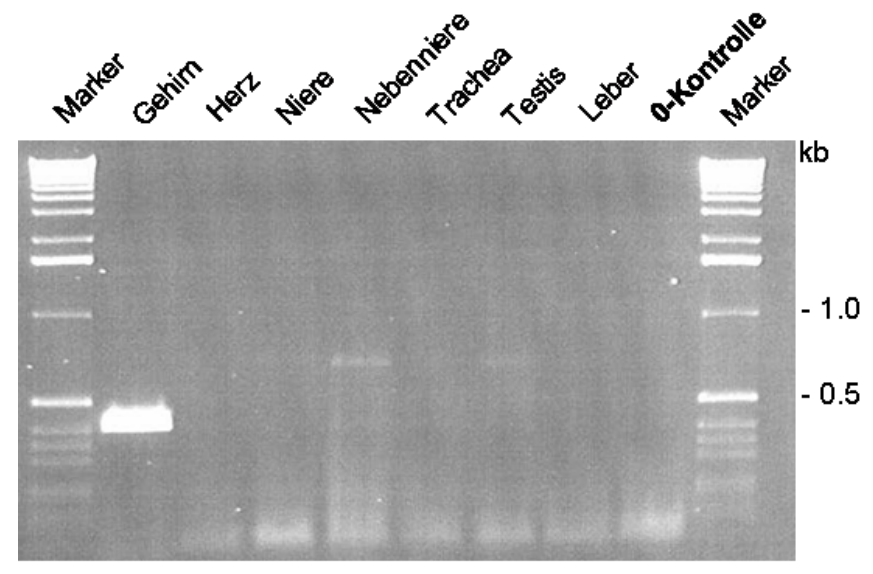

Abbildung 13: RT-PCR - ZFYVE27 Gehirn, Herz, Niere, Nebenniere, Trachea, Testis, Leber Agarosegel mit den Produkten der RT-PCRs, die mit den Primern FLJ-ORF-F und FLJ-RT-Ex4-R durchgeführt wurden. Die Beschriftung über den Spuren gibt an, welche Proben aufgetragen wurden. 


\subsubsection{Klonierung der menschlichen ZFYVE27-cDNA}

Es sollte mit Hilfe der RT-PCR die komplette kodierende Sequenz von ZFYVE27 aus humaner Gehirn-RNA analysiert werden. Da beim ersten Versuch, unter Verwendung der Primer FLJ-Nested-F und FLJ-Nested-R, keine ausreichende Menge des gewünschten Produkts erzielt werden konnte, wurde eine „Nested“PCR (2.2.6.4, S. 27) mit den Primern FLJ-ORF-F und FLJ-ORF-R durchgeführt. Diese, anhand von Datenbankinformationen generierten Primer, liegen in Exon 2 im Bereich des Start-Codons und in Exon 10 im Bereich des Stop-Codons und ermöglichen eine Amplifikation der gesamten kodierenden Sequenz von ZFYVE27 unter Erhaltung des ursprünglichen Leserasters (s. Abb. 14). Die Lage dieser Primer führt beim Vorliegen der Variante $1 \mathrm{zu}$ einem 957 bp großen Produkt. Im Falle einer Expression der Varianten 2, 3 oder 4 entstehen ungefähr $1,2 \mathrm{~kb}$ große Amplifikate.
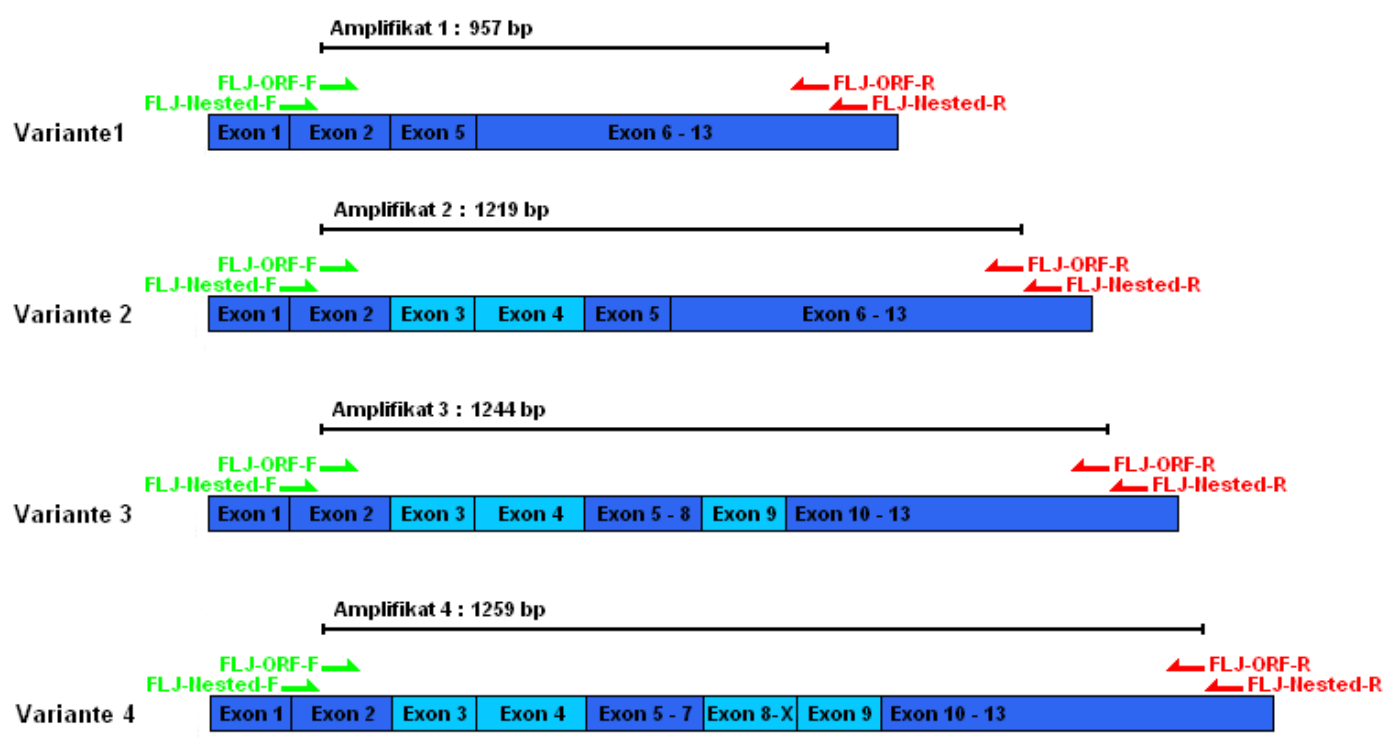

Abbildung 14: Parameter der RT-PCR komplette kodierende Sequenz

Darstellung der verwendeten Primer in Bezug zur ZFYVE27-cDNA. Die „forward“-Primer FLJNested-F und FLJ-ORF-F sind grün und die ,reverse“-Primer FLJ-ORF-R und FLJ-Nested-R rot über der cDNA dargestellt. Über den verschiedenen Varianten der cDNA sind vier der möglichen Amplifikate dargestellt.

Das Produkt der „Nested“-PCR wurde gelelektrophoretisch aufgetrennt und mit Hilfe von Ethidiumbromid unter UV-Licht-Anregung sichtbar gemacht (s. Abb. 15). Hierbei zeigte sich ein einzelnes ungefähr $1 \mathrm{~kb}$ großes Amplifikat. Andere Amplifikate konnten nicht nachgewiesen werden. Die $1 \mathrm{~kb}$ große Bande wurde aus dem Gel extrahiert, in den Vektor pGem ${ }^{\circledR}$-Teasy kloniert und anschließend 
sequenziert. Die Sequenzierung zeigte, dass es sich bei dem Insert um die $957 \mathrm{bp}$ große kodierende Sequenz der Variante 1 des ZFYVE27-Gens handelt (Genbank Nummer AK097945). Da nur dieses Amplifikat nachgewiesen werden konnte, wird es im weiteren Verlauf dieser Arbeit nur noch mit ZFYVE27-cDNA bezeichnet. Alle Positionsangaben auf DNA- und Aminosäurebene beziehen sich ebenfalls auf diese Spleißvariante.

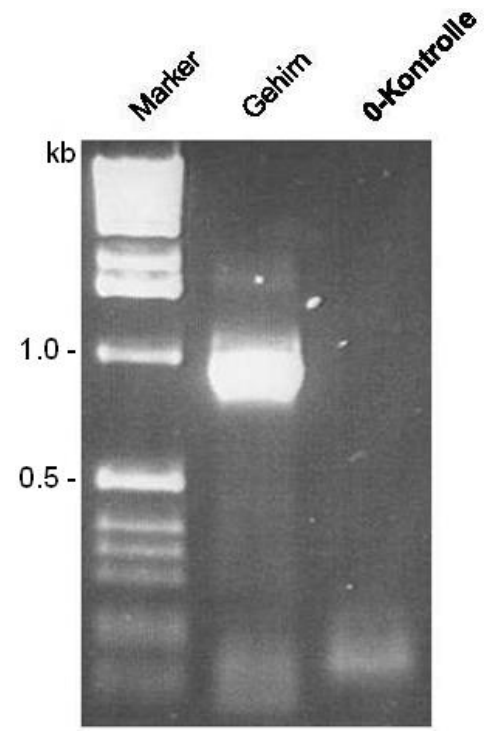

\author{
Abbildung 15: RT-PCR - ZFYVE27 Gehirn \\ Agarosegel mit dem Produkt der „Nested“ PCR \\ (Primer FLJ-ORF-F und FLJ-ORF-R). Neben dem \\ Größenstandard, „Marker“ wurde das Produkt der \\ RT-PCRs, mit RNA aus dem humanen Gehirn, \\ „Gehirn“, und ohne RNA, „0-Kontrolle, \\ aufgetragen.
}

\title{
3.2.3 Analyse der Expression des Zfyve27-Gens auf RNA-Ebene bei der Maus
}

In der Maus existiert ein dem ZFYVE27-Gen homologes Gen, dessen Sequenz zu $87 \%$ mit der menschlichen Form übereinstimmt Die Sequenz des entsprechenden Proteins ist $\mathrm{zu} 86 \%$ mit dem menschlichen ZFYVE27-Protein (Variante 3) homolog. Das bei der Maus als zfyve27 bezeichnete Gen besteht genau wie ZFYVE27 aus 13 Exons, besitzt eine FYVE-Finger-Domäne und kann 3 putative Transmembrandomänen ausbilden. Die Datenbanken liefern bei der Maus aber, im Gegensatz zum Menschen, nur Hinweise auf das Vorliegen einer einzigen Spleißvariante, welche der Variante 3 des humanen ZFYVE27 entspricht. Es sollte untersucht werden, inwieweit zfyve27 in der Maus exprimiert wird und ob Unterschiede in der Expression in verschiedenen Organen und während der embryonalen Entwicklung der Maus bestehen. Hierfür wurde RNA aus Herz-, Lungen-, Nieren-, Muskel-, Luftröhren-, Ovar-, Eileiter-, Plazenta-, Hodengewebe und aus unterschiedlich alten Maus-Embryonen gewonnen. Als erstes wurde eine 
RT-PCR (2.2.6.3, S. 27) mit RNA aus dem murinen Gehirn mit dem Primerpaar FLJ-M-F1 und FLJ-M-R3 durchgeführt, mit der die komplette kodierende Sequenz des Gens amplifiziert werden sollte (s. Abb.16).
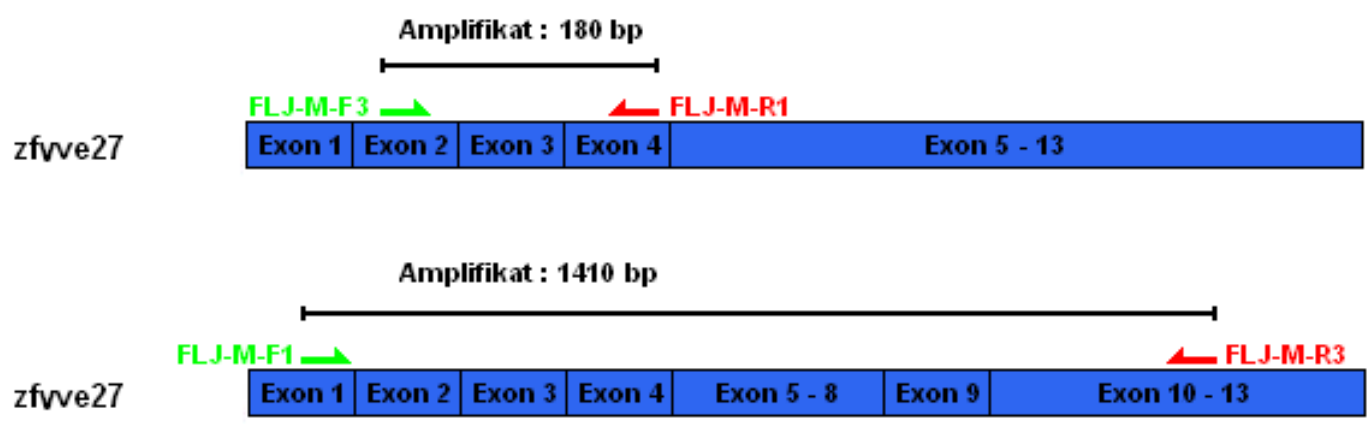

Abbildung 16: Parameter für die RT-PCR zfyve27

Die Abbildung zeigt die zfyve27-cDNA und die ungefähre Lage der für die RT-PCR verwendeten Primerpaare. Die „forward“-Primer sind grün und die „reverse“-Primer rot über der cDNA dargestellt.

Es zeigte sich bei der gelelektrophoretischen Auftrennung der Produkte und ihrer Darstellung mit Hilfe von Ethidiumbromid und UV-Licht-Anregung eine einzelne ungefähr 1,4 kb großen Bande. Diese Bande wurde aus dem Gel extrahiert und in den Vektor pGem ${ }^{\circledR}$-Teasy kloniert. Durch Sequenzierung des Inserts konnte die 1410 bp große komplette kodierende Sequenz des zfyve27-Gens identifiziert werden.

Zur weiteren Untersuchung der Gewebe wurden die Primer FLJ-M-F3 und FLJM-R1 (s. Abb. 16) verwendet, welche den Bereich zwischen Exon 2 und Exon 4 der zfyve27-cDNA einschließen. Die Effizienz der RT-PCRs wurde mit den zusätzlich verwendeten Primern GAPDH-F und GAPDH-R kontrolliert. Zum Ausschluss von Kontaminationen wurde zusätzlich eine „0-Kontrolle“ durchgeführt.

Bis auf die „0-Kontrolle“ zeigten alle untersuchten Proben bei der gelektrophoretischen Auftrennung zwei Banden. Es lagen eine ungefähr $450 \mathrm{bp}$ große Bande und eine etwa 200 bp große Bande vor. Zwischen den einzelnen Proben bestanden leichte Unterschiede in der Intensität der Banden. (s. Abb. 17). 


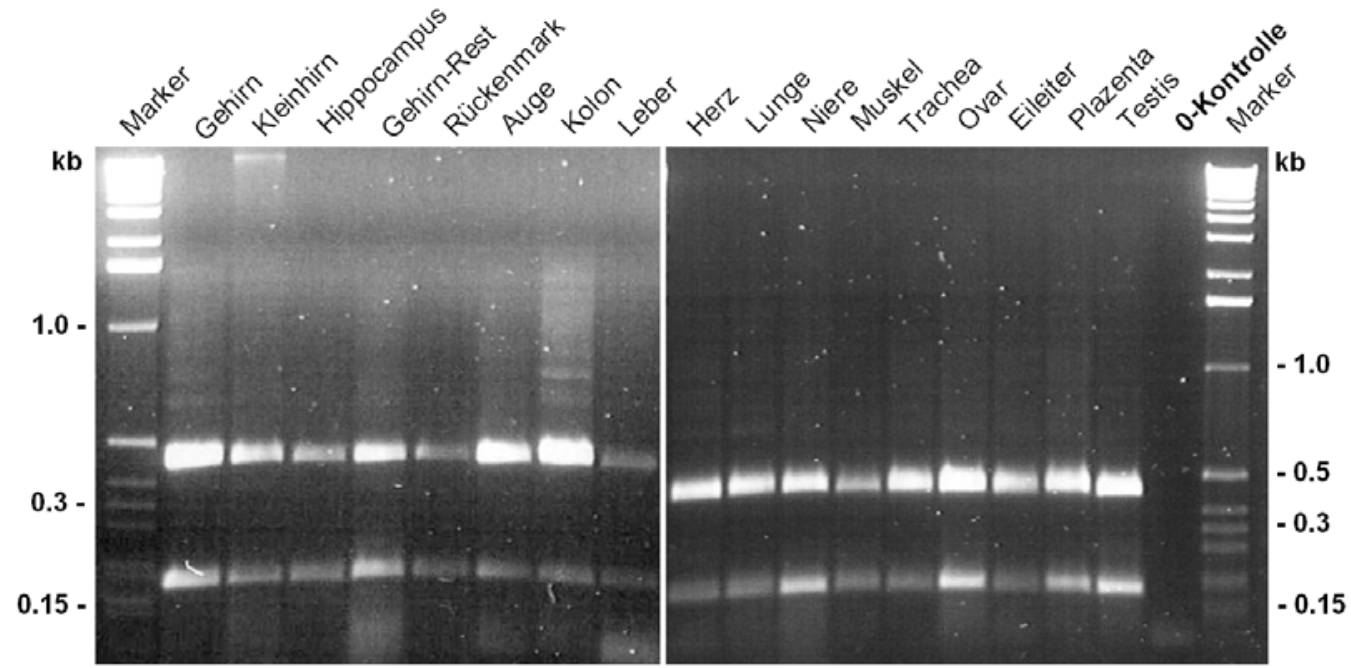

Abbildung 17: RT-PCR - Expression von zfyve27 in der Maus

Agarosegel mit den Produkten der RT-PCRs zur Untersuchung der Expression von Zfyve27 in verschiedenen Geweben der Maus. Die Beschriftung über den Spuren gibt an aus welchem Gewebe die RNA stammte, die für den Ansatz verwendet wurde.

Bei der Untersuchung der RNA der unterschiedlich alten Maus-Embryonen zeigten bei der optischen Kontrolle alle Proben eine circa 450 bp große Bande und eine ungefähr 200 bp große Bande. Neben diesen beiden Banden konnten noch weitere Produkte von schwächerer Intensität nachgewiesen werden. Die RT-PCRs mit RNA der 10,5, 12,5, 14,5, 13,5, 15,5 und 18,5 Tage alten Embryonen enthielten zusätzlich ein 600 bp großes und ein ungefähr 700 bp großes Produkt. Die RT-PCR mit der RNA des 13,5 Tage alten Maus-Embryos enthielt zudem ein etwa 900 bp großes Amplifikat. Die „0-Kontrolle“ enthielt kein Amplifikat (s. Abb. 18). 


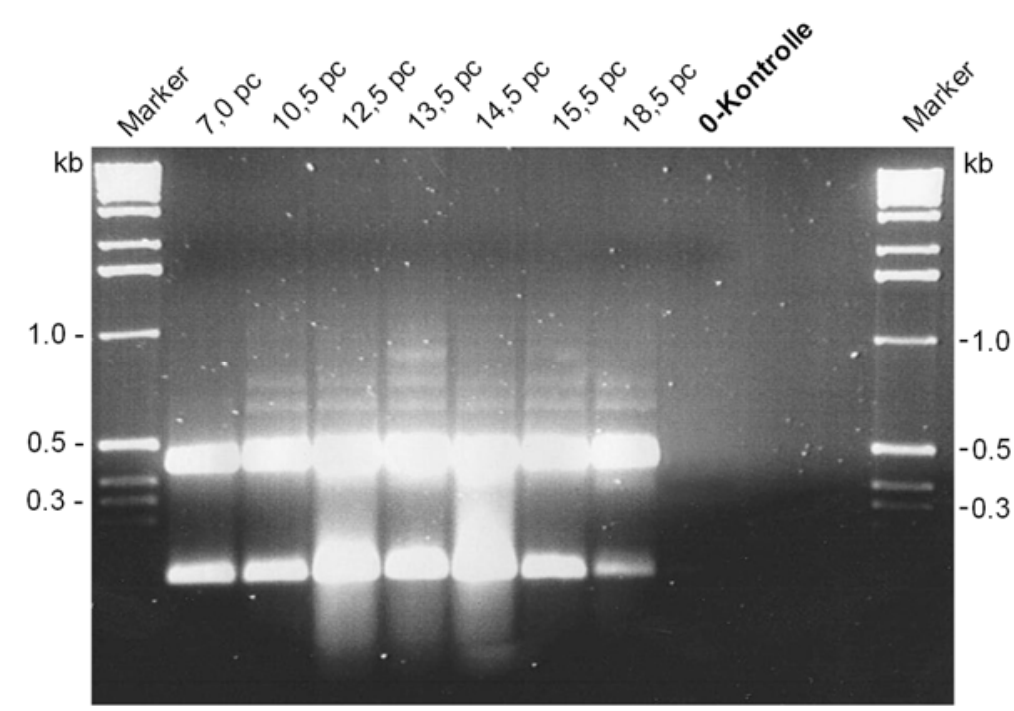

Abbildung 18: Zfvye27 Expression während der embryonalen Entwicklung

Die Abbildung zeigt die Produkte der RT-PCRs nach gelelektrophoretischer Aufgetrennung. Der Größenstandard (Marker) wurde links und rechts aufgetragen. Das Alter der untersuchten Embryonen ist in Tagen über den Spuren angegeben.

In weiteren Versuchen wurde die Expression von zfyve27 in verschiedenen Zellinien analysiert. Die untersuchten Zelllinien stammen von Sertoli-Zellen (15p1), Leydigzellen (MA-20), Neuroblastomzellen (NS20Y), Spermatogonien und Spermatozyten (GC 1,GC 2, GC 3) der Maus ab. In allen RT-PCRs konnte eine ungefähr 450 bp große Bande und eine 200 bp große Bande nachgewiesen werden. Neben diesen beiden deutlich sichtbaren Banden waren in allen Proben noch mehrere größere Banden sichtbar, die aber von sehr geringer Intensität waren. In der „0-Kontrolle“ war kein Amplifikat nachweisbar (s. Abb. 19). 


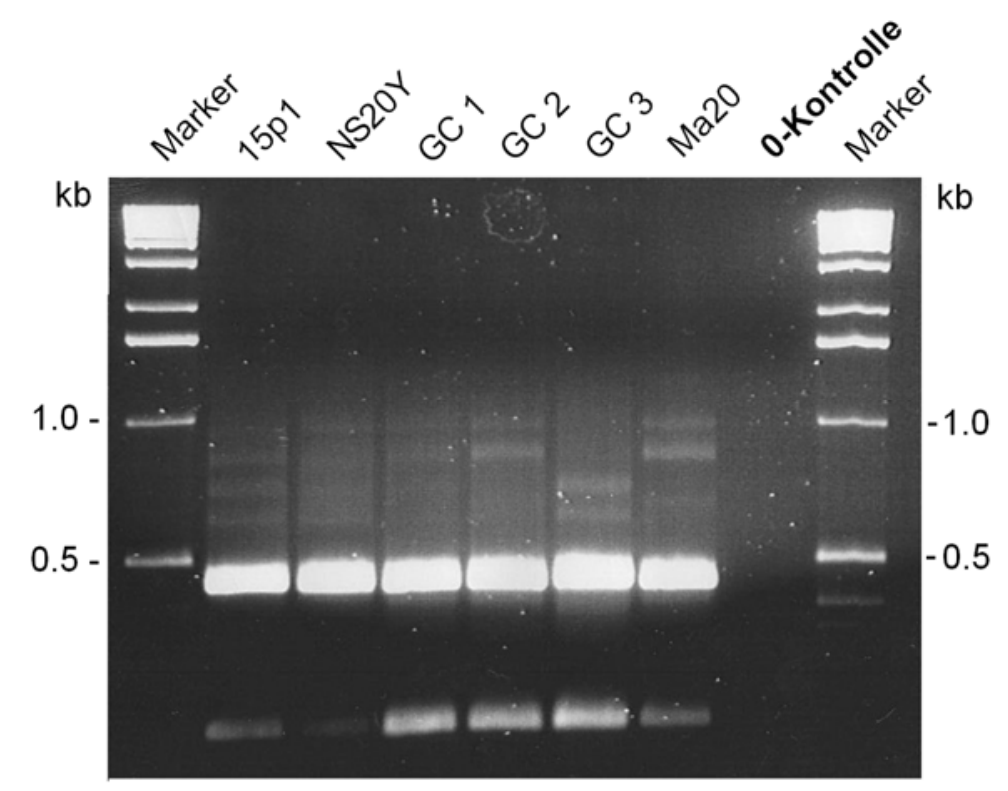

\section{Abbildung 19: RT-PCR - zfyve27 Zelllinien}

Agarosegel nach Auftrennung der Produkte der RT-PCRs zur Untersuchung der Expression von zfyve27 in verschiedenen Zellinien. Die Proben 15p1, NS20Y, GC 1, GC 2, GC 4 und Ma 20 wurden zwischen dem Größenstandard (Marker) links und rechts aufgetragen. Die Beschriftung über den Spuren gibt an, aus welchen Zellen die RNA für den jeweiligen Ansatz stammte.

\subsection{Co-Immunlokalisation}

In dieser Arbeit sollten Untersuchungen zur Funktion des ZFYVE27-Gens angestellt werden. Einen ersten Hinweis auf die Funktion des entsprechenden Proteins könnten intrazelluläre Lokalisationstudien liefern. Zudem könnte eine mögliche Co-Lokalisation mit Spastin ein weiteres Indiz für die Interaktion der beiden Proteine sein.

\subsubsection{Immunfluoreszenz-Analyse von ZFYVE27 in HeLa-Zellen}

$\mathrm{Zu}$ diesem Zweck sollte die cDNA von ZFYVE27 synthetisiert, in die Expressionsvektoren pEGFP-C1 und pQM-Ntag/A kloniert, menschliche Zervixkarzinom-Zellen der Zelllinie HeLa jeweils mit einem Vektor transfiziert (2.2.8.2, S. 30) und die Verteilung des ZFYVE27-Proteins in diesen Zellen per Immunfluoreszenz sichtbar gemacht werden (2.2.8.4, S. 31). SPG4 war zuvor schon in den Vektor pCS2 kloniert worden und wurde freundlicherweise zur Verfügung gestellt, um ZFYVE27 direkt mit Spastin vergleichen zu können. Mit 
Hilfe des pEGFP-C1-Vektors kann an das gewünschte Protein das grünfluoreszierende Peptid EGFP angehängt werden, über welches man dann das Fusionsprotein in den Zellen im Mikroskop direkt nachweisen kann. Der intrazelluläre Nachweis der durch pQM-Ntag/A und pCS2 generierten Fusionsproteine basiert hingegen auf Antikörpern, welche jeweils an das E2- oder c-myc-Epitop binden und einem zweiten Antikörper, welcher wiederum an den ersten bindet und mit einem in unserem Fall rotfluoreszierenden Farbstoff versehen ist.

Es wurde die bei der Expressionsanalyse (3.2.1, S. 42) aus menschlicher RNA des Gehirns amplifizierte ZFYVE27-cDNA (Genbank Nummer AK097945) verwendet. Die bereits in den pGem ${ }^{\circledR}-$ Teasy-Vektor klonierte cDNA wurde für eine PCR (2.2.6.1, S. 25) benutzt, bei der die Primer FLJ-BamH1 und FLJ-Hind3 gebraucht wurden, die die Schnittstellen für die Restriktionsenzyme BamHI und HindIII enthielten. Das Produkt wurde in den pGem®-Teasy-Vektor kloniert. Dieser wurde mit BamHI und HindIII restringiert (2.2.4.1, S. 23) und die cDNA per Gelelektrophorese vom Vektor getrennt. Das hierbei gewonnene Fragment ist $0,958 \mathrm{~kb}$ groß und enthält den kompletten offenen Leserahmen von Base 199 bis zu Base 1151 der ZFYVE27-cDNA. Dieses Fragment wurde mit Hilfe der Restriktionsenzyme BamHI und HindIII im korrekten Leserahmen in pEGFP-C1 kloniert, so dass das entstandene Konstrukt zur Expression des ZFYVE27-Proteins mit dem C-terminal angehängten EGFP führt. Zur Erstellung des E2-ZFYVE27Konstrukts wurde ebenfalls die ZFYVE27-cDNA verwendet. Das bereits in pGem ${ }^{\circledR}$-Teasy klonierte cDNA-Fragment wurde mit Hilfe der Restriktionsenzyme BamH1 und Kpn1 unter Erhaltung des korrekten Leserahmens direkt in den Expressionsvektor kloniert (2.2.4.2, S. 23). Zur intrazellulären Detektion des E2-ZFYVE27-Fusionsproteins wurde ein monoklonaler anti-E2-tag-Antikörper verwendet.

Die mikroskopischen Untersuchungen zeigten, dass es in den meisten Zellen zu einer deutlichen Anreicherung sowohl des GFP-ZFYVE27-, als auch des E2ZFYVE27-Fusionsproteins in punktförmigen Bereichen im Zytosol der HeLaZellen kommt (Abb.20 B, A). Im Gegensatz hierzu zeigte ein kleinerer Teil der Zellen eine gleichmäßigere Verteilung der Fusionsproteine mit besonders hoher 
Konzentration in Zellkernnähe (Abb. 20 C). Zur besseren Beurteilung, in welchen Zellkompartimenten die Fusionsproteine vorhanden sind, wurde der endosomale Marker EEA1 verwendet. Dieser bindet an das FYVE-Protein EEA1, für welches eine Bindung an frühe Endosomen wiederholt nachgewiesen werden konnte (Stenmark et al. 1996, Mills et al. 1998, Stenmark und Aasland 1999). So sollte eine Einschätzung zu eben diesem Zellkompartiment ermöglicht werden. Der direkte Vergleich mit dem EEA1-Marker könnte, aufgrund der Gemeinsamenkeit, dass sowohl ZFYVE27, als auch EEA1 eine FYVE-Domäne enthalten, ebenfalls genaueren Aufschluss über die Bedeutung der FYVE-Domäne von ZFYVE27 geben. Beim Vergleich mit EEA1 konnte in HeLa-Zellen, die eher eine punktelle Verteilung von ZFYVE27 zeigten, eine Überlagerung des Markersignals und des Signals des ZYFVE27-GFP-Fusionsproteins nachgewiesen werden. Zwei dieser Bereiche wurden in Abbildung 20 D, E und F mit Pfeilen markiert. Hingegen konnte bei der zellkernnahen Anreicherung des ZFYVE27-GFP-Fusionsproteins eine teilweise übereinstimmende Verteilung mit dem an das Endoplasmatische Retikulum bindenden Marker RTN1 (Mannan et al. 2005) gezeigt werden (Abb. 20 G, H, I). Bei der gleichzeitigen Transfektion von HeLa-Zellen mit dem GFPZFYVE27-Kontrukt und einem c-Myc-Spastin-Kontrukt war eine deutliche gemeinsame Lokalisation der beiden Proteine in rundlichen Strukturen im Zytoplasma sichtbar (Abb. 20 L). 

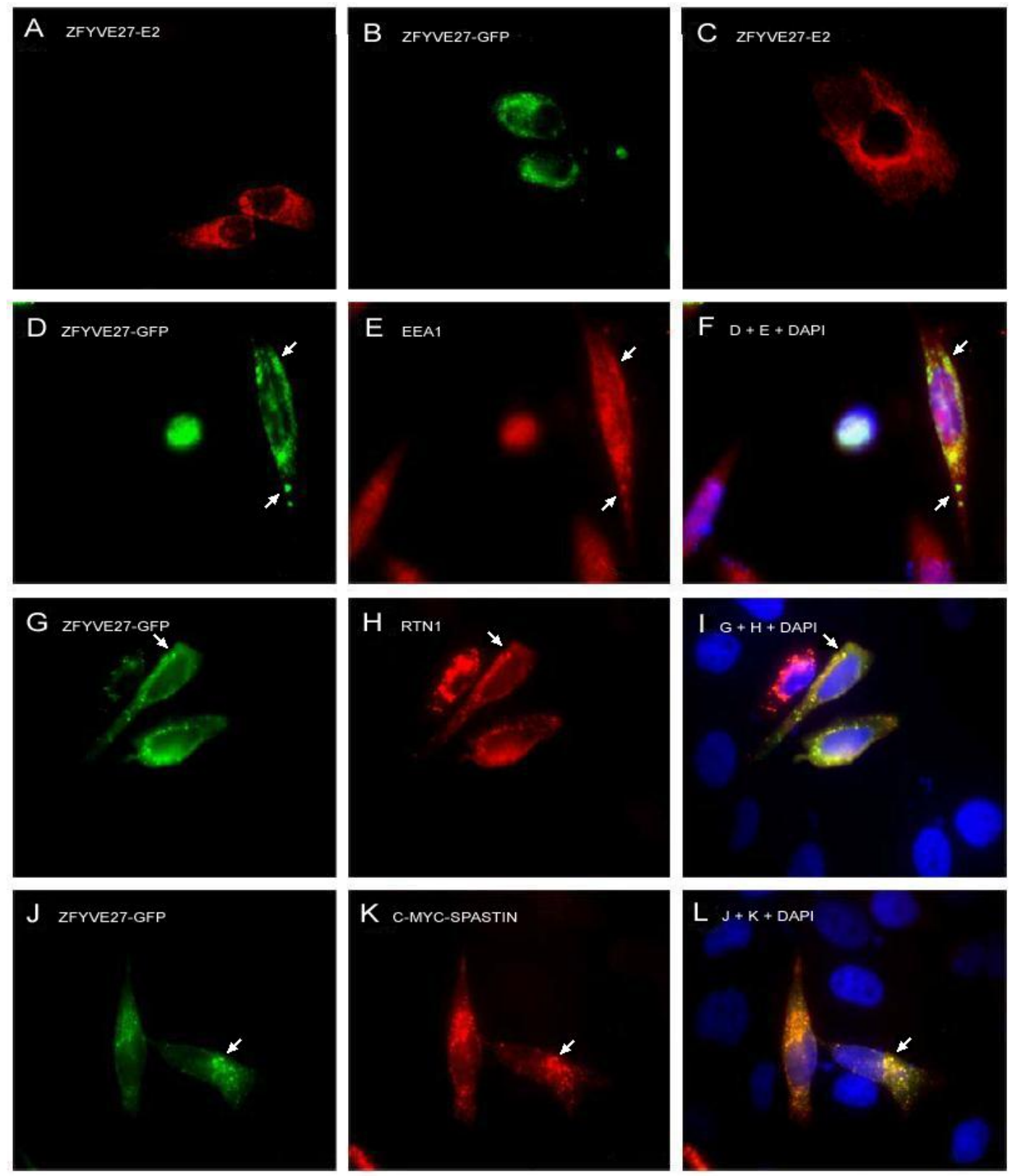

Abbildung 20: Co-Immunlokalisation von ZFYVE27 in HeLa-Zellen

Die mikroskopischen Bilder zeigen die intrazelluläre Verteilung von ZFYVE27- und SpastinFusionsprotein, sowie die der Marker EEA1 (Endosomen), RTN1 (Endoplasmatisches Retikulum) und des Farbstoffes DAPI (Zellkern) in transfizierten HeLa-Zellen. Die beiden Antikörper EEA1 (E, F) und RTN1 (H, I) emittieren jeweils rotes und DAPI (F, I, L) blaues Licht. Das rote Signal des ZFYVE27-E2-Fusionsproteins zeigt in Bild A punktuelle Anreicherungen im Zytoplasma und in Bild $\mathrm{C}$ eher diffuse, kernnahe Anreicherungen. In den Bildern B, D, G und J zeigt das grüne Signal des GFP-ZFYVE27-Fusionsproteins jeweils eine klare punktuelle Verteilung im Zytoplasma mit Aussparung des Kerns. Bei den mit GFP-ZFYVE27 transfizierten und zusätzlich mit dem EEA1-Marker behandelten Zellen zeigt das rote EEA1-Signal eine lokale, leicht diffuse Verteilung im Zytoplasma (E). Die Überlagerung der Signale zeigt in Bild F eine genaue Übereinstimmung einiger runder zytoplasmatischer Signalherde. In Bild H ist das rote Signal des RTN1-Markers in drei Zellen, jeweils mit leichten Unterschieden in der Intensität, zytosolisch an rundlichen Strukturen lokalisiert. Bei gemeinsamer Darstellung in Bild I zeigen sich teilweise lokale Überlagerungen des RTN1- und des GFP-Signals. Bei den mit GFP-ZFYVE27 (J) und cmyc-Spastin transfizierten Zellen zeigt das c-myc-Spastin-Fusionsprotein ebenfalls eine punktuelle zytosolische Verteilung (K), und die Überlagerung mit dem GFP-Signal zeigt teilweise eine CoLokalisation der beiden Proteine (L). Einzelne Bereiche, in denen eine Co-Lokalisation sichtbar ist, sind mit Pfeilen markiert. 


\subsubsection{Generierung von ZFYVE27-cDNA(c.572G>T)}

Eine Untersuchung der Aminosäuresequenz von ZFYVE27 mit dem SOSUIProgramm (http://bp.nuap.nagoya-u.ac.jp/sosui/) zeigte, dass das ZFYVE27Protein mehrere Transmembrandomänen enthalten kann. Die Varianten 2, 3 und 4 bilden demnach drei, die Variante 1 eine Transmembrandomäne. Weiterhin zeigte die Analyse mit dem SOSUI-Programm, dass der bei der Sequenzierung gefundene Basenaustausch c.572G $>\mathrm{T}$ in der kodierenden Sequenz der ZFYVE27cDNA zu einer Verschiebung einer Transmembrandomäne führen könnte. Diese Veränderung der Primärstruktur führt möglicherweise zu einer Störung der intrazellulären Verteilung des Proteins und könnte dadurch die Ursache der HSP sein. Um dies zu kontrollieren, sollte ein GFP-ZFYVE27-Konstrukt erstellt werden, welches den Basenaustausch G zu T an Position 572 der kodierenden Sequenz enthält. Mit der Immunfluoreszenz-Methode könnte dann eventuell beurteilt werden, ob die putative Mutation zu einer Störung der physiologischen Verteilung des ZFYVE27(p.G191V)-Proteins führt.

Zur Generierung der mutierten cDNA wurde die schon in den pGem ${ }^{\circledR}$-TeasyVektor klonierte ZFYVE27-cDNA verwendet. Es wurde eine PCR mit den Primern FLJ-MUT79 F, welcher die Veränderung c.572G $>$ T enthält, und FLJORF-R durchgeführt und eine weitere mit den Primern FLJ-ORF-F und FLJ-RTEx4-R. Die Primer wurden so gewählt, dass bei den beiden PCRs sich überlappende Amplifikate entstehen. In einer weiteren PCR wurden dann, zusammen mit den Primern FLJ-ORF-F und FLJ-ORF-R, die aufgereinigten Produkte der ersten beiden PCRs eingesetzt (s. Abb. 21). Nachdem das hierbei entstandene Amplifikat in den pGem ${ }^{\circledR}$-Teasy-Vektor kloniert worden war, wurde ein Zellklon, der die cDNA mit der Veränderung enthielt, nach Sequenzierung ausgewählt. So konnte die ZFYVE27-cDNA, beginnend von Base 196 bis zu Base 1149 , mit dem Basenaustausch c.572G $>$ T hergestellt werden. 


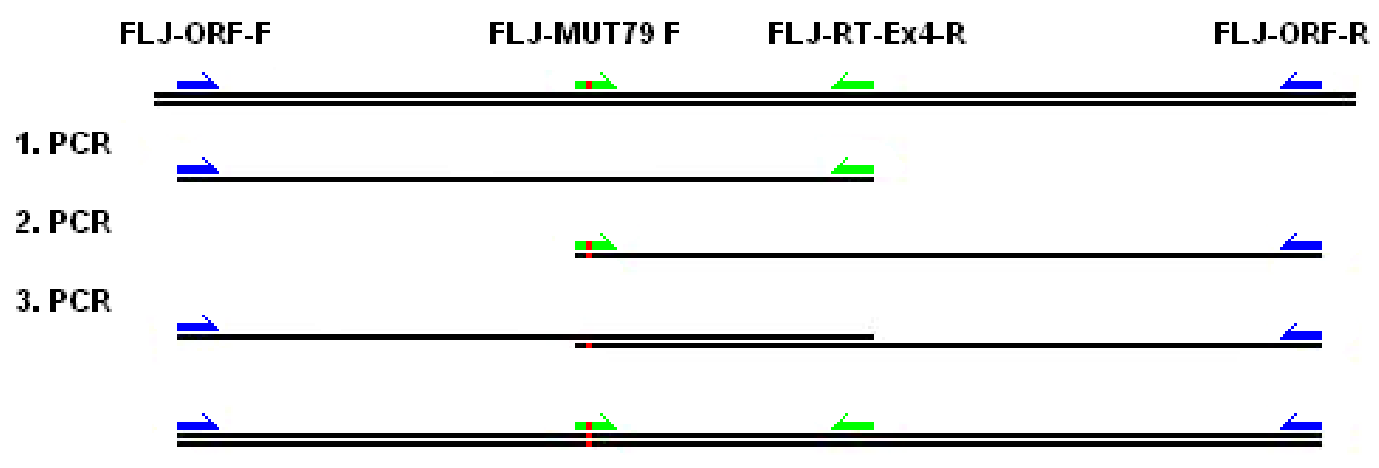

Abbildung 21: Generierung der veränderten ZFYVE27-cDNA

Das Schema zeigt die verwendeten Primer mit ihrer Bezeichnung in blau und grün über der schwarz dargestellten DNA. Die im Primer FLJ-MUT79-F enthaltene Veränderung ist rot dargestellt. Die Produkte der ersten und der zweiten PCR sind darunter dargestellt. Als letztes folgt die schematische Überschneidung dieser Produkte, die zum endgültigen Amplifikat der dritten PCR führt.

Anschließend wurden die Schnittstellen für die Restriktionsenzyme BamHI und HindIII per PCR integriert und die cDNA wieder in den pGem ${ }^{\circledR}-T e a s y-V e k t o r$ kloniert. Schließlich wurde die cDNA mit Hilfe der Restriktionsenzyme BamHI und HindIII in den pEGFP C1-Vektor kloniert. Das in den pEGFP C1-Vektor klonierte Fragment ist 0,958 kb groß und entspricht der ZFYVE27-cDNA von Base 199 bis Base 1152, enthält aber im Gegensatz zur normalen cDNA die putative Mutation. Dieses Kontrukt wurde mit GFP-ZFYVE27(p.G191V) bezeichnet. Mit ihm wurden HeLa-Zellen transfiziert und für die CoImmunlokalisations-Analyse verwendet.

\subsubsection{Immunfluoreszenz-Analyse von ZFYVE27(p.G191V) in HeLa-Zellen}

GFP-ZFYVE27(p.G191V) zeigte mehrere deutlich unterschiedliche Verteilungsmuster. In einigen HeLa-Zellen war eine Verteilung ähnlich der des normalen ZFYVE27 mit sehr punktuellen Anreicherungen des grünen GFPSignals zu erkennen (Abb. 22 D). Einige Zellen ließen dies ebensfall noch erahnen, doch schien das Kontrukt in diesen insgesamt homogener im Zytoplasma verteilt zu sein (Abb. 22 A). Ein weiterer Teil der Zellen zeigte jedoch eine markant andere Verteilung des Fusionsproteins. Das GFP-Signal war in manchen der HeLa-Zellen deutlich diffuser, mit größter Konzentration perinukleär und 
überdeckte teilweise den Zellkern (Abb. 22 B) oder es war, wie in Abbildung 22 Bild C, eine verhältnissmäßig gleichmäßige Verteilung über den gesamten Zellkörper zu erkennen. In den gleichzeitig mit GFP-ZFYVE27(p.G191V) und cMyc-Spastin transfizierten Zellen zeigte das rote Signal des c-Myc-Spastins viele lokal konzentrierte Anreicherungen im Zytoplasma (Abb. 22 E). Das veränderte ZFYVE27-Fusionsprotein hingegen zeigt im direkten Vergleich keine so klare punktuelle Konzentration (Abb. 22 D), und die Überlagerung der beiden Signale zeigte nur geringe Übereinstimmungen, die hier mit Pfeilen markiert sind.
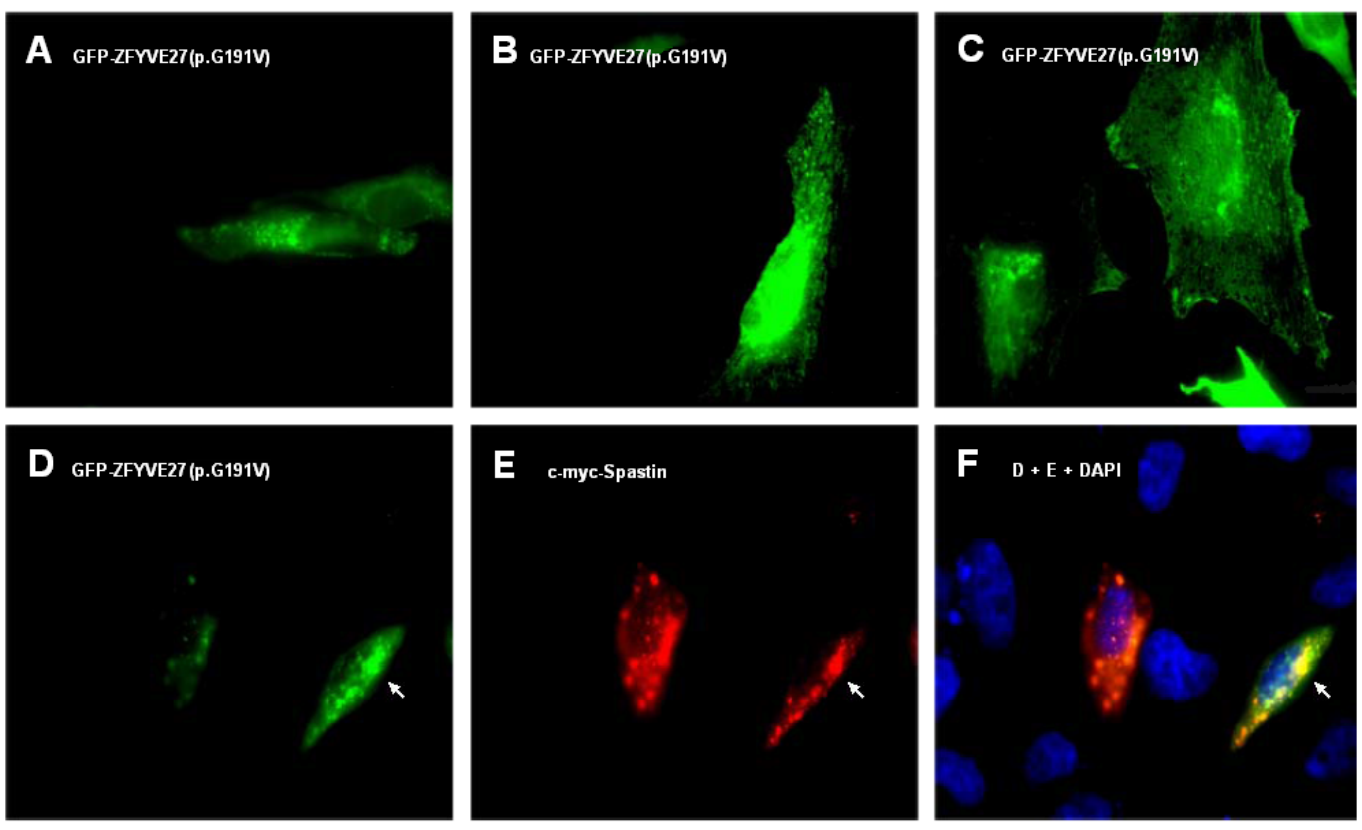

Abbildung 22: Co-Immunlokalisation von ZFYVE27(p.G191V) in HeLa-Zellen

Die mikroskopischen Bilder zeigen die intrazelluläre Verteilung des GFP-ZFYVE27(p.G191V)(grün) und des c-Myc-Spastin-Fusionsproteins (rot), sowie des Zellkernmarkers DAPI (blau).

Bei ungefähr $50 \%$ der Patienten mit autosomal dominanter HSP kann durch Sequenzierung der Gene SPG3 und SPG4 eine Mutation gefunden werden. Neben Mutationen im ZFYVE27-Gen wäre das Vorhandensein von großen Deletionen in SPG3 und SPG4, welche durch das normale Sequenzierungsverfahren nicht erkannt werden, eine weitere Erklärung hierfür. Außerdem gibt es Berichte über Familien, in denen die HSP durch Deletionen im SPG4-Gen verursacht wird (Bönsch et al. 2003, Beetz et al. 2006, Erichsen et al. 2007). Deswegen wurde in 
dieser Arbeit das SPG4-Gen von HSP-Patienten unter Verwendung der RealTime-PCR auf Deletionen untersucht.

\subsection{Deletionssuche im SPG4-Gen mit Hilfe der Real-Time-PCR}

Im Rahmen dieser Arbeit sollte die Real-Time-PCR-Methode (2.2.11, S. 34) für das SPG4-Gen etabliert werden, um bei HSP-Patienten Deletionen im SPG4-Gen detektieren zu können. Die sehr empfindliche Methode der Real-Time-PCR konnte für 15 der 17 Exons von SPG4 etabliert werden. Für die Exons 6 und 7 konnten keine Reaktionsbedingungen gefunden werden, mit denen reproduzierbare Ergebnisse erzielt werden konnten. Sie wurden deswegen in dieser Arbeit nicht untersucht.

\subsubsection{Ergebnisse der Real-Time-PCR-Untersuchung}

Von den insgesamt 91 untersuchten HSP-Patienten, bei denen durch Sequenzierung eine Mutation im SPG3- und im SPG4-Gen ausgeschlossen wurde, zeigten sieben eine Verringerung der relativen DNA-Kopienanzahl. Bei den Patientenproben 19544, 19545, 19549, 21962, 21963 und 21969 war die DNAKopienzahl des Exons 16 im Vergleich mit dem Kontroll-Amplifikat deutlich vermindert (s. Abb. 23). Die Untersuchungen ergaben bei diesen Patienten für Exon 16 eine relative Kopienzahl von ungefähr 0,5, während die Werte der anderen untersuchten Exons um 1 lagen. Die genauen Werte sind in Tabelle 2 wiedergegeben. Als Kontrollproben wurde die DNA von zwei nicht an HSP erkrankten Menschen verwendet, welche hier mit WT-1 und WT-2 bezeichnet werden. Im Vergleich mit diesen Kontrollen und den anderen SPG4-Exons betrug die Verminderung der DNA-Kopienzahl circa 50 Prozent. 


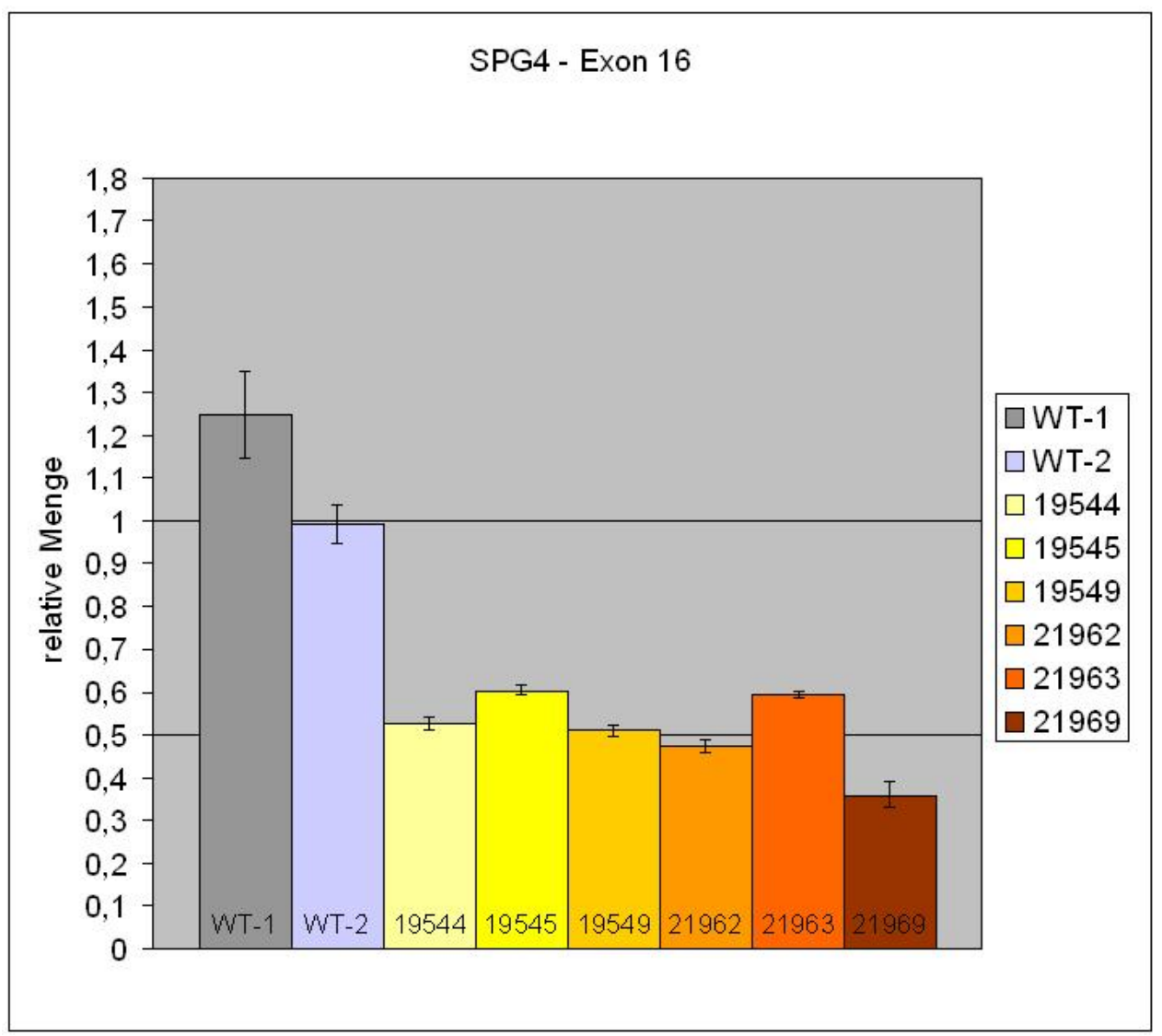

\section{Abbildung 23: relative DNA-Kopienzahl SPG4 Exon 16}

Graphische Darstellung der Real-Time-Ergebnisse der Patienten mit verminderten Werten für das Exon 16 und der Kontrollproben (WT-1, WT-2). Auf der Y-Achse ist die relative DNAKopienanzahl angegeben. Diese ist das Produkt aus der Division der Konzentration des jeweiligen Exons 16 und der Konzentration des Kontroll-Exons. Auf der X-Achse sind die Patienten-Proben und die beiden Kontroll-Proben nebeneinander als Balken dargestellt.

\begin{tabular}{|c|c|c|c|c|c|c|c|c|}
\hline & WT-1 & WT-2 & 19544 & 19545 & 19549 & 21962 & 21963 & 21969 \\
\hline $\begin{array}{c}\text { Probe } \\
\mathrm{c}_{S P G 4-E x o n ~ 16} / \mathbf{c}_{T C T}\end{array}$ & 1,24 & 0,99 & 0,52 & 0,60 & 0,50 & 0,47 & 0,59 & 0,36 \\
\hline
\end{tabular}

Tabelle 2: relative Kopienzahl SPG4 Exon 16

Die Patientenprobe 21940 zeigte bei den Untersuchungen eine verminderte DNAKopienzahl der Exons 14, 15, 16 und 17 (s. Abb. 24). Die relative Kopienzahl der Exons 14, 15, 16 war im Vergleich mit der Kontrollprobe WT-2 und den anderen SPG4-Exons der Probe um ungefähr 50 Prozent reduziert. Exon 17 zeigte eine Verringerung um 24 Prozent. Um eine putative Deletion einzugrenzen, wurde ein weiteres Amplifikat untersucht, welches ungefähr $2 \mathrm{~kb}$ in 3'-Richtung des Exon 
17 liegt. Dieses als 17-X bezeichnete Amplifikat zeigte eine relative DNAKopienzahl von etwa „1“. Tabelle 3 gibt die genauen Zahlenwerte wieder.

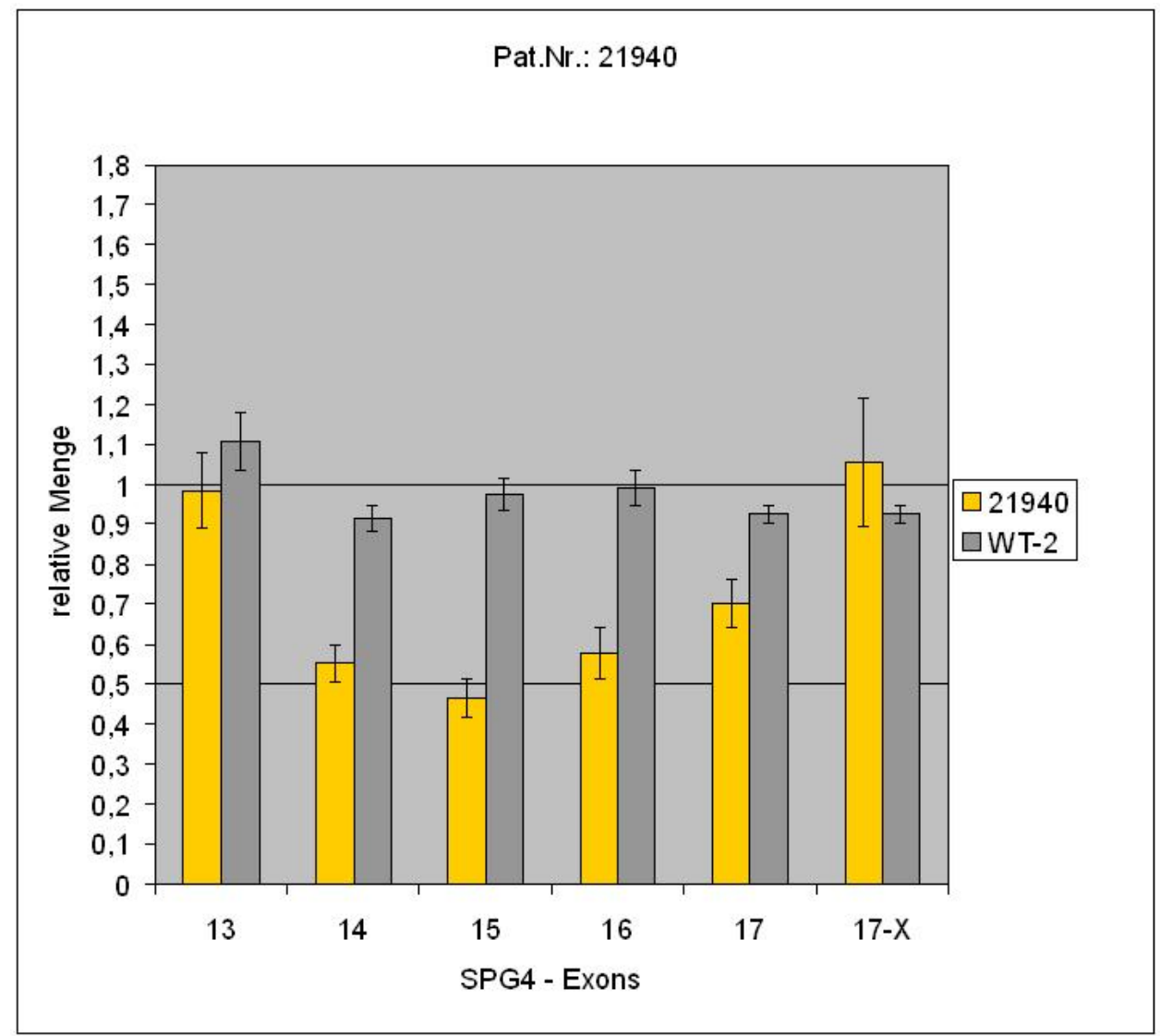

\section{Abbildung 24: Real-Time-PCR-Ergebnisse - Patient 21940 im Vergleich mit WT-2}

Graphische Darstellung der Real-Time-Ergebnisse des Patienten 21940 im Vergleich mit der Kontroll-Probe WT-2. Auf der Y-Achse ist die relative DNA-Kopienanzahl angegeben. Diese ist das Produkt aus der Division der Konzentration des jeweiligen Exons und der Konzentration des Kontroll-Exons. Auf der X-Achse sind die Werte der Exons 13 bis 17 und für das Amplifikat 17$\mathrm{X}$ der beiden untersuchten Proben nebeneinander als Balken dargestellt.

\begin{tabular}{|c|c|c|c|c|c|c|}
\hline Exon & 13 & 14 & 15 & 16 & 17 & $17-\mathrm{X}$ \\
\hline $\begin{array}{c}\text { WT-2 } \\
\text { (cSPG4-Exon/cTcT) }\end{array}$ & 1,10 & 0,91 & 0,97 & 0,99 & 0,92 & 0,92 \\
\hline $\begin{array}{c}21940 \\
\text { (cSPG4-Exon/cTcT) }\end{array}$ & 0,98 & 0,55 & 0,46 & 0,57 & 0,70 & 1,05 \\
\hline
\end{tabular}

Tabelle 3: relative Kopienzahl der Exons 13, 14, 15, 16, 17, 17-X von WT-2 und Probe 21940

Bei drei der 91 Patienten konnten keine verwertbaren Ergebnisse erzielt werden, was am ehesten durch die degradierte DNA zu erklären ist. Um die Ergebnisse zu kontrollieren, wurde bei den sieben Patienten mit möglicherweise vorliegender Deletion das Experiment wiederholt, wobei sich die Ergebnisse bestätigten. 


\subsection{2 „Long-Range“-PCR}

Um das Ergebnis der Real-Time-PCR zu verifizieren, wurde eine PCR mit Primern durchgeführt, die vor Exon 15 (Intron 14) und hinter Exon 17 liegen und so sowohl eine Amplifikation des normalen ungefähr $12 \mathrm{~kb}$ großen WildtypAllels, als auch des durch eine eventuell vorliegende Deletion verkürzten Allels ermöglichen. Als Kontrolle wurde die DNA eines Menschen ohne HSPErkrankung verwendet, hier als WT-1 bezeichnet. Zusätzlich wurde eine Reaktion als negative Kontrolle ohne DNA durchgeführt (,0-Kontrolle“).

Bei der gelelektrophoretischen Auftrennung der Produkte konnte in der Kontrollprobe WT-1 eine einzelne ungefähr $12 \mathrm{~kb}$ große Bande dargestellt werden. In den Proben 19544 und 21969 konnte neben einem 12 kb großen Amplifikat ein etwa $10 \mathrm{~kb}$ großes Amplifikat nachgewiesen werden. In Probe 19549 waren zusätzlich mehrere kleinere Banden mit einer Größe von 6 bis 11 kb vorhanden. Probe 21962 zeigte mehrere Banden im Bereich von 1 bis $3 \mathrm{~kb}$, aber keine Bande im Bereich um 12 kb. Die „0-Kontrolle“ enthielt kein Amplifikat (s. Abb. 25 und 26).

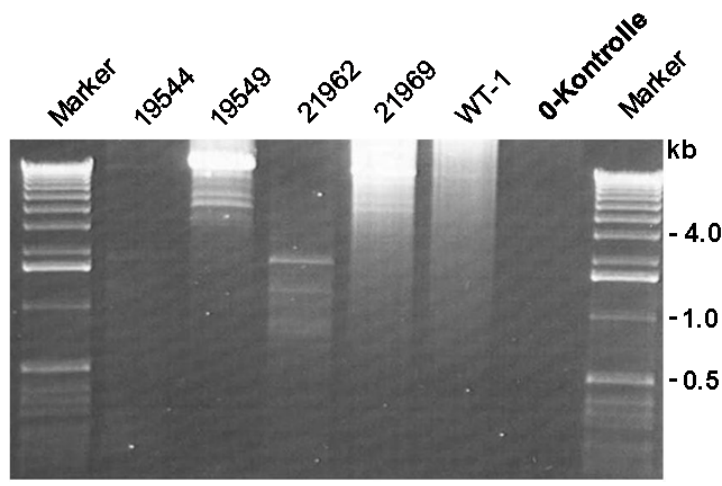

\section{Abbildung 25: „Long-Range“-PCR}

Agarosegel mit den Amplifikaten der „LongRange“-PCRs. Neben dem Größenstandard

(Marker) links und rechts wurden die Proben und die ,0-Kontrolle“ entsprechend der Beschriftung über den Spuren aufgetragen.

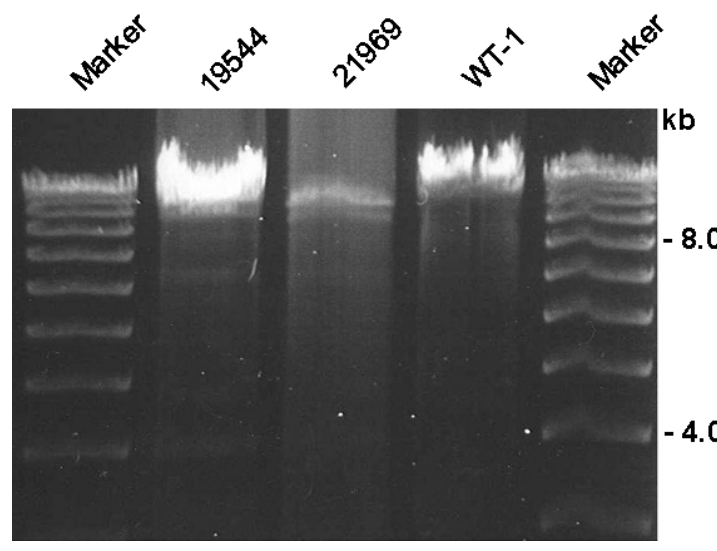

Abbildung 26: „Long-Range““-PCR - 19544, 21969, WT-1

Agarosegel mit Produkten der „Long-Range“-

8.0 PCR. Nebeneinander aufgetragen wurden der Größenstandard (Marker), die Proben 19544 21969, WT1 und der Größenstandard (Marker).

4.0 Über den Spuren ist jeweils angegeben, von welchem Patienten die DNA für den Ansatz stammt. 


\subsubsection{RT-PCR}

Die „Long-Range“-PCR (2.2.6.5, S. 27) lieferte keinen eindeutigen Beweis für das Vorliegen von Deletionen, da neben dem gewünschten Amplifikat auch immer unspezifische Produkte nachweisbar waren. Es sollte nun mit Hilfe der RTPCR kontrolliert werden, ob eine mögliche Deletion auf RNA-Ebene nachgewiesen werden konnte. Hiermit würde einerseits bewiesen werden, dass eine Deletion vorliegt, als auch geklärt werden, ob es $\mathrm{zu}$ einer effektiven Expression des mutierten Allels kommt. Es wurde RNA aus dem Blut der Patienten gewonnen (2.2.3.1, S. 19) und für eine Reverse-Transkriptase-Reaktion mit anschließender PCR verwendet. Hierbei wurden die Primer SPG4-RNA-F4 und SPG4-RNA-R2 eingesetzt, die den Bereich von Exon 14 bis Exon 17 einschließen und so bei einer Deletion in einem Allel zwei verschieden große Amplifikate erzeugen sollten. Als Kontrolle wurden RT-PCRs mit der RNA von zwei Menschen, bei denen keine HSP-Erkrankung vorliegt, durchgeführt. Diese werden hier als „WT-1“ und „WT-2“ bezeichnet.

Alle untersuchten Proben ergaben ein ungefähr 1,4 kb großes Fragment (s. Abb. 27). In den Patientenproben 21962 und 21963 ließ sich bei der optischen Kontrolle zusätzlich ein kleineres Amplifikat vermuten, welches in Abbildung 27 mit weissen Pfeilen markiert ist. Der Versuch, dieses nach Gelextraktion in pGem ${ }^{\circledR}-$ Teasy zu klonieren und zu sequenzieren gelang wiederholt nicht.

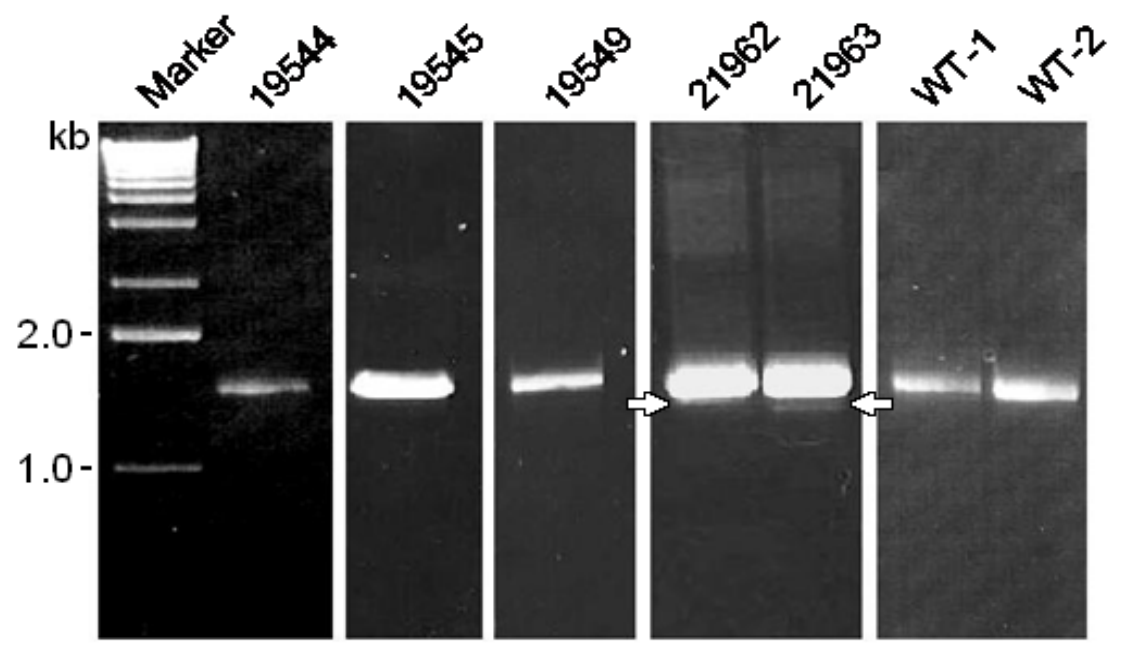

Abbildung 27: RT-PCR - SPG4 Deletions-Kandidaten

Agarosegel mit den Produkten der RT-PCRs. Über den Spuren ist angegeben, welche Probe aufgetragen wurde. 


\subsubsection{Southernblot}

Die bisherigen Untersuchungen lieferten keine eindeutige Bestätigung der Ergebnisse der Real-Time-PCR, deswegen sollten die Deletionen mit Hilfe der Southernblot-Methode (2.2.9.1, S. 32) endgültig auf DNA-Ebene verifiziert werden. Hierzu wurde mittels des Programms „webcutter“ (http://rna.lundberg.gu.se/cutter2/) eine Karte der RestriktionsenzymSchnittstellen erstellt und anhand dieser die Enzyme EcoR1 und Stu1 für die Southernblot-Analyse gewählt (s. Abb. 28).

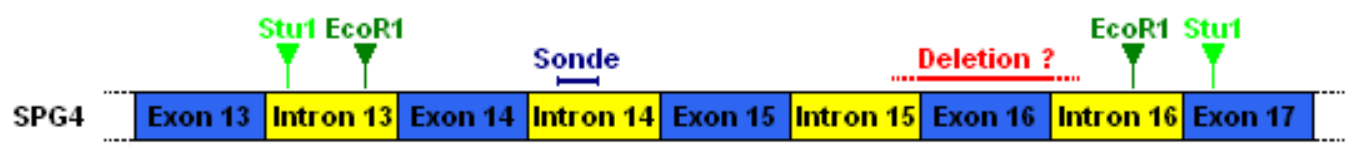

\section{Abbildung 28: Restriktions-Schnittstellen EcoR1 und Stu1}

Die Abbildung zeigt die ungefähre Lage der Restriktionsenzym-Schittstellen (grün), der Sonde (blau) und der eventuell vorliegenden Deletion (rot) im Bezug zum SPG4-Gen. Exons sind blau und Introns gelb dargestellt.

Das Restriktionsenzym EcoR1 schneidet die humane DNA u.a. im Bereich des Introns 13 und im Intron 16, so dass bei Vorliegen des normalen, nicht deletierten Gens ein ungefähr $9 \mathrm{~kb}$ großes Fragment entsteht. Die Schnittstellen von Stu1 liegen in Intron 13 und in Exon 17 und lassen bei Restriktion des normalen SPG4Gens ein ungefähr 12 kb großes Fragment entstehen. Als Sonde wurde bei diesem Southernblot ein 590 bp großer Abschnitt des Introns 14 unter Verwendung der Primer SB-Sonde-F und SB-Sonde-R amplifiziert. Da die TaqmanUntersuchungen keinen Hinweis auf eine Deletion von Exon 15 geliefert hatten, sollte die Sonde auch bei Vorliegen einer Deletion an das entsprechende Fragment binden können. Von jeder Patienten-Probe wurde ein Ansatz mit EcoR1 und ein Ansatz mit Stu1 restringiert und untersucht. Zusätzlich wurde eine DNA-Probe von einem nicht an HSP erkrankten Menschen untersucht. Diese wirde hier als WT-1 bezeichnet.

Die radioaktive Sonde markierte bei Restriktion mit EcoR1 in den Proben WT-1, 19544, 25950, 19549, 21962 und 21963 ein einzelnes ungefähr 9 kb großes Fragment (s. Abb. 29). Bei Restriktion mit Stu1 konnte in denselben Proben eine Bindung der Sonde an ein einzelnes ungefähr $12 \mathrm{~kb}$ großes Fragment nachgewiesen werden. Bei der Untersuchung der Probe 19545 konnte auch bei 
Wiederholung des Experiments keine Bindung der Sonde nachgewiesen werden. Keine Probe zeigte weitere Fragmente und somit eindeutig auch keine Hinweise auf eine vorliegende Deletion.

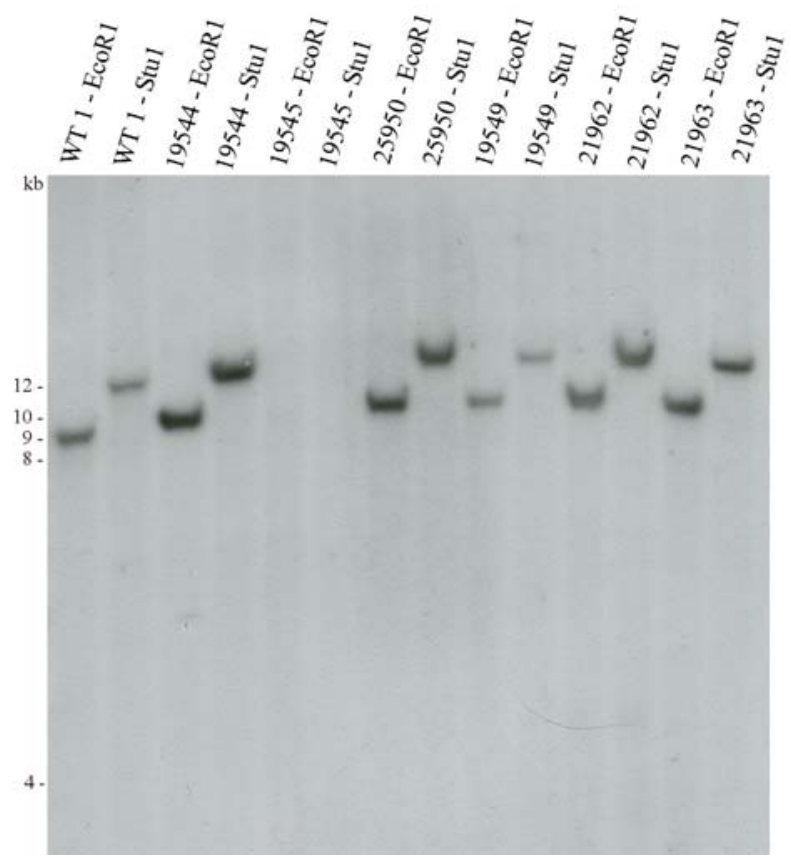

\section{Abbildung 29: Southernblot}

Röntgenfilm, der das Ergebnis der Hybridisierung zeigt. Die Spuren enthalten der Beschriftung entsprechend die mit EcoR1 und $S t u 1$ restringierten Patientenproben. Der Größenstandard ist nicht mit abgebildet. 


\section{Diskussion}

\subsection{Problemstellung}

Die hereditären spastischen Paraplegien bilden eine heterogene Gruppe neurodegenerativer Erkrankungen, für welche bisher 41 Loci identifiziert werden konnten (Salinas et al. 2008), wobei 70 bis 80 Prozent aller HSP-Erkrankungen autosomal-dominant vererbt werden. Bei ungefähr 50 Prozent der autosomaldominanten Krankheitsfälle kann eine Mutation in den Genen SPG3 oder SPG4 als Ursache der HSP nachgewiesen werden. Für einen großen Teil der Fälle verbleiben die für die Krankheit verantwortlichen Gene unbekannt. Eine der möglichen Erklärungen für diese bisher nicht geklärten Fälle könnte in Mutationen anderer Gene liegen, welche durch eine Interaktion mit dem von SPG4 codierten Protein Spastin die Funktion des Spastins verändern und so die Entstehung der Krankheit auslösen. Mit der Y2H-Methode wurde nach Interaktionspartnern des Spastins gesucht und hierbei unter anderem ZFYVE27 identifiziert (Mannan et al. 2006). Das Ziel dieser Arbeit ist die Überprüfung der Interaktion zwischen dem hypothetischen Protein ZFYVE27 und Spastin und die Identifizierung von Mutationen im ZFYVE27-Gen bei AD-HSP-diagnostizierten Patienten.

ZFYVE27 ist noch nicht untersucht worden und zu Beginn dieser Arbeit lagen keine Erkenntnisse über das ZFYVE27-Gen und das entsprechende Protein vor. Es sollten deswegen grundlegende Informationen über den Aufbau, die Expression und intrazelluläre Verteilung von ZFYVE27 gewonnnen werden, um so eventuell Rückschlüsse auf seine Funktion ziehen zu können. Eine weitere naheliegende Ursache für die AD-HSP könnten Deletionen in den Genen SPG3 und SPG4 sein, welche durch die angewandte Sequenzanalyse nicht nachgewiesen werden. Daher sollte das SPG4-Gen bei AD-HSP-diagnostizierten Patienten mit Hilfe der RealTime-PCR-Methode auf Deletionen hin untersucht werden 


\subsection{ZFYVE27}

Das hypothetische Protein ZFYVE27, das je nach Spleißvariante aus 318 bis 416 Aminosäuren besteht, enthält im N-terminalen Bereich eine FYVE-Domäne und nach Analyse-Ergebnissen mit dem SOSUI-Programm (http://bp.nuap.nagoyau.ac.jp/sosui/) ein oder drei Transmembrandomänen im C-terminalen-Bereich. Bisher wurden beim Menschen mehr als 27 Proteine mit einer solchen FYVEDomäne identifiziert. Die strukturell ähnlichen Proteine können über die FYVEDomäne mit PI3P Kontakt aufnehmen und aufgrund dessen an Membranstrukturen der Zelle gebunden sein. Besonders an Endosomen scheint ein Großteil der FYVE-Proteine zu binden und so wird ihnen, ihrer Lokalisation entsprechend, eine Funktion bei intrazellulären Transportprozessen zugeschrieben Bekannt ist aber auch eine Beteiligung an der Regulation des Zytoskeletts und bei der Vermittlung von Signalkomplexen. Außergewöhnlich für ein Mitglied der FYVE-Proteinfamilie ist bei ZFYVE27 das Vorkommen mehrerer hydrophober Transmembrandomänen, die in dieser Form bei keinem der bisher bekannten FYVE-Proteine nachgewiesen werden konnten. Obwohl schon eine Reihe der FYVE-Proteine Bestandteil vielfacher Untersuchungen war, lässt sich für die Familie dieser Proteine keine einheitliche Einteilung finden. $\mathrm{Zu}$ den bereits gut charakterisierten fügen sich immer weitere, neue und teilweise sehr unterschiedliche Mitglieder hinzu. Um dennoch eventuell Rückschlüsse auf die Eigenschaften, Funktionen und Aufgaben von ZFYVE27 ziehen zu können, sollen im folgenden Teil die wichtigsten Vertreter der FYVE-Familie dargestellt und Unterschiede bzw. Gemeinsamkeiten mit ZFYVE27 aufgezeigt werden.

\subsubsection{FYVE-Finger-Proteinfamilie}

Die Bezeichnung der FYVE-Domäne wurde zum ersten Mal 1996 verwendet, als Stenmark et al. das Protein EEA1 untersuchten und eine Zinkionen-bindende Domäne im C-terminalen Bereich des Proteins identifizierten. Neben EEA1 konnte diese Domäne auch in den Proteinen Fablp, YOTP und Vps27p nachgewiesen werden und so wurden die Anfangsbuchstaben dieser vier Proteine für die Namensgebung verwendet. Bis heute konnten beim Menschen 27, im Fadenwurm (C. elegans) 13 und in Hefe (S. cerevisiae) 5 FYVE-Proteine 
identifiziert werden. Während einige Bereiche konserviert blieben, weitete sich im Laufe der Evolution die Verwendung dieser Proteine aus und es entstanden Moleküle mit unterschiedlichsten Aufgaben. Entsprechend vielfältig sind die funktionellen Gruppen, die neben der FYVE-Domäne auftreten, aber auch die Eigenschaften der einzelnen FYVE-Domänen an sich. Die Tabelle 4 zeigt eine Übersicht über die FYVE-Proteinfamilie mit ihren bekanntesten Vertretern.

\begin{tabular}{|c|c|c|}
\hline Bezeichnung & Struktur & Funktion \\
\hline $\begin{array}{l}\text { EEA1 } \\
\text { Rabenosyn-5/ Vac1p }\end{array}$ & $\begin{array}{l}\text { IQ-Motiv, ZFIRE finger, } \\
\text { coiled-coil }\end{array}$ & Rab-Effektoren \\
\hline Rabip4 & RUN & \\
\hline FCCD1 & RUN, coiled-coil & $?$ \\
\hline ANKHZN & BTB, Ankyrin-Repeats & Endosom-Zytoskelett Interaktion \\
\hline FENS-1 & WD-Repeats & Endozytose \\
\hline $\begin{array}{l}\text { MTMR3 } \\
\text { FYVE-DSP }\end{array}$ & PI3P-Phosphatase & Autophagozytose-Regulation \\
\hline $\begin{array}{l}\text { Fgd1, 2, 3/ YOTB } \\
\text { Frabin }\end{array}$ & DH, PH & Actin Zytoskelett-Steuerung \\
\hline $\begin{array}{l}\text { SARA } \\
\text { Endofin }\end{array}$ & Smad, TGFß-binding & Rezeptor-Signalvermittlung \\
\hline PIKfyve/ Fablp & $\begin{array}{l}\text { PI3P 5-Kinase, DEP, } \\
\text { Chaperon }\end{array}$ & MVB/Membran-Recycling \\
\hline Hrs/Vps27p & $\begin{array}{l}\text { VHS,UIM, coiled-coil, } \\
\text { Clathrin-box }\end{array}$ & $\begin{array}{l}\text { Endosom-Lysosom-Vermittlung } \\
\text { Clathrin/MVB-Ausbildung }\end{array}$ \\
\hline DFCP1 (TAFF1) & Doppel-FYVE-Domain & $?$ \\
\hline ZFYVE27 & Transmembran-Domäne & $?$ \\
\hline \multicolumn{3}{|c|}{$\begin{array}{l}\text { Tabelle 4: FYVE-Protein-Familie } \\
\text { Die Tabelle zeigt eine Auswahl der bekanntesten FYVE-Proteine mit ihrer Bezeichnung, ihren } \\
\text { funktionellen Domänen und ihrer vermuteten Funktion. Die Bezeichnung der Proteine, die gleichfalls } \\
\text { in H. sapiens, C. elegans oder S. cerevisiae nachgewiesen werden konnten, sind durch einen / getrennt. }\end{array}$} \\
\hline
\end{tabular}


Die FYVE-Domäne ist durch vier streng konservierte CxxC Bereiche definiert, welche für die Bindung von Zinkionen verantwortlich sind. Insgesamt besteht sie aus 60-80 Aminosäuren, in denen die funktionellen Bereiche WxxD, R(R/H)HHR und RVC eine wichtige Aufgabe für ihre Funktion erfüllen (Stenmark et al. 2002, Blatner et al. 2004, Hayakawa et al. 2004). Diese ebenfalls konservierten Bereiche wurden so in sehr ähnlicher Form in allen FYVE-Domänen gefunden und stehen bei der Bindung an PI3P in direktem Kontakt mit der Kopfgruppe des Inositols. In Abbildung 30 sind diese für die Eigenschaften der Domäne entscheidenden Bereiche blau markiert, außerdem zeigt die Abbildung 30 eine Übersicht über die weiteren Strukturmerkmale und den genauen Aufbau der Domäne. Untersuchungen zur Bindung an PI3P zeigten, dass ein als „Turretloop“ bezeichneter Bereich die Bindungsfähigkeit an membrangebundenes PI3P steigert, indem er in direkte Wechselwirkung mit der Membran tritt (Misra und Hurley 1999, Mao et al. 2000). Die Membranbindungsfähigkeit der einzelnen FYVE-Domäne ist zwar sehr selektiv, jedoch bei den meisten FYVE-Proteine nicht stark genug, um in vivo eigenständig für die Bindung an endosomale Strukturen zu sorgen. Die Bindungsfähigkeit der Moleküle wird deswegen durch unterschiedliche Mechanismen erhöht. Einige FYVE-Proteine besitzen hierzu zusätzlich andere funktionelle Gruppen, die ebenfalls membranbindende Eigenschaften besitzen oder aber mehrere FYVE-Domänen führen durch ihre synergistische Wirkung zu einer Bindung an die Membran. Dabei können diese in einem Molekül vorhanden sein, wie bei DFCP1, oder aber in 2 gleichen FYVEProteinen, die sich zu einem Dimer zusammenfügen (Derubeis et al. 2000, Raiborg et al. 2001).

Es hat sich gezeigt, dass die Fähigkeit der FYVE-Proteine mit sich selbst Dimere auszubilden verbreitet ist und, wie bei EEA1, durch sogenannte coiled-coilBereiche begünstigt werden kann (Stenmark et al. 2002). Weiterhin konnte innerhalb der FYVE-Domäne ein als „Dimerinterface“ bezeichneter Bereich identifiziert werde, welcher ebenfalls die Homodimer-Bildung unterstützt (Dumas et al. 2001). Durch die gemeinsame Wirkung der FYVE-Domänen eines solchen Dimers erhöht sich die Bindungsstärke soweit, dass in einigen Fällen auch ohne 
Wirkung anderer funktioneller Gruppen eine endosomale Lokalisation erreicht wird (Hayakawa et al. 2004).

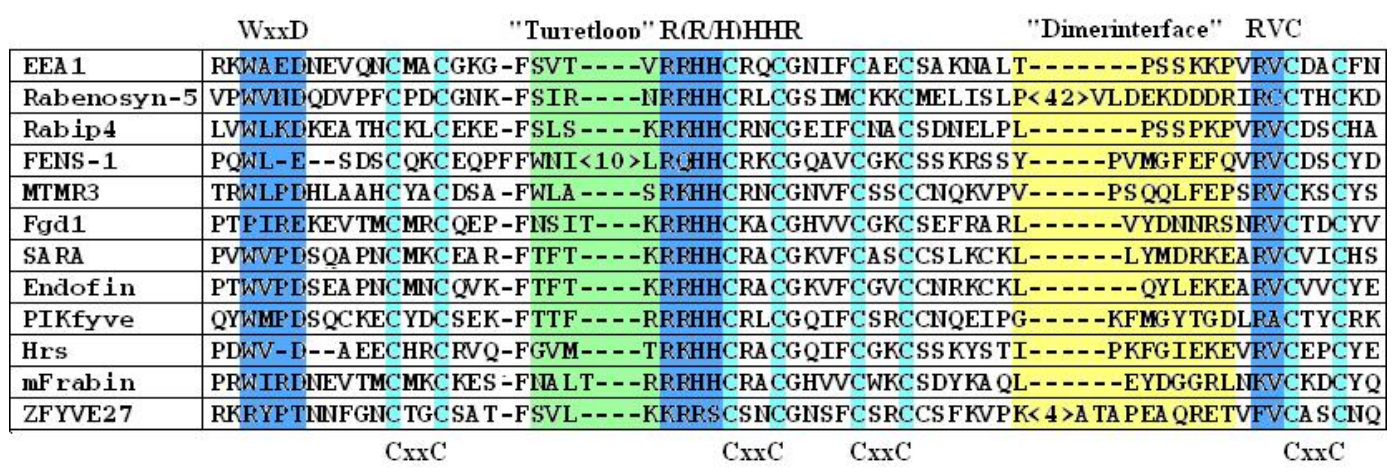

\section{Abbildung 30: Struktureller Aufbau der FYVE-Domäne}

Die Grafik zeigt die Aminosäuresequenz einiger FYVE-Domänen. Die konservierten und für die Funktion entscheidenden Bereiche sind farblich kenntlich gemacht - die zinkionen-bindenden Cysteine hellblau, die direkt mit PI3P in Kontakt stehenden Bereiche blau, das „Dimerinterface“ gelb und der „Turretloop“ grün.

Insgesamt lassen die Untersuchungen der FYVE-Domänen darauf schließen, dass durch das Zusammenspiel vieler einzelner Bereiche und unterschiedlicher Mechanismen eine Feinregulierung der FYVE-Proteine ermöglicht wird. Schon geringe Unterschiede in den funktionellen Bereichen der FYVE-Domäne (WxxD, R(R/H)HHR, RVC, „Turretloop“, „Dimerinterface“) und den begleitenden funktionellen Domänen können $\mathrm{zu}$ deutlichen Veränderungen der Bindungseigenschaften führen. Es konnte gezeigt werden, dass die FYVEDomänen nur bei ganz bestimmten Bedingung an Membranen binden und so eine Art des Ein- und Ausschaltens möglich ist, welches u. a. von der PhosphoinositolKonzentration, dem pH-Wert oder der Konformation des Proteins abhängt (Lee et al. 2005).

\subsubsection{EEA1}

Dieses konservierte Protein ist mit Rab5-GTP und einem Transferrin-Rezeptor an frühen Endosomen co-lokalisiert (Mu et al. 1995) und enthält neben der FYVEDomäne im C-terminalen Bereich eine als IQ-Motiv bezeichnete Rab-5-bindende, funktionelle Gruppe (Stenmark et al. 1996). Eine weitere Rab-5-bindende Sequenz findet sich im N-terminalen Bereich. Während die Bindung von FYVE an Membranstrukturen selektiv über PI3P erfolgt, bindet das IQ-Motiv selektiv an 
Rab-5-GTP. Die Eigenschaften dieser beiden funktionellen Gruppen führen zu einer sehr selektiven Bindung von EEA1 an junge Endosomen, da nur hier PI3P und Rab-5 in ausreichend hoher Konzentration zu finden sind (Wiedemann und Cockcroft 1998). Es konnte weiter gezeigt werden, dass trotz der Kombination der Bindungstellen die Fähigkeit an Endosomen zu binden davon abhängig ist, dass EEA1 mit sich selbst Dimere ausbilden kann (Callaghan et al. 1999). Funktionell konnte für EEA1 eine Aufgabe bei der Fusion von Endosomen nachgewiesen werden (Mills et al. 1998). Dabei könnte EEA1 möglicherweise über das Cterminal gelegenen IQ-Motiv und die FYVE-Domäne zunächst an junge Endosomen binden und dann über die N-terminal gelegene Rab-5-Bindungsstelle Kontakt zu einem anderen Endosom aufnehmen (Stenmark und Aasland 1999).

\subsubsection{PIKfyve/Fab1p}

$\mathrm{Zu}$ dem in der Hefe vorkommenden Fablp gibt es bei den Säugetieren das homologe PIKfyve. Beide besitzen neben der im N-terminalen Bereich liegenden FYVE-Domäne einen Bereich mit Phosphoinositol-Kinase-Aktivität (Shisheva et al. 1999, Sbrissa et al. 1999). Daneben enthält PIKfyve im mittleren Bereich noch weitere bisher wenig bekannte funktionelle Bereiche. Ähnlich den Eigenschaften von EEA1 konnte für PIKfyve auch eine Bindung über PI3P an membranöse Strukturen festgestellt werden, es wurde aber eine Assoziation mit eher älteren Endosomen nachgewiesen. Die Bindung erfolgt sowohl über die FYVE-Domäne als auch durch die katalytische Domäne, wobei die Affinität der Kinase-Bindung deutlich geringer ist (Sbrissa et al. 2002). PIKfyve scheint über die PI-KinaseAktivität an der Reifung von Endosomen beteiligt zu sein, jedoch ist besonders die Funktion und Regelung der DEP- und HSP-Chaperon-Domäne noch ungeklärt (Shisheva 2008).

\subsubsection{Hrs/ Vps27p}

Hrs, eines der wenigen FYVE-Proteine, bei dem die FYVE-Domäne im Cterminalen Molekülbereich liegt, enthält eine VHS-Domäne, eine clathrinbindende Domäne, eine coiled-coil-Region und einen mit Ubiquitin interagierenden Bereich. Auch für Hrs wurde eine deutlich Co-Lokalisation mit 
EEA1 an jungen Endosomen nachgewiesen (Komada und Soriano 1999; Raiborg et al. 2001). Stahelin et al konnten durch Röntgenkristall-Untersuchung an Vps27p und dem dazu homologen Hrs zeigen, dass die Proteine als Dimere an zwei membrangebundene PI3P binden (2002). Sie stellten gleichfalls fest, dass der erste Kontakt über Lys181 und Lys182 aufgenommen wird und dann der Rest der Domäne möglicherweise durch eine Konformationsänderung in die Membran „eintaucht“. Es scheint, als ob Hrs hauptsächlich als Rekrutierungstelle für andere Proteine an den jungen Endosomen fungiert und so eine Rolle bei der Koordinierung der Endosomen und bei der Ausbildung von MVB einnimmt (Bache et al. 2003).

\subsubsection{Frabin, Fgd1-3 / YOTB}

Dieser Gruppe von FYVE-Proteinen ist neben der FVYE-Domäne gemein, dass sie C-terminal zwei membranbindungsfähige $\mathrm{PH}$-Domänen und eine $\mathrm{DH}$-Domäne enthalten, welche eine Funktion bei der Regelung des GTP-Haushalts besitzt. Die Unterschiede zwischen ihnen liegen im N-terminalen Bereich, wo Fgd1 einen prolinreichen Bereich enthält, mit dem es über einen Interaktionspartner an FAktin binden kann, wohingegen die bei Frabin dort vorhandenen FAB-Domäne direkt an F-Aktin bindet. Dementsprechend konnte für diese Gruppe eine cytoskelettsteuernde Funktion nachgewiesen werden (Nakanishi und Takai 2008).

\subsubsection{SARA/Endofin}

Sowohl für SARA als auch für das sehr ähnliche Endofin konnte eine funktionelle Verbindung zu Signalvermittlungsprozessen hergestellt werden. Diese beiden FYVE-Proteine können über eine entsprechende Bindungsstelle an TGFßRezeptoren binden und fungieren, wohl über die zusätzliche Bindung von SmadProteinen, als Regulatoren einer TGFß-Signalkette. Immunfluoreszenzanalysen haben auch für diese beiden FYVE-Vertreter eine intrazelluläre Lokalisation an jungen Endosomen ergeben. Während für SARA eine Bindung von Smad 2 und 3 nachgewiesen wurde, scheint Endofin mit Smad $4 \mathrm{zu}$ interagieren (Tsukazaki et al. 1998, Chen et al. 2007). 


\subsubsection{Eigenschaften von ZFYVE27}

\subsubsection{Expression in Homo sapiens und Mus musculus}

In den zur Expression von ZFYVE27 durchgeführten Untersuchung konnte beim Menschen auf RNA-Ebene, von den 4 theoretisch bestehenden Spleißvarianten, nur die 2751 bp große Variante 1 und diese auch nur im Gehirn nachgewiesen werden (3.2.1, S. 41). Sowohl in Abbildung 13 als auch in Abbildung 15 ist jeweils nur die der Variante 1 entsprechende Bande deutlich sichtbar. Die Varianten 2 bis 4 scheinen in den untersuchten Geweben nicht oder in zu geringem Maße exprimiert zu werden, als dass sie durch RT-PCR nachgewiesen werden konnten. Ein Hinweis hierfür könnten die in Abbildung 13 schwach sichtbaren Banden in der Nebennieren- und der Testis-Probe sein. Diese Amplifikate könnten durch minimalste Expression der größeren Spleißvarianten bedingt sein. Eine weitere Analyse dieser Banden zur Ermittlung ihrer Sequenz gelang aufgrund der geringen Konzentration des Produkts nicht. Da jedoch auch bei der Amplifikation der gesamten cDNA nur Variante 1 nachgewiesen werden konnte (3.2.2, S. 44), ist es wahrscheinlicher, dass es sich bei den Banden um unspezifische Produkte der PCR handelt. Im Gegensatz hierzu zeigten die RTPCR-Analysen bei der Maus (3.2.3, S. 45) sowohl in allen Geweben adulter Mäuse, den untersuchten Zelllinien als auch im Gewebe embryonaler Mäuse nur die der Variante 4 von ZFYVE27 entsprechende Bande.

Dies deutet darauf hin, dass beim Menschen nur im Gehirn eine relevante Expression des ZFYVE27-Gens stattfindet, und dass wahrscheinlich nur Variante 1 exprimiert wird, während in der Maus eine ubiquitäre Expression erfolgt; Dies spricht für eine spezielle Rolle von ZFYVE27 für das menschliche ZNS. Hierfür würde ebenso sprechen, dass Shirane und Nakayama für Zfyve27 eine Beteiligung bei der Ausbildung von Neuriten nachweisen konnten (2006). 


\subsubsection{Intrazelluläre Lokalisation}

Die mikroskopischen Untersuchungen der mit den ZFYVE27-Kontrukten transfizierten HeLa-Zellen (3.3, S. 49) zeigten größtenteils eine endosomale Lokalisation des Proteins. Sowohl das mit GFP als auch das mit E2 markierte ZFYVE27 schienen sich im Zytoplasma in rundlichen Bereichen anzusammeln. Ein ähnliches Verteilungsmuster wurde in dieser Form schon bei anderen endosomalen FYVE-Proteinen nachgewiesen (Stenmark et al. 1996, Tsukazaki et al. 1998, Lorenzo et al. 2005), und auch der Vergleich mit dem endosomalen Marker EEA1 ergab eine Übereinstimmung der Signale und damit einen deutlichen Hinweis auf die Co-Lokalisation von ZFYVE27 mit EEA1 an jungen Endosomen. Auffällig war weiterhin, dass einige Zellen eine leicht andere Verteilung des Signals zeigten, welche eher dem tubulären System entprach. Die Überlagerung mit dem Marker RTN1, der an das Endoplasmatische Retikulum bindet, zeigte in diesen Fällen teilweise Übereinstimmungen, was dafür sprechen könnte, dass sich ZFYVE27 in einigen Zellen auch am Endoplasmatischen Retikulum befindet. Eine Erklärung für die unterschiedliche Lokalisation in einzelnen Zellen könnte sein, dass der physiologische Weg ZFYVE27 vom endoplasmatischen Retikulum, wo es gebildet werden könnte, zu den Endosomen führt. Je nach Lage des Zellstoffwechsels und den momentanen Anforderungen an die Zelle könnten so unterschiedliche Mengen des Proteins in diesen beiden Bereichen angetroffen werden.

Das ebenfalls untersuchte Spastin war in den Untersuchungen an vesikulären Strukturen in Kernnähe lokalisert. Das Signal des c-myc-Spastin-Proteins zeigte eine Anreicherung an runden Strukturen im Zytoplasma, wie es auch schon in anderen Arbeiten zuvor nachgewiesen werden konnte (Errico et al. 2002). Die hier gezeigte Bindung von Spastin an vesikuläre Strukturen (Abb. 22 F) und der Vergleich mit dem GFP-ZFYVE27-Protein könnte den Verdacht bestätigen, dass beide intrazellulär zusammen auftreten. Die beiden Signale zeigen eine deutliche Übereinstimmung im kernnahen Zytoplasma an rundlichen Strukturen (Abb. 21 $\mathrm{K}$ ), was, zusammen mit der Übereinstimmung mit dem EEA1-Marker, für eine Co-Lokalisation der beiden Proteine an Endosomen spricht. In der Literatur gibt es sowohl Hinweise darauf, dass Spastin an perinukleären Vesikeln oder dem 
Zellkern vorkommen kann, als auch Hinweise auf eine Bindung an Mikrotubuli und die Zentromerregion (Errico et al. 2004, Beetz et al. 2004). Es scheint so, als ob dieses unterschiedliche Auftreten von Zellart und Zellzyklusphase abhängig ist. Eine definitive Klärung der intrazellulären Lokalisation von Spastin steht deswegen noch aus, doch die nachgewiesene örtliche Verbindung innerhalb der Zelle ist ein weiteres Indiz für eine, durch die Y2H-Methode schon vermutete, Interaktion zwischen Spastin und ZFYVE27. Zusätzlich konnten Mannan et al. die Interaktion auch durch Co-Immunpräzipitation nachweisen (2006). In welcher Art diese Verbindung stattfindet und welche Konsequenzen sie für die Funktion der beiden Partner hat, bleibt hingegen offen und eventuell Bestandteil weiterer Untersuchungen.

\subsubsection{Struktureller Aufbau und Funktion}

Wie weiter oben gezeigt wurde, gehören zur Gruppe der FYVE-Proteine Vertreter mit unterschiedlichsten Aufgaben und sehr verschiedenem Aufbau. Keines der bisher bekannten FYVE-Proteine besitzt, wie ZFYVE27, eine Transmembrandomäne. Dies lässt vermuten, dass ZFYVE27 zu einer neuen Untergruppe mit möglicherweise bisher so nicht nachgewiesener Funktion gehört. Auch die FYVE-Domäne an sich unterscheidet sich in einzelnen Punkten deutlich vom Großteil der bisher bekannten. So ist das WxxD-Motiv nicht vorhanden und auch die Bereiche $\mathrm{R}(\mathrm{R} / \mathrm{H}) \mathrm{HHR}$ und RVC weisen Unterschiede zu den anderen FYVE-Proteinen auf (s. Abb. 30). Da in dieser Arbeit gezeigt werden konnte, dass ZFYVE27 u.a. an jungen Endosomen lokalisiert ist (3.3, S.49), kann davon ausgegangen werden, dass hierfür die FYVE-Domäne, trotz der Strukturabweichungen, zumindest mitverantwortlich ist. Das „Dimerinterface“ von ZFYVE27 ist im Vergleich mit den meisten anderen FYVE-Proteinen um einige Aminosäuren erweitert, was vielleicht zu einer starken Dimerisierung und hierüber, trotz der alterierten WxxC-, RVC- und R(R/H)HHR-Gruppe, zu einer allein durch die FYVE-Domäne bedingten Bindung an Endosomen führen könnte. Eben eine solche Abhängigkeit der Membranbindung an das Dimerinterface konnte für das FYVE-Protein SARA nachgewiesen werden (Hayakawa et al. 2004). Jedoch konnte für die FYVE-Domäne von Fgd1, das genau wie ZFYVE27 das WxxD-Motiv nicht besitzt, gezeigt werden, dass es sowohl einzeln als auch 
als Dimer nicht an Endosomen bindet (Hayakawa et al. 2004), was eher gegen eine Bindung eines ZFYVE27-Dimers alleine über die FYVE-Domäne spricht. Außerdem zeigte sich, dass Fgd1 nicht spezifisch an PI3P bindet, sondern auch mit PI5P Kontakt aufnehmen kann (Sankaran et al. 2001). Wahrscheinlich besitzt die FYVE-Domäne von ZFYVE27 aufgrund des fehlenden WxxD-Motivs eine eher schwache PI3P-Bindungsfähigkeit und ist deswegen intrazellulär an den Ort mit der höchsten PI3P-Konzentration, die jungen Endosomen, gebunden. Dass ZFYVE27 überhaupt an Endosomen bindet, könnte möglicherweise durch die Transmembrandomäne bedingt sein. Es konnte schon für mehrere FYVE-Proteine gezeigt werden, dass die Bindung über die FYVE-Domäne an PI3P nicht stark genug ist, um alleine für eine Lokalisierung an eine Membran $\mathrm{zu}$ sorgen (Wiedemann und Cockcroft 1998, Raiborg et al. 2001). Die im N-terminalen Bereich liegende Transmembrandomäne könnte als stabilisierende Gruppe wirken, die synergistisch mit der FYVE-Domäne die Bindung von ZFYVE27 an die Endosomen unterstützt. Für den Fall, dass die FYVE-Domäne aber dennoch eigenständig für die endosomale Lokalisation verantwortlich ist, wäre auch denkbar, dass über die Transmembrandomäne eine Bindung an ein anderes Zellkompartiment erfolgt. ZFYVE27 könnte also als Verbindungsmolekül zwischen jungen Endosomen und einer anderen Membranstruktur fungieren, wie es auch schon für EEA1 vermutet wurde (Stenmark und Aasland 1999).

Wahrscheinlich ist, dass die Funktion von ZFYVE27 direkt mit dem endosomalen System in Zusammenhang steht. Um jedoch genauere Aussagen über die Funktion von ZYFVE27 treffen zu können, müssen weitere Untersuchungen durchgeführt werden. Hierbei wäre besonders interessant zu untersuchen, ob es spezifisch an PI3P bindet, inwieweit die Membranbindung von der Transmembrandomäne abhängig ist und, falls nein, an welches Kompartiment die Transmembrandomäne bindet. Untersuchungen an Zellen mit unterdrückter oder ausgeschalteter Expression könnten dann weitere Hinweise auf den Einfluss von ZFYVE27 auf die Zellkompartimente geben. 


\subsubsection{Mutationsanalyse von AD-HSP-Patienten}

Die Sequenzanalyse der 43 HSP-Patienten mit autosomal dominantem Erbgang ergab zwei Basenaustausche im 5' untranslatierten Bereich (c.187T $>$ A, c. $117 \mathrm{C}>\mathrm{T}$ ) und einen im Bereich von Intron 7 (IVS7+57T $>\mathrm{C}$ ). Ob diese Bereiche genregulierende Funktionen besitzen, wurde nicht untersucht und bleibt $\mathrm{zu}$ überprüfen. Eine weitere heterozygote Veränderung liegt in Exon 2 (c.127C $>$ T). Der hier erfolgte Austausch von Cytosin durch Thymidin an Position 127 der cDNA führt zu keinem Aminosäurenaustausch, da sowohl das ursprüngliche Codon CTC, als auch das neu entstandene Codon CTT für die Aminosäure Leucin codieren. Anders verhält es sich bei der im Exon 6 gefundenen Veränderung c.572G $>$ T. Hier ist das ursprünglich für Glycin codierende Triplett GGC zu GTC geändert, was zu einem Austausch von Glycin durch Valin führt. Sowohl Glycin als auch Valin zeichnen sich durch apolare Moleküleigenschaften aus, wobei Valin durch den größeren, apolaren Rest stärkere hydrophobe Eigenschaften besitzt. Keine der 5 Veränderungen wurde mehrmals in den untersuchten Patientenproben gefunden. Zum Ausschluß eines Polymorphismus wurden 100 weitere Wildtypchromosomen vergeblich auf die Veränderung c.572G $>$ T hin untersucht, dennoch besteht der gefundene Basenaustausch laut SNP-Datenbank in unterschiedlichen ethnischen Populationen (Martignoni et al. 2008). Da nicht ausgeschlossen werden konnte, dass die Sequenzvariante p.G191V je nach Population verschiedene pathogenetische Eigenschaften besitzen kann, wie es schon für andere genetische Veränderungen gezeigt werden konnte (Pollak et al. 2007), erfolgte die Aufnahme einer genauen Familienanamnese und Untersuchung der Familienmitglieder der betroffenen Patientin.

Anamnestisch bestand bei der von uns identifizierten Trägerin von c.572G $>\mathrm{T}$ (III.2) ein Spitzfuß beidseits, als sich im Alter von ungefähr 50 Jahren Gangstörungen einstellten. Im Verlauf kam es zu zunehmender Hyperreflexie und Spastizität an den unteren Extremitäten, mit positiven Pyramidenbahnzeichen und pathologischem Fußklonus. Die Sensibilität stellte sich $\mathrm{zu}$ allen Zeitpunkten normal dar. Durch weitere Progredienz der motorischen Einschränkungen konnte die Patientin ab 2006 ohne Hilfe nicht mehr das Bett verlassen. Die Familienanamnese ergab, dass die Großmutter (I.1) vor ihrem Tode ebenfalls an 
ähnlichen Symptomen gelitten hatte. Ob der Vater der Patientin (II.1) vor seinem Tod Zeichen der HSP zeigte, ließ sich aufgrund der eingeschränkten Anamnese und des Todeszeitpunktes nicht genau klären. Während eine Tocher (IV.4) bis heute keinerlei Anzeichen der Krankheit zeigt, bestanden bei der anderen Tochter der Patientin (IV.2) im Alter von 47 Jahren ein Spitzfuß, Gangstörungen, Fußklonus, sowie Hyperreflexie und Spastizität an der unteren Extremität und bei ihrem Sohn (IV.3) Spitzfuß, Gangstörung und eine Spastik der Beine. Eine genaue Bestimmung des onset-Alters war aufgrund der eingeschränkten Anamnesemöglichkeit nicht mehr möglich. Niemand von den betroffenen Personen zeigte Anzeichen für eine Störung der kognitiven Funktionen oder zusätzliche neurologische Symptome, wie man sie bei einer komplizierten Form der HSP erwarten würde. Es ist deswegen davon auszugehen, dass es sich bei der in dieser Familie aufgetreten Erkrankung um eine reine, autosomal-dominant vererbte Form der HSP handelt.

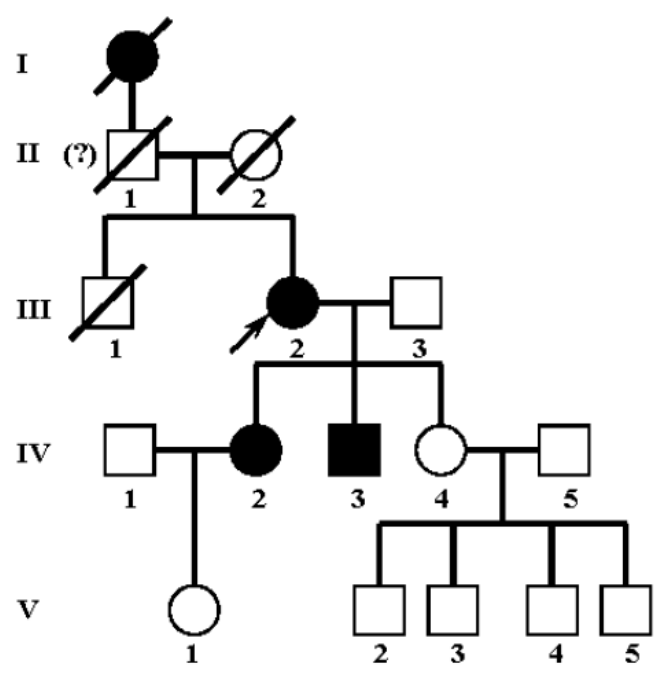
Abbildung 31:
Stammbaum der betroffenen Familie über fünf Generationen. Der schwarzen Pfeil markiert die Trägerin bei der die Veränderung c. $572 \mathrm{G}>\mathrm{T}$ zuerst gefunden wurde.

Die Sequenzanalysen von IV.2, IV.3 und IV.4 erbrachten eine Übereinstimmung von Phänotyp und Genotyp. Während die, wie oben beschrieben, an HSP erkrankten IV.2 und IV.3 heterozygote Träger von c.572G $>$ T sind, konnte beim gesunden IV.4 nur das homozygote Wildtyp-Allel nachgewiesen werden. Diese Ergebnisse könnten ein Hinweis darauf sein, dass der Polymorphismus c.572G $>$ T in Zusammengang mit der HSP-Erkrankung in dieser Familie steht.

Auf zellulärer Ebene wurde die Wirkung der Mutation durch die Immunfluoreszenz-Untersuchungen kontrolliert (3.3.3, S. 54). Das mit der 
Mutation versehene GFP-ZFYVE27(p.G191V)-Protein zeigte im Vergleich mit der normalen Version eine veränderte intrazelluläre Verteilung. Zwar waren auch Zellen sichtbar, bei denen das mutierte Protein, wie beim physiologischen ZFYVE27, offensichtlich an Endosomen lokalisiert war (Abb. 22 A), war jedoch in einem Teil der Zellen die normale Verteilung komplett aufgehoben. Dabei zeigten sich zwei unterschiedliche Muster: Einmal gab es Zellen, bei denen sich das Fusionsprotein in Zellkernnähe anreicherte, was einer massiven Bindung am Endoplasmatischen Retikulum entsprechen könnte (Abb. 22 B), und in einigen Zellen scheint es zur Bindung an die Plasmamembran gekommen zu sein. Dies stellte sich in einer sehr gleichmäßigen Signalverteilung über das gesamte Zytoplasma dar (Abb. 22 C). Auffällig war weiterhin, dass es Abstufungen zwischen der ,endosomalen/endoplasmatischen“-Verteilung und der diffusen zu geben schien. Das Auftreten dieser unterschiedlichen Verteilungsmuster wirft weitere Fragen auf: Ist die eingebrachte Veränderung tatsächlich der Grund für die stärkere Bindung an das ER und die Plasmamembran oder handelt es sich viel mehr um einen Fehler in der Versuchsreihe? Warum zeigt die mutierte ZFYVE27Version ein so breites, uneinheitliches Verteilungsspektrum? Eine Möglichkeit hierfür könnte über die putative Dimerisierungsfähigkeit von ZFYVE27 führen. Wie weiter oben gezeigt werden konnte, gibt die Struktur der FYVE-Domäne begründeten Anlass dazu, davon auszugehen, dass ZFYVE27 mit sich selbst Dimere ausbilden kann. Falls dies zutrifft, könnte ein Teil des GFPZFYVE27(G191V)-Proteins mit dem physiologischen ZFYVE27 dimerisieren und so zu der normalen Lokalisation an jungen Endosomen führen. Ein ähnlicher Mechanismus wurde schon für die FYVE-Proteine MTMR-3, das physiologischerweise zytosolisch auftritt (Walker et al. 2001), und das homologe MTMR-4 nachgewiesen. Durch Immunfluoreszenz konnte gezeigt werden, dass bei einer Überexpression von MTMR-4 auch MTMR-3 an Endosomen gebunden vorkommt (Lorenzo et al. 2005). Um dies letztendlich klären zu können, müssen weitere Versuche zur Dimerisierungsfähigkeit von ZFYVE27 durchgeführt werden. 
Fraglich ist weiterhin, wie die eingebrachte Mutation zur Veränderung der Membranbindungsfähigkeit und damit zur Veränderung der intrazellulären Verteilung führen kann. Die Aminosäure 191 ist kein Bestandteil einer bekannten funktionellen Gruppe, eine essentielle Aufgabe des Bereichs für die Funktion des Proteins ist dennoch anzunehmen, da die betroffene Aminosäure in allen eukaryotischen Organismen strikt konserviert ist (s. Tabelle 32).

\begin{tabular}{|c|l|l|}
\hline Mensch & CTT CTG GGC ACA GTC & LLGTV \\
\hline Chimpanse & CTT CTG GGC ACA GTC & LLGTV \\
\hline Stier & CTC CTG GGC ACG GTT & LLGTV \\
\hline Maus & CTT CTG GGC ATG GTG & LLGMV \\
\hline Ratte & CTT CTG GGC ATG GTT & LLGMV \\
\hline
\end{tabular}

Abbildung 32:

Vergleich der Basen- und Aminosäuresequenz einiger Säugetiere des betroffenen Abschnitts aus Exon 6. Die Base c.572 und die Aminosäure p.191 des entsprechenden Codons sind grau unterlegt.

Außerdem zeigte sich, dass die Veränderung, die unmittelbar N-terminal der Transmembrandomäne liegt, bei der Simulierung der Transmembrandomänen zu einer Alterierung der Struktur führen kann. Die Transmembrandomäne 3 wird durch den Austausch p.G191V um drei Aminosäuren in N-terminale Richtung verschoben, möglicherweise aufgrund der größeren Lipophilität von Valin. Diese Änderung des dreidimensionalen Molekülaufbaus könnte die Eigenschaften der Transmembrandomäne direkt verändern oder aber, über eine Konformationsänderung des im C-terminalen Bereich liegenden Zink-Fingers, indirekt die membranbindenden Eigenschaften von ZFYVE27 beeinflussen.

Dass Störungen in den endosomalen Abläufen zu unterschiedlichen Erkrankungen führen können, konnte schon vielfach gezeigt werden. Filimonenko et al. (2007) haben nachgewiesen, dass einige neurodegenerative Erkrankungen, wie ALS und frontotemporale Demenz, durch Störung der Autophagozytose, ein Prozess an dem auch das FYVE-Protein Hrs beteiligt ist, ausgelöst werden können. Eine Form des M. Charcot-Marie-Tooth kann durch Mutationen in FIG4, einer Phosphoinositol(3,5)Di-Phosphat-5'Phosphatase, hervorgerufen werden. Die Störung im Phosphoinositol-Haushalt führt zu vergrößerten Endosomstrukturen. 
Ähnliche Veränderungen konnten auch bei Ausschaltung von PIKfyve, mit dem FIG4 interagiert, nachgewiesen werden (Chow et al. 2007), und Mutationen in PIKfyve können zum Francois-Neetens-Syndrom, das durch eine hereditäre Dystrophy der Cornea definiert ist, führen (Li et al. 2005). Eine weitere Erkrankung, an deren Ursprung ein FYVE-Protein beteiligt ist, ist das AarskogScott-Syndrom. Pasteris et al. haben 1994 Mutationen in Fgd1 als Ursache für die auch als facio-genitale Dysplasie bekannte Krankheit nachgewiesen. Die Mutationen in Fgd1 scheinen eine Störung des Zytoskeletts in Osteoblasten zu verursachen und so für die klinisch führenden Knochenfehlbildungen verantwortlich zu sein. Es ist also anzunehmen, dass eine Störung von ZFYVE27 theoretisch durchaus als Ursache für die Entstehung der HSP in Frage kommt. Zum genauen Pathomechnismus der HSP gibt es unterschiedliche Hypothesen. Da schon mehreren HSP-loci-kodierten Proteinen eine Verbindung zu intrazelluären Transportvorgängen nachgewiesen werden konnte, sind und bleiben diese dabei ein Kernpunkt. So scheinen SPG1, SPG3, SPG4 und SPG10 direkt an den Aufgaben des Zytoskeletts beteiligt zu sein (Reid et al. 2002, Zhao et al. 2001, Errico et al. 2002, Fink 2003), und das Protein SNX15, das Homologien zu SPG20 aufweist, scheint bei der Organisation des endosomalen Netzwerkes zu fungieren (Barr et al. 2000). Die FYVE-Proteine passen hierzu sehr gut ins Bild und auch die in dieser Arbeit zu ZFYVE27 gezeigten Ergebnisse lassen sich mit der Theorie des gestörten intrazellulären Transportes bei HSP-Erkrankten gut vereinbaren. Da die genaue Funktion von ZFYVE27 jedoch ungeklärt bleibt, ist besonders erwähnenswert, dass es eventuell eine Verbindung zu Autophagozytose-Prozessen besitzt. Ferreirinha et al. (2004) konnten bei Ausschaltung von SPG7 in Mäusen eine Ansammlung von Mitochondrien und Neurofilamenten in Axonen nachweisen, bevor diese degenerieren. Diese Ansammlungen könnten ein Hinweis auf eine gestörte Phagozytose von zelleigenen Bestandteilen sein. Dies ist wiederum ein Vorgang an dem sowohl PI3P als auch FYVE-Proteine direkt beteiligt sind (Petiot et al. 2000). Auch das Hefeprotein Etf1 erfüllt bei einer speziellen Art der Autophagozytose in S. cerevisiae eine essentielle Aufgabe und besitzt einige Übereinstimmungen mit ZFYVE27. Etf1 enthält zwar keine komplette FYVE-Domäne, es kann jedoch über den Bereich KKPAKK, der dem funktionellen FYVE-Abschnitt R(R/H)HHR entsprechen könnte, mit PI3P Verbindung aufnehmen, und die beiden Proteine 
besitzen zudem eine gleichgroße Transmembrandomäne (Wurmser und Emr 2002). Homologievergleiche der beiden DNA-Sequenzen ergeben zwar keine besondere Übereinstimmung, aber die Ähnlichkeit der funktionellen Bereiche könnte auf eine homologe Aufgabe hinweisen.

\subsection{Deletionen in SPG4}

SPG4 und Spastin sind momentan sowohl bei der Diagnostik als auch für die Erforschung der Grundlagen der HSP der zentralste Ansatzpunkt. Mit ungefähr 40\% wird der bisher größte Anteil der AD-HSP-Fälle durch eine der über 100 bekannten Mutationen im SPG4-Gen verursacht. Unter den Mutationen finden sich Missense-, Nonsense- und Spleiß-Mutationen, sowie Deletionen und Insertionen in leicht unterschiedlicher Häufigkeit (Fonknechten et al. 2000, Sauter et al. 2002). Da die Sequenzierung der exonischen Bereiche eines Gens heterozygote Deletionen nicht nachweisen kann wenn diese die Primerbindungsstelle enthalten, wurden im Rahmen dieser Arbeit 88 AD-HSPPatienten, bei denen die Sequenzierung von SPG3 und SPG4 keine Mutation ergeben hatte, mit Hilfe der Real-Time-PCR auf Deletionen im SPG4-Gen hin untersucht. Die Wahrscheinlichkeit dafür, dass in diesem Patienten-Kontingent eine Deletionen im SPG4-Gen vorliegt, war nach den oben genannten, bekannten Daten als hoch einzuschätzen.

Bei der Etablierung der Methode kam es jedoch zu erheblichen Problemen. Obwohl die Erfahrungen aus den regelmäßig zur Diagnostik durchgeführten Sequenzanalysen von SPG4 mitberücksichtigt wurden, kam es schon bei der Amplifikation zu unbefriedigenden Ergebnissen. Es wurde teilweise kein, zu wenig, oder mehrere unterschiedliche Fragmente amplifiziert. Es mussten multiple Primerkombinationen und Reaktionsbedingungen getestet werden, um schließlich für 15 der 17 Exons reproduzierbare Ergebnisse zu erzielen.

Die Untersuchungen der 88 Patientenproben ergaben für 7 Patienten den dringenden Verdacht auf eine Deletion (3.4.1, S. 56). Dabei war auffällig, dass in allen dieser 7 Proben Exon 16 heterozygot deletiert zu sein schien. Diese Häufigkeit von Deletionen in diesem Bereich ist bisher nicht beschrieben worden. 
Jedoch hat sich gezeigt, dass ein Großteil der Spastin-Mutationen den Bereich der AAA-Kassette, zu dem auch das Exon 16 gehört, betreffen (Hazan et al. 1999, Sauter et al. 2002). Zur Verifizierung der Ergebnisse auf DNA- und RNA-Ebene wurden bewusst Methoden mit einer hohen Spezifität gewählt. Dabei ergaben sich sowohl bei der „Long-Range“-PCR als auch bei der RT-PCR Ergebnisse, die für eine Deletion sprachen, jedoch diese nicht eindeutig bewiesen. Die „LongRange“-PCR der Proben 19544 und 21969 zeigte eine dem normalen Allel entsprechende $12 \mathrm{~kb}$-große Bande und gleichzeitig eine $\sim 2 \mathrm{~kb}$ kleinere Bande, so wie man es bei einer Deletion in diesem Bereich erwarten würde. Es zeigten sich jedoch in mehreren Reaktionsansätzen multiple kleinere Banden (s. Abb. 25, S. 59), was auf eine ungenügende Spezifität der Reaktion hindeutete.

Bei den RT-PCRs zeigte sich neben dem Amplifikat des normalen Allels in zwei Proben ein kleineres Produkt, das dem um Exon 16 verkürzten Spastin entsprach. Dieses lag jedoch in so geringer Konzentration vor, dass es nur schwierig optisch nachweisbar war und nicht sequenziert werden konnte. Falls eine Deletion im SPG4-Gen vorliegen sollte, wäre dies gut durch einen Abbau der eventuell funktionslosen RNA zu erklären. Das Ergebnis der Southernblot-Untersuchung ergab für die Proben 19544, 19549, 25950, 29162 und 29163, dass keine Deletion zwischen Intron 14 und Exon 17 besteht. Dies steht im direkten Gegensatz zu den Ergebnissen der Real-Time-PCR. Aufgrund der Tatsache, dass hierbei zwei Methoden angewendet wurden, von denen die Real-Time-PCR sehr viel empfindlicher für Fehler ist, kann davon ausgegangen werden, dass die erzielten Ergebnisse zumindest für das Exon 16 nicht korrekt sind. Hierfür gibt es unterschiedliche Ursachen: Das verwendete genetische Material war teilweise schon mehrere Jahre alt, was zu einer hohen Degradierungsrate geführt haben könnte. In diesem Falle könnte zwar das gewünschte Amplifikat nachgewiesen worden sein, jedoch wäre es möglich, dass die für die Beurteilung wichtig Effizienz der Reaktion gemindert wurde und so der Eindruck eines deletierten Bereichs entstand. Weiterhin wurden aufgrund der Schwierigkeiten bei der Etablierung der Methode für das SPG4-Gen teilweise Amplifikate gewählt, die größer sind als es für die Auswertung optimal gewesen wäre. Auch dies könnte zu einer Herabsetzung der Reaktionseffizienz geführt haben. Dass individuelle Fehler bei der Durchführung der Experimente zu den falschen Ergebnissen geführt haben, lässt sich nicht vollkommen ausschließen, jedoch wurden die Real- 
Time-Ergebnisse bei der Durchführung durch eine zweite Person, in einem anderen Labor, weitesgehend reproduziert.

Die hier erzielten Ergebnisse schließen Deletionen im SPG4-Gen nicht aus und im Hinblick auf die oben geschilderten Fakten zur Mutationsverteilung sind diese weiterhin als wahrscheinlich anzusehen, jedoch scheint die Real-Time-Methode für die schwer amplifizierbaren Bereiche des SPG4-Gens nicht geeignet zu sein. 


\section{Zusammenfassung}

Die hereditären spastischen Paraplegien (HSP) sind eine klinisch und genetisch heterogene Gruppe erblicher neurodegenerativer Erkrankungen, welche durch eine progrediente spastische Paraparese und Hyperreflexie der unteren Extremitäten gekennzeichnet sind. Sie können autosomal-dominant, autosomal rezessiv und X-chromosomal vererbt werden. Für einen Teil der autosomaldominanten Fälle können Mutation in den Genen SPG3 und SPG4 nachgewiesen werden, bei einem Großteil der Erkrankungen bleiben die verantwortlichen Gene jedoch unbekannt. In dieser Arbeit sollte deswegen die Charakterisierung von ZFYVE27, eines Interaktionspartners von Spastin und damit potentiellen Kandidatengens für die AD-HSP, erfolgen und nach Deletionen im SPG4-Gen gesucht werden.

Es wurde gezeigt, dass ZFYVE27, welches $\mathrm{zu}$ einer als FYVE-Proteine bezeichneten Gruppe gehört, ausschließlich im Gehirn des Menschen effektiv exprimiert wird. Im Gegensatz hierzu ergab der Vergleich mit dem homologen Mausgen zfyve27 für dieses eine ubiquitäre Expression. Es konnte weiterhin nachgewiesen werden, dass ZFYVE27 intrazellulär an das Endoplasmatische Retikulum und an Endosomen gebunden und mit Spastin co-lokalisiert ist.

Die für das Deletionsscreening verwendete Real-Time-PCR erwies sich unter den angewandte Bedingungen als nicht verlässlich genug, und obwohl Ergebnisse anderer Arbeiten eben diese in AD-HSP-Patienten nachweisen konnten, gelang es im Rahmen dieser Arbeit nicht, Deletionen im SPG4-Gen zu finden.

Durch die Sequenzanalyse von ZFYVE27 bei 43 Patienten mit klinisch diagnostizierter AD-HSP wurden fünf Veränderungen auf genomischer Ebene nachgewiesen. Dass der hierbei identifizierte Polymorphismus c.572G $>\mathrm{T}$ die Ursache der HSP in einer der untersuchten Familien ist und ZFYVE27 somit an der Pathogenese der HSP beteiligt ist, konnte jedoch nicht bewiesen werden. 


\section{Literaturverzeichnis}

Altschul SF, Gish W, Miller W, Myers EW, Lipman DJ (1990): Basic local alignment search tool. J. Mol. Biol. 215: 403-410.

Bache KG, Brech A, Mehlum A, Stenmark H (2003): Hrs regulates multivesicular body formation via ESCRT recruitment to endosomes. J. Cell Biol. 162: 435-442.

Barr VA, Phillips SA, Taylor SI, Haft CR (2000): Overexpression of a novel sorting nexin, SNX15, affects endosome morphology and protein trafficking. Traffic 11: 904-916.

Beetz C, Brodhun M, Moutzouris K, Kiehntopf M, Berndt A, Lehnert D, Deufel T, Bastmeyer M, Schickel J (2004): Identification of nuclear localisation sequences in spastin (SPG4) using a novel Tetra-GFP reporter system. Biochem. Biophys. Res. Commun. 318: 1079-1084.

Beetz C, Nygren AO, Schickel J, Auer-Grumbach M, Bürk K, Heide G, Kassubek J, Klimpe S, Klopstock T, Kreuz F, Otto S, Schüle R, Schöls L, Sperfeld AD, Witte OW, Deufel T (2006): High frequency of partial SPAST deletions in autosomal dominant hereditary spastic paraplegia. Neurology 67: 1926-1930.

Behan WM, Maia M (1974): Strümpell's familial spastic paraplegia: genetics and neuropathology. J. Neurol. Neurosurg. Psychiatry 37: 8-20.

Birnboim HC, Doly J (1979): A rapid alkaline extraction procedure for screening recombinant plasmid DNA. Nucleic Acids Res. 24: 1513-1523.

Blatner NR, Stahelin RV, Diraviyam K, Hawkins PT, Hong W, Murray D, Cho W (2004): The molecular basis of the differential subcellular localization of FYVE domains. J. Biol. Chem. 279: 53818-53827. 
Boehm D, Herold S, Kuechler A, Liehr T, Laccone F (2004): Rapid detection of subtelomeric deletion/duplication by novel real-time quantitative PCR using SYBR-green dye. Hum. Mutat. 2004 23: 368-378.

Bönsch D, Schwindt A, Navratil P, Palm D, Neumann C, Klimpe S, Schickel J, Hazan J, Weiller C, Liepert J (2003): Mutation in the spastin gene paraparesis type 4 (SPG4) depend on the type of Motor system abnormalities in hereditary spastic. J. Neurol. Neurosurg. Psychiatry 74:1109-1112.

Bruyn RPM, Scheltens F (1991): Hereditary spastic paraparesis (StrümpellLorrain). Handbook of clinical neurology 15: 301-318.

Callaghan J, Nixon S, Bucci C, Toh BH, Stenmark H (1999): Direct interaction of EEA1 with Rab5b. Eur. J. Biochem. 265: 361-366.

Chen YG, Wang Z, Ma J, Zhang L, Lu Z (2007): Endofin, a FYVE domain protein, interacts with Smad4 and facilitates transforming growth factor-beta signaling. J. Biol. Chem. 282: 9688-9695.

Chow CY, Zhang Y, Dowling JJ, Jin N, Adamska M, Shiga K, Szigeti K, Shy ME, Li J, Meisler MH (2007): Mutation of FIG4 causes neurodegeneration in the pale tremor mouse and patients with CMT4J. Nature 448: 68-72.

Derubeis AR, Young MF, Jia L, Robey PG, Fisher LW (2000): Double FYVEcontaining protein 1 (DFCP1): isolation, cloning and characterization of a novel FYVE finger protein from a human bone marrow cDNA library. Gene 255: 195203.

Dumas JJ, Merithew E, Sudharshan E, Rajamani D, Hayes S, Lawe D, Corvera S, Lambright DG (2001): Multivalent endosome targeting by homodimeric EEA1. Mol Cell. $\underline{8}:$ 947-958. 
Erichsen AK, Inderhaug E, Mattingsdal M, Eiklid K, Tallaksen CM (2007): Seven novel mutations and four exon deletions in a collection of Norwegian patients with SPG4 hereditary spastic paraplegia. Eur. J. Neurol. 14: 809-814.

Errico A, Ballabio A, Rugarli EI (2002): Spastin, the protein mutated in autosomal dominant hereditary spastic paraplegia, is involved in microtubule dynamics. Hum Mol Genet. 11: 153-163.

Errico A, Claudiani P, D'Addio M, Rugarli EI (2004): Spastin interacts with the centrosomal protein NA14, and is enriched in the spindle pole, the midbody and the distal axon. Hum. Mol. Genet. 13: 2121-2132.

Feinberg AP, Vogelstein B (1983): A technique for radiolabeling DNA restriction endonuclease fragments to high specific activity. Anal. Biochem. 132: 6-13.

Ferreirinha F, Quattrini A, Pirozzi M, Valsecchi V, Dina G, Broccoli V, Auricchio A, Piemonte F, Tozzi G, Rugarli EI (2004): Axonal degeneration in paraplegindeficient mice is associated with abnormal mitochondria and impairment of axonal transport. J. Clin. Invest. 113: 231-242.

Filimonenko M, Stuffers S, Raiborg C, Yamamoto A, Malerød L, Fisher EM, Isaacs A, Brech A, Stenmark H, Simonsen A (2007): Functional multivesicular bodies are required for autophagic clearance of protein aggregates associated with neurodegenerative disease. J. Cell. Biol. 179: 485-500.

Fink JK (2003): The hereditary spastic paraplegias: nine genes and counting. Arch. Neurol. 60: 1045-1049.

Fink JK, Heiman-Patterson T, Bird T, Cambi F, Dubé MP, Figlewicz DA, Haines JL, Heiman-Patterson T, Hentati A, Siddique T (1996): Hereditary spastic paraplegia: advances in genetic research. Hereditary Spastic Paraplegia Working group. Neurology $\underline{46}$ : 1507-1514 
Fonknechten N, Mavel D, Byrne P, Davoine CS, Cruaud C, Bönsch D, Samson D, Coutinho P, Hutchinson M, Hazan J (2000): Spectrum of SPG4 mutations in autosomal dominant spastic paraplegia. Hum Mol Genet. 9: 637-644.

Hayakawa A, Hayes SJ, Lawe DC, Sudharshan E, Tuft R, Fogarty K, Lambright D, Corvera S (2004): Structural basis for endosomal targeting by FYVE domains. J. Biol. Chem. 279: 5958-5966.

Hazan J, Fonknechten N, Mavel D, Paternotte C, Samson D, Artiguenave F, Davoine CS, Cruaud C, Durr A, Weissenbach J (1999): Spastin, a new AAA protein, is altered in the most frequent form of autosomal dominant spastic paraplegia. Nat. Genet. 23: 296-303.

Komada M, Soriano P (1999): Hrs, a FYVE finger protein localized to early endosomes, is implicated in vesicular traffic and required for ventral folding morphogenesis. Genes Dev. 13: 1475-1485.

Lee SA, Eyeson R, Cheever ML, Geng J, Verkhusha VV, Burd C, Overduin M, Kutateladze TG (2005): Targeting of the FYVE domain to endosomal membranes is regulated by a histidine switch. Proc. Natl. Acad. Sci. USA. 102: 13052-13057.

Li S, Tiab L, Jiao X, Munier FL, Zografos L, Frueh BE, Sergeev Y, Smith J, Rubin B, Schorderet DF (2005): Mutations in PIP5K3 are associated with François-Neetens mouchetée fleck corneal dystrophy. Am. J. Hum. Genet. 77: 5463.

Lo Nigro C, Cusano R, Scaranari M, Cinti R, Forabosco P, Morra VB, De Michele G, Santoro L, Davies S, Hurst J, Seri M (2000): A refined physical and transcriptional map of the SPG9 locus on 10q23.3-q24.2. Eur. J. Hum. Genet. $\underline{8}$ : $777-782$.

Lorenzo O, Urbé S, Clague MJ (2005): Analysis of phosphoinositide binding domain properties within the myotubularin-related protein MTMR3. J. Cell. Sci. 118: 2005-2012. 
Mannan AU (2008): Response to Martignoni et al. Am. J. Hum. Genet. $\underline{\text { 83, }}$ 127147.

Mannan AU, Boehm J, Sauter SM, Rauber A, Byrne PC, Neesen J, Engel W (2005): Spastin, the most commonly mutated protein in hereditary spastic paraplegia interacts with Reticulon 1 an endoplasmic reticulum protein. Neurogenetics 7: 93-103.

Mannan AU, Krawen P, Sauter SM, Boehm J, Chronowska A, Paulus W, Neesen J, Engel W (2006): ZFYVE27 (SPG33), a novel spastin-binding protein, is mutated in hereditary spastic paraplegia. Am. J. Hum. Genet. 79: 351-357.

Mao Y, Nickitenko A, Duan X, Lloyd TE, Wu MN, Bellen H, Quiocho FA (2000): Crystal structure of the VHS and FYVE tandem domains of Hrs, a protein involved in membrane trafficking and signal transduction. Cell 100: 447-456.

Martignoni M, Riano E, Rugarli EI (2008): The role of ZFYVE27/protrudin in hereditary spastic paraplegia. Am. J. Hum. Genet. 83: 127-128.

Mills IG, Jones AT, Clague MJ (1998): Involvement of the endosomal autoantigen EEA1 in homotypic fusion of early endosomes. Curr. Biol. $\underline{8}$ : 881884.

Misra S, Hurley JH (1999): Crystal structure of a phosphatidylinositol 3phosphate-specific membrane-targeting motif, the FYVE domain of Vps27p. Cell 97: 657-666.

Mu FT, Callaghan JM, Steele-Mortimer O, Stenmark H, Parton RG, Campbell PL, McCluskey J, Yeo JP, Tock EP, Toh BH (1995): EEA1, an early endosomeassociated protein. EEA1 is a conserved alpha-helical peripheral membrane protein flanked by cysteine "fingers" and contains a calmodulin-binding IQ motif. J. Biol. Chem. 270: 13503-13511. 
Nakanishi H, Takai Y (2008): Frabin and other related Cdc42-specific guanine nucleotide exchange factors couple the actin cytoskeleton with the plasma membrane. J. Cell. Mol. Med. 12: 1169-1176.

Pasteris NG, Cadle A, Logie LJ, Porteous ME, Schwartz CE, Stevenson RE, Glover TW, Wilroy RS, Gorski JL (1994): Isolation and characterization of the faciogenital dysplasia (Aarskog-Scott syndrome) gene: a putative Rho/Rac guanine nucleotide exchange factor. Cell 79: 669-678.

Petiot A, Ogier-Denis E, Blommaart EF, Meijer AJ, Codogno P (2000): Distinct classes of phosphatidylinositol 3'-kinases are involved in signaling pathways that control macroautophagy in HT-29 cells. J. Biol. Chem. 275: 992-998.

Pollak A, Skórka A, Mueller-Malesińska M, Kostrzewa G, Kisiel B, Waligóra J, Krajewski P, Ołdak M, Korniszewski L, Ploski R (2007): M34T and V37I mutations in GJB2 associated hearing impairment: evidence for pathogenicity and reduced penetrance. Am. J. Med Genet. A. 143A: 2534-2543.

Raiborg C, Bremnes B, Mehlum A, Gillooly DJ, D'Arrigo A, Stang E, Stenmark H (2001): FYVE and coiled-coil domains determine the specific localisation of Hrs to early endosomes. J. Cell. Sci. 114: 2255-2263.

Reid E (1997): Pure hereditary spastic paraplegia. J. Med. Genetics 34: 499-503.

Reid E, Kloos M, Ashley-Koch A, Hughes L, Bevan S, Svenson IK, Graham FL, Gaskell PC, Dearlove A, Rubinsztein DC, Marchuk DA (2002): A kinesin heavy chain (KIF5A) mutation in hereditary spastic paraplegia (SPG10). Am. J. Hum. Genet. 71: 1189-1194.

Salinas S, Proukakis C, Crosby A, Warner TT (2008): Hereditary spastic paraplegia: clinical features and pathogenetic mechanisms. Lancet Neurol. $\underline{7}$ : 1127-1138. 
Sankaran VG, Klein DE, Sachdeva MM, Lemmon MA (2001): High-affinity binding of a FYVE domain to phosphatidylinositol 3-phosphate requires intact phospholipid but not FYVE domain oligomerization. Biochemistry $\underline{40}$ : 85818587.

Sauter S, Miterski B, Klimpe S, Bönsch D, Schöls L, Visbeck A, Papke T, Hopf HC, Engel W, Neesen J (2002): Mutation analysis of the spastin gene (SPG4) in patients in Germany with autosomal dominant hereditary spastic paraplegia. Hum. Mutat. 20: 127-132.

Sbrissa D, Ikonomov OC, Shisheva A (1999): PIKfyve, a mammalian ortholog of yeast Fab1p lipid kinase, synthesizes 5-phosphoinositides. Effect of insulin. J. Biol. Chem. 274: 21589-21597.

Sbrissa D, Ikonomov OC, Shisheva A (2002): Phosphatidylinositol 3-phosphateinteracting domains in PIKfyve. Binding specificity and role in PIKfyve. Endomenbrane localization. J. Biol. Chem. 277: 6073-6079.

Shirane M, Nakayama KI (2006): Protrudin induces neurite formation by directional membrane trafficking. Science $\underline{314}$ : 818-821.

Shisheva A (2008): PIKfyve: Partners, significance, debates and paradoxes. Cell. Biol. Int. 32: 591-604.

Shisheva A, Sbrissa D, Ikonomov O (1999): Cloning, characterization, and expression of a novel Zn2+-binding FYVE finger-containing phosphoinositide kinase in insulin-sensitive cells. Mol. Cell. Biol. 19: 623-634.

Skre H (1974): Hereditary spastic paraplegia in Western Norway. Clin. Genet. $\underline{6}$ : 165-183.

Stahelin RV, Long F, Diraviyam K, Bruzik KS, Murray D, Cho W (2002): Phosphatidylinositol 3-phosphate induces the membrane penetration of the FYVE domains of Vps27p and Hrs. J. Biol. Chem. 277: 26379-26388. 
Stenmark H, Aasland R, Toh BH, D'Arrigo A (1996): Endosomal localization of the autoantigen EEA1 is mediated by a zinc-binding FYVE finger. J. Biol. Chem. 271: 24048-24054.

Stenmark H, Aasland R (1999): FYVE-finger proteins--effectors of an inositol lipid. J. Cell Sci. 112: 4175-4183.

Stenmark H, Aasland R, Driscoll PC (2002): The phosphatidylinositol 3phosphate-binding FYVE finger. FEBS Lett. 513: 77-84.

Tsukazaki T, Chiang TA, Davison AF, Attisano L, Wrana JL (1998): SARA, a FYVE domain protein that recruits Smad2 to the TGFbeta receptor. Cell 95: 779791.

Walker DM, Urbé S, Dove SK, Tenza D, Raposo G, Clague MJ (2001): Characterization of MTMR3. an inositol lipid 3-phosphatase with novel substrate specificity. Curr. Biol. 11:1600-1605.

Werdelin L (1986): Hereditary ataxias. Occurrence and clinical features. Acta Neurol. Scand. Suppl. 106: 1-124.

Wiedemann C, Cockcroft S (1998): Vesicular transport. Sticky fingers grab a lipid. Nature 394: 426-427.

Wurmser AE, Emr SD (2002): Novel PtdIns(3)P-binding protein Etf1 functions as an effector of the Vps34 PtdIns 3-kinase in autophagy. J. Cell. Biol. 158: 761-772.

Zhao X, Alvarado D, Rainier S, Lemons R, Hedera P, Weber CH, Tukel T, Apak M, Heiman-Patterson T, Fink JK (2001): Mutations in a newly identified GTPase gene cause autosomal dominant hereditary spastic paraplegia. Nat. Genet. 29: 326-331. 


\section{Anhang}

\section{1 cDNA, kodierende Sequenz und Aminosäuresequenz der menschlichen ZFYVE27-Spleißvarianten}

\subsubsection{Transcript Variante 1 (Genbanknummer AK097945.1)}

cDNA: 2746 bp

CDS: 956 bp

AS: 318

\begin{tabular}{|c|c|c|}
\hline 1 & AGAGCGATTCGCGTCCCGGAAGCGGCGGTGGCGGCCGCGGCGTAGGCGGAGCGGCGTTCA & \\
\hline 61 & GGGAGATTTTCGGACCTGCGACTTCCGAACAACCCTGGCAGGAGGACCGGGGGAGGCCTG & \\
\hline 121 & AAGAAACGCTCCGGGGCCCAGTGGCTCTACCCCTGCTCCTGCCCGACCCTGCCGCCTCCC & \\
\hline \multirow[t]{2}{*}{181} & TCACGGAGCCAGCGGCCGGGATGCAGACATCAGAACGTGAGGGGAGTGGGCCGGAGCTGA & \\
\hline & $\begin{array}{llllllllllllll}M & Q & T & S & E & R & E & G & S & G & P & E & L & S\end{array}$ & 14 \\
\hline \multirow[t]{2}{*}{241} & GCCCCAGCGTGATGCCCGAGGCTCCCCTGGAGTCTCCACCTTTTCCTACCAAGTCCCCAG & \\
\hline & $\begin{array}{llllllllllllllllllll}P & S & V & M & P & E & A & P & L & E & S & P & P & F & P & T & K & S & P & A\end{array}$ & 34 \\
\hline \multirow[t]{2}{*}{301} & CGTTTGACCTTTTCAACTTGGTTCTCTCCTACAAGAGGCTGGAGATCTACCTGGAACCCT & \\
\hline & $\begin{array}{llllllllllllllllllll}\mathrm{F} & \mathrm{D} & \mathrm{L} & \mathrm{F} & \mathrm{N} & \mathrm{L} & \mathrm{V} & \mathrm{L} & \mathrm{S} & \mathrm{Y} & \mathrm{K} & \mathrm{R} & \mathrm{L} & \mathrm{E} & \mathrm{I} & \mathrm{Y} & \mathrm{L} & \mathrm{E} & \mathrm{P} & \mathrm{L}\end{array}$ & 54 \\
\hline \multirow[t]{2}{*}{361} & TGAAGGATGCAGGTGATGGTGTTCGATACTTGCTCAGCTTGATCCAGCTGGAGGCCTTCC & \\
\hline & $\begin{array}{llllllllllllllllllll}K & D & A & G & D & G & V & R & Y & L & L & S & L & I & Q & L & E & A & F & L\end{array}$ & 74 \\
\hline \multirow[t]{2}{*}{421} & TGAGCCGCCTGTGCTGCACATGTGAAGCCGCCTACCGCGTGCTGCACTGGGAGAACCCCG & \\
\hline & $\begin{array}{llllllllllllllllllll}S & R & L & C & C & T & C & E & A & A & Y & R & V & L & H & W & E & N & P & V\end{array}$ & 94 \\
\hline \multirow[t]{2}{*}{481} & TCGTGTCCTCACAGTTCTATGGGGCTCTTCTGGGCACAGTCTGCATGCTGTATTTGCTGC & \\
\hline & $\begin{array}{lllllllllllllllllllll}\mathrm{V} & \mathrm{S} & \mathrm{S} & \mathrm{Q} & \mathrm{F} & \mathrm{Y} & \mathrm{G} & \mathrm{A} & \mathrm{L} & \mathrm{L} & \mathrm{G} & \mathrm{T} & \mathrm{V} & \mathrm{C} & \mathrm{M} & \mathrm{L} & \mathrm{Y} & \mathrm{L} & \mathrm{L} & \mathrm{P}\end{array}$ & 114 \\
\hline \multirow[t]{2}{*}{541} & CACTCTGCTGGGTTCTCACCCTTTTAAACAGCACGCTCTTTCTGGGGAATGTGGAGTTCT & \\
\hline & $\begin{array}{llllllllllllllllllll}\mathrm{L} & \mathrm{C} & \mathrm{W} & \mathrm{V} & \mathrm{L} & \mathrm{T} & \mathrm{L} & \mathrm{L} & \mathrm{N} & \mathrm{S} & \mathrm{T} & \mathrm{L} & \mathrm{F} & \mathrm{L} & \mathrm{G} & \mathrm{N} & \mathrm{V} & \mathrm{E} & \mathrm{F} & \mathrm{F}\end{array}$ & 134 \\
\hline \multirow[t]{2}{*}{601} & TCCGAGTTGTGTCTGAGTACAGGGCATCTCTGCAGCAGAGGATGAACCCAAAGCAGGAAG & \\
\hline & $\begin{array}{lllllllllllllllllll}R & V & V & S & E & Y & R & A & S & L & Q & Q & R & M & N & P & K & Q & E\end{array}$ & 154 \\
\hline \multirow[t]{2}{*}{661} & AGCATGCCTTTGAGAGTCCTCCACCACCAGATGTTGGGGGGAAGGATGGTCTGATGGACA & \\
\hline & $\begin{array}{llllllllllllllllll}H & A & F & E & S & P & P & P & P & D & V & G & G & K & D & G & L & M\end{array}$ & 174 \\
\hline 721 & GCACGCCTGCCCTCACACCCACGGAGGACCTCACACCGGGCAGCGTGGAGGAGGCTGAGG & \\
\hline & $\begin{array}{llllllllllllllllllll}\mathrm{T} & \mathrm{P} & \mathrm{A} & \mathrm{L} & \mathrm{T} & \mathrm{P} & \mathrm{T} & \mathrm{E} & \mathrm{D} & \mathrm{L} & \mathrm{T} & \mathrm{P} & \mathrm{G} & \mathrm{S} & \mathrm{V} & \mathrm{E} & \mathrm{E} & \mathrm{A} & \mathrm{E} & \mathrm{E}\end{array}$ & 194 \\
\hline
\end{tabular}




\begin{tabular}{|c|c|c|}
\hline 781 & AGGCTGAGCCAGATGAAGAGTTTAAAGATGCGATTGAGGAGGATGATGAGGGCGCCCCGT & \\
\hline & $\begin{array}{llllllllllllll}P & D & E & E & F & K & D & A & I & E & E & D & D & E\end{array}$ & 214 \\
\hline 841 & GCCCAGCAGAGGATGAGCTGGCCCTGCAGGACAACGGGTTCCTGAGCAAGAATGAGGTGC & \\
\hline & $\begin{array}{ccccccccccccccc}\mathrm{L} & \mathrm{A} & \mathrm{L} & \mathrm{Q} & \mathrm{D} & \mathrm{N} & \mathrm{G} & \mathrm{F} & \mathrm{L} & \mathrm{S} & \mathrm{K} & \mathrm{N} & \mathrm{E} & \mathrm{V} & \mathrm{L}\end{array}$ & 234 \\
\hline 901 & TGCGCAGCAAGGTGTCTCGGCTCACGGAGCGGCTCCGCAAGCGCTACCCCACCAACAACT & \\
\hline & $\begin{array}{llllllllllllllll}K & V & S & R & L & T & E & R & L & R & K\end{array}$ & 254 \\
\hline 961 & TCGGGAACTGCACGGGCTGCTCGGCCACCTTCTCAGTGCTGAAGAAGAGGCGGAGCTGCA & \\
\hline & $\begin{array}{llllllllllllllllllll}G & N & C & T & G & C & S & A & T & F & S & V & L & K & K & R & R & S & C & S\end{array}$ & 274 \\
\hline 1021 & GTAATTGTGGAAACAGCTTCTGCTCTCGATGCTGCTCCTTCAAGGTGCCCAAGTCCTCCA & \\
\hline & $\begin{array}{llllllllllllllllllll}N & C & G & N & S & F & C & S & R & C & C & S & F & K & V & P & K & S & S & M\end{array}$ & 294 \\
\hline 1081 & TGGGGGCCACAGCCCCTGAAGCCCAGAGGGAGACTGTGTTTGTGTGTGCCTCGTGTAACC & \\
\hline & $\begin{array}{llllllllllllllllllll}G & A & \text { T } & A & \text { P } & \text { E } & \text { A } & \text { Q } & \text { R } & \text { E } & \text { T } & \text { V } & \text { F } & \text { V } & \text { C } & \text { A } & \text { S } & \text { C } & \text { N } & \text { Q }\end{array}$ & 314 \\
\hline 1141 & AGACCTTGAGCAAGTGAGAAGAGAGGCCAGGGTCCAACCAGGCACCCGTCCTTGGGACCA & \\
\hline & $\begin{array}{lllll}\mathrm{T} & \mathrm{L} & \mathrm{S} & \mathrm{K} & *\end{array}$ & 318 \\
\hline 1201 & GCAGTAGACCCCCCACTCTCCCCACCCCTGGCCCACTGTGGTGTGTGCTGGGCAAATGTG & \\
\hline 1261 & GCCTGAATGCTAGGTAGGCTTCCCCTTCCTTCCTCACTCTCTCCAGCTGGATTCTGGAGC & \\
\hline 1321 & TGTTCTCCATCCATGAGAGTGGCTGGCAATGGCTGCTCTCAATCCCTTGAGGGAGAAGAG & \\
\hline 1381 & CCCCTGGAGGGCCTGGCATGTTTGTCCTGCTCTGCCTGGGACTGAGCGAGTGGACTTAGG & \\
\hline 1441 & GCTGGGCAGGCAGTAGCCACCAGAGGGCAGCAGCGAACTAGGCCAGGCCTGACTGGGGTC & \\
\hline 1501 & TGAAGATCAGGGTCAGTGTGGCTGTGCCTGGGAATTCCAGACCTGAGGTTGGGAAAAGAG & \\
\hline 1561 & GTTTTTCTCCTGCAGGGTACTGGGCCAGGCCCTCAGCCTCAGAGAGCTTGCAGAAGGGCT & \\
\hline 1621 & TGGGAGTGCCACACCCCATCTCTGCTGATTGAATGTCCCTCCAGGCACCAGGATCTCATC & \\
\hline 1681 & ATTTCCCCATCAGAGGGTGTGGCCAGGCCTAACAAGACCATGGGTGCTTCTAGAAACAGG & \\
\hline 1741 & GTTGAATTTCCCAGATTCCCTGAGAGGAGAATGTGTATAGGAGGGTTTGGCTGAGTCCTT & \\
\hline 1801 & CAGCGTAAGTGGAGGAAAGCTTGGGGAAGCCCCAATAGCTGGACAGACCTCGGCCTCCCC & \\
\hline 1861 & TCGAAGACACCTCAATTCACAGACTCTCAGCCCACACAATGCCCCAGTGTCCCCAGCTCC & \\
\hline 1921 & GCTGGAGCAGCTGCAGGGCACTTGGATCACAACTTCTGCACCCTCTGTCCAGAGTCTAGG & \\
\hline 1981 & GCAGTCCTCCACTGGCCCAGCACTCCAGTTTCCTTTCCCTGCCTCTTGTCCAATGGAGTG & \\
\hline 2041 & GGAGGCCAGGTGAGTGGAGCAGAGGTCCTGAAGCCCTTGACCCCTGGGGGCCTGGGTAGT & \\
\hline 2101 & GTAGGATCTCGCTGGGCTGGGTCCTGGATTCCAGGGCTATTCCCTGGAGGACAGTCTCAG & \\
\hline 2161 & TTATGGGATAAGGCCCCCTGGGGGTCTCCATTTCTTTCCAACAGTTTCATGTTCACTACT & \\
\hline 2221 & GGACTCTTACGGGCTCAGTATCTCTCCCTTAGCCATGAGCTGGCTCAGGCATCCCTTCCC & \\
\hline 2281 & TTCCCTGGAGCTGCCCTGCCTTTCTCAAGTATTTATTTATTTATTGCATGGTTCCTGGGA & \\
\hline 2341 & ACATGTGGCACAAGTAATGGGATGAGGAGGAATTGGGGGTGGGGGTCTTCTACCTAGGAC & \\
\hline 2401 & TCTTCCCTGGAGTCATGGGCTGCCTGGGACCCAGGACCCATGAGGGGGCTGAGAGGTTTC & \\
\hline 2461 & TACACTCGAGGAGCAGGGGTCCAGAGAGGCAGGCTGGGGAGGCAAGGGACCCATCCTAGG & \\
\hline 2521 & CCCGCTTTCTTGCCGAGCCAAGCAGCTTAGCTGGGGCTGTGCAGCCAGGGGCTTACCCAG & \\
\hline 2581 & GCCAGTGGAGGTGCCACAGCCCTGGGGAGCCAGACAGGCTTTGGTATCGTATCGCCTCTG & \\
\hline 2641 & TGTCCTTTTAAGAGAGGAGAGTTCAGTACCCCGTGCTTTCTTTACACTGGAAAGGAACTA & \\
\hline 2701 & AAAGGATCTCTGTGTCTATGGAGAATTGTCAATAAAAAGGCCTCAAGCTT & 2751 \\
\hline
\end{tabular}




\subsubsection{Transcript Variante 2 (Genbanknummer NM_001002262.2)}

cDNA: $3010 \mathrm{bp}$

CDS: $1415 \mathrm{bp}$

AS: 404

\begin{tabular}{|c|c|c|}
\hline 1 & AGAGCGATTCGCGTCCCGGAAGCGGCGGTGGCGGCCGCGGCGTAGGCGGAGGAGATTTTC & \\
\hline 61 & $\begin{array}{l}\text { GGACCTGCGACTTCCGAACAACCCTGGCAGGAGGAGCGGCGTTCAGCCGGGGGAGGCCTG } \\
\end{array}$ & \\
\hline 121 & AAGAAACGCTCCGGGGCCCAGTGGCTCTACCCCTGCTCCTGCCCGACCCTGCCGCCTCCC & \\
\hline \multirow[t]{2}{*}{181} & TCACGGAGCCAGCGGCCGGGATGCAGACATCAGAACGTGAGGGGAGTGGGCCGGAGCTGA & \\
\hline & $\begin{array}{llllllllllllll}M & Q & \text { T } & \text { S } & \text { E } & \text { R } & \text { E } & G & \text { S } & \text { G } & \text { P } & \text { E } & \text { L } & \text { S }\end{array}$ & 14 \\
\hline \multirow[t]{2}{*}{241} & GCCCCAGCGTGATGCCCGAGGCTCCCCTGGAGTCTCCACCTTTTCCTACCAAGTCCCCAG & \\
\hline & $\begin{array}{llllllllllllllllllll}\mathrm{P} & \mathrm{S} & \mathrm{V} & \mathrm{M} & \mathrm{P} & \mathrm{E} & \mathrm{A} & \mathrm{P} & \mathrm{L} & \mathrm{E} & \mathrm{S} & \mathrm{P} & \mathrm{P} & \mathrm{F} & \mathrm{P} & \mathrm{T} & \mathrm{K} & \mathrm{S} & \mathrm{P} & \mathrm{A}\end{array}$ & 34 \\
\hline \multirow[t]{2}{*}{301} & CGTTTGACCTTTTCAACTTGGTTCTCTCCTACAAGAGGCTGGAGATCTACCTGGAACCCT & \\
\hline & $\begin{array}{llllllllllllllllll}\mathrm{L} & \mathrm{F} & \mathrm{N} & \mathrm{L} & \mathrm{V} & \mathrm{L} & \mathrm{S} & \mathrm{Y} & \mathrm{K} & \mathrm{R} & \mathrm{L} & \mathrm{E} & \mathrm{I} & \mathrm{Y} & \mathrm{L} & \mathrm{E} & \mathrm{P} & \mathrm{L}\end{array}$ & 54 \\
\hline \multirow[t]{2}{*}{361} & TGAAGGATGCAGGTGATGGTGTTCGATACTTGCTCAGGTGGCAGATGCCTTTGTGTTCCT & \\
\hline & $\begin{array}{llllllllllllllllllll}K & \mathrm{D} & \mathrm{A} & \mathrm{G} & \mathrm{D} & \mathrm{G} & \mathrm{V} & \mathrm{R} & \mathrm{Y} & \mathrm{L} & \mathrm{L} & \mathrm{R} & \mathrm{W} & \mathrm{Q} & \mathrm{M} & \mathrm{P} & \mathrm{L} & \mathrm{C} & \mathrm{S} & \mathrm{L}\end{array}$ & 74 \\
\hline \multirow[t]{2}{*}{421} & TGCTGACCTGCCTGGGCCTCAACGTCTTGTTCCTCACTTTGAATGAGGGTGCATGGTACT & \\
\hline & $\begin{array}{lllllllllllllll}\mathrm{L} & \mathrm{N} & \mathrm{V} & \mathrm{L} & \mathrm{F} & \mathrm{L} & \mathrm{T} & \mathrm{L} & \mathrm{N} & \mathrm{E} & \mathrm{G} & \mathrm{A} & \mathrm{W} & \mathrm{Y} & \mathrm{S}\end{array}$ & 94 \\
\hline \multirow[t]{2}{*}{481} & CAGTAGGTGCCCTGATGATTTCAGTGCCCGCCCTGCTGGGCTACCTTCAGGAGGTTTGCC & \\
\hline & $\begin{array}{llllllllllllllllllll}V & G & A & L & M & I & S & V & P & A & L & L & G & Y & L & Q & E & V & C & R\end{array}$ & 114 \\
\hline \multirow[t]{2}{*}{541} & GGGCACGGCTGCCTGATTCCGAGCTGATGCGGAGGAAGTATCATAGCGTGAGGCAGGAGG & \\
\hline & $\begin{array}{lllllllllllllllllll}\mathrm{A} & \mathrm{R} & \mathrm{L} & \mathrm{P} & \mathrm{D} & \mathrm{S} & \mathrm{E} & \mathrm{L} & \mathrm{M} & \mathrm{R} & \mathrm{R} & \mathrm{K} & \mathrm{Y} & \mathrm{H} & \mathrm{S} & \mathrm{V} & \mathrm{R} & \mathrm{Q} & \mathrm{E}\end{array}$ & 134 \\
\hline \multirow[t]{2}{*}{601} & ACCTGCAGAGAGGTCGCCTGTCTCGTCCCGAGGCCGTGGCTGAGGTGAAGAGCTTCTTGA & \\
\hline & $\begin{array}{llllllllllllllllllll}\mathrm{L} & \mathrm{Q} & \mathrm{R} & \mathrm{G} & \mathrm{R} & \mathrm{L} & \mathrm{S} & \mathrm{R} & \mathrm{P} & \mathrm{E} & \mathrm{A} & \mathrm{V} & \mathrm{A} & \mathrm{E} & \mathrm{V} & \mathrm{K} & \mathrm{S} & \mathrm{F} & \mathrm{L} & \mathrm{I}\end{array}$ & 154 \\
\hline \multirow[t]{2}{*}{661} & TCCAGCTGGAGGCCTTCCTGAGCCGCCTGTGCTGCACATGTGAAGCCGCCTACCGCGTGC & \\
\hline & $\begin{array}{llllllllllllllllllll}\mathrm{Q} & \mathrm{L} & \mathrm{E} & \mathrm{A} & \mathrm{F} & \mathrm{L} & \mathrm{S} & \mathrm{R} & \mathrm{L} & \mathrm{C} & \mathrm{C} & \mathrm{T} & \mathrm{C} & \mathrm{E} & \mathrm{A} & \mathrm{A} & \mathrm{Y} & \mathrm{R} & \mathrm{V} & \mathrm{L}\end{array}$ & 174 \\
\hline \multirow[t]{2}{*}{721} & TGCACTGGGAGAACCCCGTCGTGTCCTCACAGTTCTATGGGGCTCTTCTGGGCACAGTCT & \\
\hline & $\begin{array}{lllllllllllllllllll} & \text { W } & E & N & P & V & V & S & S & Q & F & Y & G & A & L & L & G & T & V\end{array}$ & 194 \\
\hline \multirow[t]{2}{*}{781} & GCATGCTGTATTTGCTGCCACTCTGCTGGGTTCTCACCCTTTTAAACAGCACGCTCTTTC & \\
\hline & $\begin{array}{llllllllllllllllllll}M & L & Y & L & L & P & L & C & W & V & L & T & L & L & N & S & T & L & F & L\end{array}$ & 214 \\
\hline \multirow[t]{2}{*}{841} & TGGGGAATGTGGAGTTCTTCCGAGTTGTGTCTGAGTACAGGGCATCTCTGCAGCAGAGGA & \\
\hline & $\begin{array}{lllllllllllllllllll}G & N & V & E & F & F & R & V & V & S & E & Y & R & A & S & L & Q & Q & R\end{array}$ & 234 \\
\hline \multirow[t]{2}{*}{901} & TGAACCCAAAGCAGGAAGAGCATGCCTTTGAGAGTCCTCCACCACCAGATGTTGGGGGGA & \\
\hline & $\begin{array}{llllllllllllllllllll}N & P & K & Q & E & E & H & A & F & E & \text { S } & P & P & P & P & D & V & G & G & K\end{array}$ & 254 \\
\hline \multirow[t]{2}{*}{961} & AGGATGGTCTGATGGACAGCACGCCTGCCCTCACACCCACGGAGGACCTCACACCGGGCA & \\
\hline & $\begin{array}{lllllllllllllllllll}\mathrm{D} & \mathrm{G} & \mathrm{L} & \mathrm{M} & \mathrm{D} & \mathrm{S} & \mathrm{T} & \mathrm{P} & \mathrm{A} & \mathrm{L} & \mathrm{T} & \mathrm{P} & \mathrm{T} & \mathrm{E} & \mathrm{D} & \mathrm{L} & \mathrm{T} & \mathrm{P} & \mathrm{G}\end{array}$ & 274 \\
\hline \multirow[t]{2}{*}{1021} & GCGTGGAGGAGGCTGAGGAGGCTGAGCCAGATGAAGAGTTTAAAGATGCGATTGAGGAGG & \\
\hline & $\begin{array}{lllllllllllllllllll}V & \mathrm{E} & \mathrm{E} & \mathrm{A} & \mathrm{E} & \mathrm{E} & \mathrm{A} & \mathrm{E} & \mathrm{P} & \mathrm{D} & \mathrm{E} & \mathrm{E} & \mathrm{F} & \mathrm{K} & \mathrm{D} & \mathrm{A} & \mathrm{I} & \mathrm{E} & \mathrm{E}\end{array}$ & 294 \\
\hline
\end{tabular}




\begin{tabular}{|c|c|c|}
\hline 1081 & ATGATGAGGGCGCCCCGTGCCCAGCAGAGGATGAGCTGGCCCTGCAGGACAACGGGTTCC & \\
\hline & $\begin{array}{lllll} & \mathrm{D} & \mathrm{E} & \mathrm{L} & \mathrm{A}\end{array}$ & 314 \\
\hline 1141 & TGAGCAAGAATGAGGTGCTGCGCAGCAAGGTGTCTCGGCTCACGGAGCGGCTCCGCAAGC & \\
\hline & $\begin{array}{llllllllllll}\mathrm{L} & \mathrm{R} & \mathrm{S} & \mathrm{K} & \mathrm{V} & \mathrm{S} & \mathrm{R} & \mathrm{L} & \mathrm{T} & \mathrm{E} & \mathrm{R} \\
\end{array}$ & 334 \\
\hline 1201 & GCTACCCCACCAACAACTTCGGGAACTGCACGGGCTGCTCGGCCACCTTCTCAGTGCTGA & \\
\hline & $\begin{array}{lllllllllllllll} & G & N & C & T & G & C & S & A & T & F & S & V & L & K\end{array}$ & 354 \\
\hline 1261 & AGAAGAGGCGGAGCTGCAGTAATTGTGGAAACAGCTTCTGCTCTCGATGCTGCTCCTTCA & \\
\hline & $\begin{array}{llllllllllllllllll}\mathrm{R} & \mathrm{S} & \mathrm{C} & \mathrm{S} & \mathrm{N} & \mathrm{C} & \mathrm{G} & \mathrm{N} & \mathrm{S} & \mathrm{F} & \mathrm{C} & \mathrm{S} & \mathrm{R} & \mathrm{C} & \mathrm{C} & \mathrm{S} & \mathrm{F} & \mathrm{K}\end{array}$ & 374 \\
\hline 1321 & AGGTGCCCAAGTCCTCCATGGGGGCCACAGCCCCTGAAGCCCAGAGGGAGACTGTGTTTG & \\
\hline & $\begin{array}{llllllllllllllll}K & \mathrm{~S} & \mathrm{~S} & \mathrm{M} & \mathrm{G} & \mathrm{A} & \mathrm{T} & \mathrm{A} & \mathrm{P} & \mathrm{E} & \mathrm{A} & \mathrm{Q} & \mathrm{R} & \mathrm{E} & \mathrm{T} & \mathrm{V}\end{array}$ & 394 \\
\hline 1381 & TGTGTGCCTCGTGTAACCAGACCTTGAGCAAGTGAGAAGAGAGGCCAGGGTCCAACCAGG & \\
\hline & $\begin{array}{lllllllllll}C & A & S & C & N & Q & T & L & S & K & *\end{array}$ & 411 \\
\hline 1441 & CACCCGTCCTTGGGACCAGCAGTAGACCCCCCACTCTCCCCACCCCTGGCCCACTGTGGT & \\
\hline 1501 & GTGTGCTGGGCAAATGTGGCCTGAATGCTAGGTAGGCTTCCCCTTCCTTCCTCACTCTCT & \\
\hline 1561 & CCAGCTGGATTCTGGAGCTGTTCTCCATCCATGAGAGTGGCTGGCAATGGCTGCTCTCAA & \\
\hline 1621 & TCCCTTGAGGGAGAAGAGCCCCTGGAGGGCCTGGCATGTTTGTCCTGCTCTGCCTGGGAC & \\
\hline 1681 & TGAGCGAGTGGACTTAGGGCTGGGCAGGCAGTAGCCACCAGAGGGCAGCAGCGAACTAGG & \\
\hline 1741 & CCAGGCCTGACTGGGGTCTGAAGATCAGGGTCAGTGTGGCTGTGCCTGGGAATTCCAGAC & \\
\hline 1801 & CTGAGGTTGGGAAAAGAGGTTTTTCTCCTGCAGGGTACTGGGCCAGGCCCTCAGCCTCAG & \\
\hline 1861 & AGAGCCTGCAGAAGGGCTTGGGAGTGCCACACCCCATCTCTGCTGATTGAATGTCCCTCC & \\
\hline 1921 & AGGCACCAGGATCTCATCATTTCCCCATCAGAGGGTGTGGCCAGGCCTAACAAGACCATG & \\
\hline 1981 & GGTGCTTCTAGAAACAGGGTTGAAGTTCCCAGATTCCCTGAGAGGAGAATGTGTATAGGA & \\
\hline 2041 & GGGTTTGGCTGAGTCCTTCAGCGTTAAGTGGAGGAAAGCTTGGGGAAGCCCCAATAGCTG & \\
\hline 2101 & GACAGACCTCGGCCTCCCCTCGAAGACACCTCAATTCACAGACTCTCAGCCCACACAATG & \\
\hline 2161 & CCCCAGTGTCCCCAGCTCCGCTGGAGCAGCTGCAGGGCACTTGGATCACAACTTCTGCAC & \\
\hline 2221 & CCTCTGTCCAGAGTCTAGGGCAGTCCTCCACTGGCCCAGCACTCCAGTTTCCTTTCCCTG & \\
\hline 2281 & CCTCTTGTCCAATGGAGTGGGAGGCCAGGTGAGTGGAGCAGAGGTCCTGAAGCCCTTGAC & \\
\hline 2341 & CCCTGGGGGCCTGGGTAGTGTAGGATCTCGCTGGGCTGGGTCCTGGATTCCAGGGCTATT & \\
\hline 2401 & CCCTGGAGGACAGTCTCAGTTATGGGATAAGGCCCCCTGGGGGTCTCCATTTCTTTCCAA & \\
\hline 2461 & CAGTTTCATGTTCACTACTGGACTCTTACGGGCTCAGTATCTCTCCCTTAGCCATGAGCT & \\
\hline 2521 & GGCTCAGGCATCCCTTCCCTTCCCTGGAGCTGCCCTGCCTTTCTCAAGTATTTATTTATT & \\
\hline 2581 & TATTGCATGGTTCCTGGGAACATGTGGCACAAGTAATGGGATGAGGAGGAATTGGGGGTG & \\
\hline 2641 & GGGGTCTTCTACCTAGGACTCTTCCCTGGAGTCATGGGCTGCCTGGGACCCAGGACCCAT & \\
\hline 2700 & GAGGGGGCTGAGAGGTTTCTACACTCGAGGAGCAGGGGTCCAGAGAGGCAGGCTGGGGAG & \\
\hline 2761 & GCAAGGGACCCATCCTAGGCCCGCTTTCTTGCCGAGCCAAGCAGCTTAGCTGGGGCTGTG & \\
\hline 2821 & CAGCCAGGGGCTTACCCAGGCCAGTGGAGGTGCCACAGCCCTGGGGAGCCAGACAGGCTT & \\
\hline 2881 & TGGTATCGTATCGCCTCTGTGTCCTTTTAAGAGAGGAGAGTTCAGTACCCCGTGCTTTCT & \\
\hline 2941 & TTACACTGGAGAGGAACTAAAAGGATCTCTGTGTCTATGGAGAATTGTCAATAAAAAGGC & \\
\hline 3001 & CTCAAGCTTC & \\
\hline
\end{tabular}




\subsubsection{Transcript Variante 3 (Genbanknummer: NM_144588)}

cDNA: $3031 \mathrm{bp}$

CDS: 1436 bp

AS: 411

\begin{tabular}{|c|c|c|}
\hline 1 & AGAGCGATTCGCGTCCCGGAAGCGGCGGTGGCGGCCGCGGCGTAGGCGGAGGAGATTTTC & \\
\hline 61 & $\begin{array}{l}\text { GGACCTGCGACTTCCGAACAACCCTGGCAGGAGGAGCGGCGTTCAGCCGGGGGAGGCCTG } \\
\end{array}$ & \\
\hline 121 & AAGAAACGCTCCGGGGCCCAGTGGCTCTACCCCTGCTCCTGCCCGACCCTGCCGCCTCCC & \\
\hline \multirow[t]{2}{*}{181} & TCACGGAGCCAGCGGCCGGGATGCAGACATCAGAACGTGAGGGGAGTGGGCCGGAGCTGA & \\
\hline & $\begin{array}{llllllllllllll}M & Q & \text { T } & \text { S } & \text { E } & \text { R } & \text { E } & G & \text { S } & \text { G } & \text { P } & \text { E } & \text { L } & \text { S }\end{array}$ & 14 \\
\hline \multirow[t]{2}{*}{241} & GCCCCAGCGTGATGCCCGAGGCTCCCCTGGAGTCTCCACCTTTTCCTACCAAGTCCCCAG & \\
\hline & $\begin{array}{llllllllllllllllllll}\mathrm{P} & \mathrm{S} & \mathrm{V} & \mathrm{M} & \mathrm{P} & \mathrm{E} & \mathrm{A} & \mathrm{P} & \mathrm{L} & \mathrm{E} & \mathrm{S} & \mathrm{P} & \mathrm{P} & \mathrm{F} & \mathrm{P} & \mathrm{T} & \mathrm{K} & \mathrm{S} & \mathrm{P} & \mathrm{A}\end{array}$ & 34 \\
\hline \multirow[t]{2}{*}{301} & CGTTTGACCTTTTCAACTTGGTTCTCTCCTACAAGAGGCTGGAGATCTACCTGGAACCCT & \\
\hline & $\begin{array}{llllllllllllllllll}\mathrm{L} & \mathrm{F} & \mathrm{N} & \mathrm{L} & \mathrm{V} & \mathrm{L} & \mathrm{S} & \mathrm{Y} & \mathrm{K} & \mathrm{R} & \mathrm{L} & \mathrm{E} & \mathrm{I} & \mathrm{Y} & \mathrm{L} & \mathrm{E} & \mathrm{P} & \mathrm{L}\end{array}$ & 54 \\
\hline \multirow[t]{2}{*}{361} & TGAAGGATGCAGGTGATGGTGTTCGATACTTGCTCAGGTGGCAGATGCCTTTGTGTTCCT & \\
\hline & $\begin{array}{llllllllllllllllllll}K & \mathrm{D} & \mathrm{A} & \mathrm{G} & \mathrm{D} & \mathrm{G} & \mathrm{V} & \mathrm{R} & \mathrm{Y} & \mathrm{L} & \mathrm{L} & \mathrm{R} & \mathrm{W} & \mathrm{Q} & \mathrm{M} & \mathrm{P} & \mathrm{L} & \mathrm{C} & \mathrm{S} & \mathrm{L}\end{array}$ & 74 \\
\hline \multirow[t]{2}{*}{421} & TGCTGACCTGCCTGGGCCTCAACGTCTTGTTCCTCACTTTGAATGAGGGTGCATGGTACT & \\
\hline & $\begin{array}{lllllllllllllll}\mathrm{L} & \mathrm{N} & \mathrm{V} & \mathrm{L} & \mathrm{F} & \mathrm{L} & \mathrm{T} & \mathrm{L} & \mathrm{N} & \mathrm{E} & \mathrm{G} & \mathrm{A} & \mathrm{W} & \mathrm{Y} & \mathrm{S}\end{array}$ & 94 \\
\hline \multirow[t]{2}{*}{481} & CAGTAGGTGCCCTGATGATTTCAGTGCCCGCCCTGCTGGGCTACCTTCAGGAGGTTTGCC & \\
\hline & $\begin{array}{llllllllllllllllllll}V & G & A & L & M & I & S & V & P & A & L & L & G & Y & L & Q & E & V & C & R\end{array}$ & 114 \\
\hline \multirow[t]{2}{*}{541} & GGGCACGGCTGCCTGATTCCGAGCTGATGCGGAGGAAGTATCATAGCGTGAGGCAGGAGG & \\
\hline & $\begin{array}{lllllllllllllllllll}\mathrm{A} & \mathrm{R} & \mathrm{L} & \mathrm{P} & \mathrm{D} & \mathrm{S} & \mathrm{E} & \mathrm{L} & \mathrm{M} & \mathrm{R} & \mathrm{R} & \mathrm{K} & \mathrm{Y} & \mathrm{H} & \mathrm{S} & \mathrm{V} & \mathrm{R} & \mathrm{Q} & \mathrm{E}\end{array}$ & 134 \\
\hline \multirow[t]{2}{*}{601} & ACCTGCAGAGAGGTCGCCTGTCTCGTCCCGAGGCCGTGGCTGAGGTGAAGAGCTTCTTGA & \\
\hline & $\begin{array}{llllllllllllllllllll}\mathrm{L} & \mathrm{Q} & \mathrm{R} & \mathrm{G} & \mathrm{R} & \mathrm{L} & \mathrm{S} & \mathrm{R} & \mathrm{P} & \mathrm{E} & \mathrm{A} & \mathrm{V} & \mathrm{A} & \mathrm{E} & \mathrm{V} & \mathrm{K} & \mathrm{S} & \mathrm{F} & \mathrm{L} & \mathrm{I}\end{array}$ & 154 \\
\hline \multirow[t]{2}{*}{661} & TCCAGCTGGAGGCCTTCCTGAGCCGCCTGTGCTGCACATGTGAAGCCGCCTACCGCGTGC & \\
\hline & $\begin{array}{llllllllllllllllllll}\mathrm{Q} & \mathrm{L} & \mathrm{E} & \mathrm{A} & \mathrm{F} & \mathrm{L} & \mathrm{S} & \mathrm{R} & \mathrm{L} & \mathrm{C} & \mathrm{C} & \mathrm{T} & \mathrm{C} & \mathrm{E} & \mathrm{A} & \mathrm{A} & \mathrm{Y} & \mathrm{R} & \mathrm{V} & \mathrm{L}\end{array}$ & 174 \\
\hline \multirow[t]{2}{*}{721} & TGCACTGGGAGAACCCCGTCGTGTCCTCACAGTTCTATGGGGCTCTTCTGGGCACAGTCT & \\
\hline & $\begin{array}{lllllllllllllllllll} & \text { W } & E & N & P & V & V & S & S & Q & F & Y & G & A & L & L & G & T & V\end{array}$ & 194 \\
\hline \multirow[t]{2}{*}{781} & GCATGCTGTATTTGCTGCCACTCTGCTGGGTTCTCACCCTTTTAAACAGCACGCTCTTTC & \\
\hline & $\begin{array}{llllllllllllllllllll}M & L & Y & L & L & P & L & C & W & V & L & T & L & L & N & S & T & L & F & L\end{array}$ & 214 \\
\hline \multirow[t]{2}{*}{841} & TGGGGAATGTGGAGTTCTTCCGAGTTGTGTCTGAGTACAGGGCATCTCTGCAGCAGAGGA & \\
\hline & $\begin{array}{lllllllllllllllllll}G & N & V & E & F & F & R & V & V & S & E & Y & R & A & S & L & Q & Q & R\end{array}$ & 234 \\
\hline \multirow[t]{2}{*}{901} & TGAACCCAAAGCAGGAAGAGCATGCCTTTGAGAGTCCTCCACCACCAGATGTTGGGGGGA & \\
\hline & $\begin{array}{llllllllllllllllllll}N & P & K & Q & E & E & H & A & F & E & \text { S } & P & P & P & P & D & V & G & G & K\end{array}$ & 254 \\
\hline \multirow[t]{2}{*}{961} & AGGATGGTCTGATGGACAGCACGCCTGCCCTCACACCCACGGAGGACCTCACACCGGGCA & \\
\hline & $\begin{array}{lllllllllllllllllll}\mathrm{D} & \mathrm{G} & \mathrm{L} & \mathrm{M} & \mathrm{D} & \mathrm{S} & \mathrm{T} & \mathrm{P} & \mathrm{A} & \mathrm{L} & \mathrm{T} & \mathrm{P} & \mathrm{T} & \mathrm{E} & \mathrm{D} & \mathrm{L} & \mathrm{T} & \mathrm{P} & \mathrm{G}\end{array}$ & 274 \\
\hline \multirow[t]{2}{*}{1021} & GCGTGGAGGAGGCTGAGGAGGCTGAGCCAGATGAAGAGTTTAAAGATGCGATTGAGGAGA & \\
\hline & $\begin{array}{lllllllllllllllllll}V & E & E & A & E & E & A & E & P & D & E & E & F & K & D & A & I & E & E\end{array}$ & 294 \\
\hline
\end{tabular}




\begin{tabular}{|c|c|c|}
\hline 1081 & $\begin{array}{l}\text { CCCACTTGGTGGTGCTGGAGGATGATGAGGGCGCCCCGTGCCCAGCAGAGGATGAGCTGG } \\
\end{array}$ & \\
\hline & $\begin{array}{lllllllllllll}L & E & D & D & E & G & A & P & C & P & A & E & D\end{array}$ & 314 \\
\hline 1141 & CCCTGCAGGACAACGGGTTCCTGAGCAAGAATGAGGTGCTGCGCAGCAAGGTGTCTCGGC & \\
\hline & $\begin{array}{lllllllllllllll}G & F & L & S & K & N & E & V & L & R & S & K & V & S & R\end{array}$ & 334 \\
\hline 1201 & $\begin{array}{l}\text { TCACGGAGCGGCTCCGCAAGCGCTACCCCACCAACAACTTCGGGAACTGCACGGGCTGCT } \\
\end{array}$ & \\
\hline & $\begin{array}{llllllllllllllllllll}T & \mathrm{E} & \mathrm{R} & \mathrm{L} & \mathrm{R} & \mathrm{K} & \mathrm{R} & \mathrm{Y} & \mathrm{P} & \mathrm{T} & \mathrm{N} & \mathrm{N} & \mathrm{F} & \mathrm{G} & \mathrm{N} & \mathrm{C} & \mathrm{T} & \mathrm{G} & \mathrm{C} & \mathrm{S}\end{array}$ & 354 \\
\hline 1261 & CGGCCACCTTCTCAGTGCTGAAGAAGAGGCGGAGCTGCAGTAATTGTGGAAACAGCTTCT & \\
\hline & $\begin{array}{llllllllllllllllllll}\mathrm{A} & \mathrm{T} & \mathrm{F} & \mathrm{S} & \mathrm{V} & \mathrm{L} & \mathrm{K} & \mathrm{K} & \mathrm{R} & \mathrm{R} & \mathrm{S} & \mathrm{C} & \mathrm{S} & \mathrm{N} & \mathrm{C} & \mathrm{G} & \mathrm{N} & \mathrm{S} & \mathrm{F} & \mathrm{C}\end{array}$ & 374 \\
\hline 1321 & GCTCTCGATGCTGCTCCTTCAAGGTGCCCAAGTCCTCCATGGGGGCCACAGCCCCTGAAG & \\
\hline & $\begin{array}{llllllllllllllllllll}S & R & C & C & S & F & K & V & P & K & S & S & M & G & A & T & A & P & E & A\end{array}$ & 394 \\
\hline 1381 & CCCAGAGGGAGACTGTGTTTGTGTGTGCCTCGTGTAACCAGACCTTGAGCAAGTGAGAAG & \\
\hline & $\begin{array}{lllllllllllllllll}Q & R & E & T & V & F & V & C & A & S & C & N & Q & T & L & S & K\end{array}$ & 411 \\
\hline 1441 & AGAGGCCAGGGTCCAACCAGGCACCCGTCCTTGGGACCAGCAGTAGACCCCCCACTCTCC & \\
\hline 1501 & CCACCCCTGGCCCACTGTGGTGTGTGCTGGGCAAATGTGGCCTGAATGCTAGGTAGGCTT & \\
\hline 1561 & ССССTTCCTTCCTCACTCTCTCCAGCTGGATTCTGGAGCTGTTCTCCATCCATGAGAGTG & \\
\hline 1621 & GCTGGCAATGGCTGCTCTCAATCCCTTGAGGGAGAAGAGCCCCTGGAGGGCCTGGCATGT & \\
\hline 1681 & TTGTCCTGCTCTGCCTGGGACTGAGCGAGTGGACTTAGGGCTGGGCAGGCAGTAGCCACC & \\
\hline 1741 & AGAGGGCAGCAGCGAACTAGGCCAGGCCTGACTGGGGTCTGAAGATCAGGGTCAGTGTGG & \\
\hline 1801 & CTGTGCCTGGGAATTCCAGACCTGAGGTTGGGAAAAGAGGTTTTTCTCCTGCAGGGTACT & \\
\hline 1861 & GGGCCAGGCCCTCAGCCTCAGAGAGCCTGCAGAAGGGCTTGGGAGTGCCACACCCCATCT & \\
\hline 1921 & CTGCTGATTGAATGTCCCTCCAGGCACCAGGATCTCATCATTTCCCCATCAGAGGGTGTG & \\
\hline 1981 & GCCAGGCCTAACAAGACCATGGGTGCTTCTAGAAACAGGGTTGAAGTTCCCAGATTCCCT & \\
\hline 2041 & GAGAGGAGAATGTGTATAGGAGGGTTTGGCTGAGTCCTTCAGCGTTAAGTGGAGGAAAGC & \\
\hline 2101 & TTGGGGAAGCCCCAATAGCTGGACAGACCTCGGCCTCCCCTCGAAGACACCTCAATTCAC & \\
\hline 2161 & AGACTCTCAGCCCACACAATGCCCCAGTGTCCCCAGCTCCGCTGGAGCAGCTGCAGGGCA & \\
\hline 2221 & CTTGGATCACAACTTCTGCACCCTCTGTCCAGAGTCTAGGGCAGTCCTCCACTGGCCCAG & \\
\hline 2281 & CACTCCAGTTTCCTTTCCCTGCCTCTTGTCCAATGGAGTGGGAGGCCAGGTGAGTGGAGC & \\
\hline 2341 & AGAGGTCCTGAAGCCCTTGACCCCTGGGGGCCTGGGTAGTGTAGGATCTCGCTGGGCTGG & \\
\hline 2401 & GTCCTGGATTCCAGGGCTATTCCCTGGAGGACAGTCTCAGTTATGGGATAAGGCCCCCTG & \\
\hline 2461 & GGGGTCTCCATTTCTTTCCAACAGTTTCATGTTCACTACTGGACTCTTACGGGCTCAGTA & \\
\hline 2521 & TCTCTCCCTTAGCCATGAGCTGGCTCAGGCATCCCTTCCCTTCCCTGGAGCTGCCCTGCC & \\
\hline 2581 & TTTCTCAAGTATTTATTTAATTATTGCATGGTTCCTGGGAACATGTGGCACAAGTAATGG & \\
\hline 2641 & GATGAGGAGGAATTGGGGGTGGGGGTCTTCTACCTAGGACTCTTCCCTGGAGTCATGGGC & \\
\hline 2700 & TGCCTGGGACCCAGGACCCATGAGGGGGCTGAGAGGTTTCTACACTCGAGGAGCAGGGGT & \\
\hline 2761 & CCAGAGAGGCAGGCTGGGGAGGCAAGGGACCCATCCTAGGCCCGCTTTCTTGCCGAGCCA & \\
\hline 2821 & AGCAGCTTAGCTGGGGCTGTGCAGCCAGGGGCTTACCCAGGCCAGTGGAGGTGCCACAGC & \\
\hline 2881 & CCTGGGGAGCCAGACAGGCTTTGGTATCGTATCGCCTCTGTGTCCTTTTAAGAGAGGAGA & \\
\hline 2941 & GTTCAGTACCCCGTGCTTTCTTTACACTGGAGAGGAACTAAAAGGATCTCTGTGTCTATG & \\
\hline 3001 & GAGAATTGTCAATAAAAAGGCCTCAAGCTTC & 3031 \\
\hline
\end{tabular}




\subsubsection{Transcript Variante 4 (Genbanknummer NM_001002261.2)}

cDNA: $3046 \mathrm{bp}$

CDS: $1451 \mathrm{bp}$

AS: 416

\begin{tabular}{|c|c|c|}
\hline 1 & AGAGCGATTCGCGTCCCGGAAGCGGCGGTGGCGGCCGCGGCGTAGGCGGAGGAGATTTTC & \\
\hline 61 & $\begin{array}{l}\text { GGACCTGCGACTTCCGAACAACCCTGGCAGGAGGAGCGGCGTTCAGCCGGGGGAGGCCTG } \\
\end{array}$ & \\
\hline 121 & AAGAAACGCTCCGGGGCCCAGTGGCTCTACCCCTGCTCCTGCCCGACCCTGCCGCCTCCC & \\
\hline \multirow{2}{*}{181} & TCACGGAGCCAGCGGCCGGGATGCAGACATCAGAACGTGAGGGGAGTGGGCCGGAGCTGA & \\
\hline & $\begin{array}{llllllllllllll}M & Q & T & S & E & R & E & G & S & G & P & E & L & S\end{array}$ & 14 \\
\hline \multirow[t]{2}{*}{241} & GCCCCAGCGTGATGCCCGAGGCTCCCCTGGAGTCTCCACCTTTTCCTACCAAGTCCCCAG & \\
\hline & $\begin{array}{llllllllllllllllllll}\mathrm{P} & \mathrm{S} & \mathrm{V} & \mathrm{M} & \mathrm{P} & \mathrm{E} & \mathrm{A} & \mathrm{P} & \mathrm{L} & \mathrm{E} & \mathrm{S} & \mathrm{P} & \mathrm{P} & \mathrm{F} & \mathrm{P} & \mathrm{T} & \mathrm{K} & \mathrm{S} & \mathrm{P} & \mathrm{A}\end{array}$ & 34 \\
\hline \multirow[t]{2}{*}{301} & CGTTTGACCTTTTCAACTTGGTTCTCTCCTACAAGAGGCTGGAGATCTACCTGGAACCCT & \\
\hline & $\begin{array}{llllllll}L & E & I & Y & L & E & P & L\end{array}$ & 54 \\
\hline \multirow[t]{2}{*}{361} & TGAAGGATGCAGGTGATGGTGTTCGATACTTGCTCAGGTGGCAGATGCCTTTGTGTTCCT & \\
\hline & $\begin{array}{llllllllllllllllllll}K & D & A & G & D & G & V & R & Y & L & L & R & W & Q & M & P & L & C & S & L\end{array}$ & 74 \\
\hline \multirow[t]{2}{*}{421} & TGCTGACCTGCCTGGGCCTCAACGTCTTGTTCCTCACTTTGAATGAGGGTGCATGGTACT & \\
\hline & $\begin{array}{llllllllllllllllllll}\mathrm{L} & \mathrm{T} & \mathrm{C} & \mathrm{L} & \mathrm{G} & \mathrm{L} & \mathrm{N} & \mathrm{V} & \mathrm{L} & \mathrm{F} & \mathrm{L} & \mathrm{T} & \mathrm{L} & \mathrm{N} & \mathrm{E} & \mathrm{G} & \mathrm{A} & \mathrm{W} & \mathrm{Y} & \mathrm{S}\end{array}$ & 94 \\
\hline \multirow[t]{2}{*}{481} & CAGTAGGTGCCCTGATGATTTCAGTGCCCGCCCTGCTGGGCTACCTTCAGGAGGTTTGCC & \\
\hline & $\begin{array}{llllllllllllllllllll}V & G & A & L & M & I & S & V & P & A & L & L & G & Y & L & Q & E & V & C & R\end{array}$ & 114 \\
\hline \multirow[t]{2}{*}{541} & GGGCACGGCTGCCTGATTCCGAGCTGATGCGGAGGAAGTATCATAGCGTGAGGCAGGAGG & \\
\hline & $\begin{array}{llllllllllllllllllll}\mathrm{A} & \mathrm{R} & \mathrm{L} & \mathrm{P} & \mathrm{D} & \mathrm{S} & \mathrm{E} & \mathrm{L} & \mathrm{M} & \mathrm{R} & \mathrm{R} & \mathrm{K} & \mathrm{Y} & \mathrm{H} & \mathrm{S} & \mathrm{V} & \mathrm{R} & \mathrm{Q} & \mathrm{E} & \mathrm{D}\end{array}$ & 134 \\
\hline \multirow[t]{2}{*}{601} & ACCTGCAGAGAGGTCGCCTGTCTCGTCCCGAGGCCGTGGCTGAGGTGAAGAGCTTCTTGA & \\
\hline & $\begin{array}{lllllllllllllllll}\mathrm{L} & \mathrm{Q} & \mathrm{R} & \mathrm{G} & \mathrm{R} & \mathrm{L} & \mathrm{S} & \mathrm{R} & \mathrm{P} & \mathrm{E} & \mathrm{A} & \mathrm{V} & \mathrm{A} & \mathrm{E} & \mathrm{V} & \mathrm{K} & \mathrm{S}\end{array}$ & 154 \\
\hline \multirow[t]{2}{*}{661} & TCCAGCTGGAGGCCTTCCTGAGCCGCCTGTGCTGCACATGTGAAGCCGCCTACCGCGTGC & \\
\hline & $\begin{array}{llllllllllllllllllll}\mathrm{Q} & \mathrm{L} & \mathrm{E} & \mathrm{A} & \mathrm{F} & \mathrm{L} & \mathrm{S} & \mathrm{R} & \mathrm{L} & \mathrm{C} & \mathrm{C} & \mathrm{T} & \mathrm{C} & \mathrm{E} & \mathrm{A} & \mathrm{A} & \mathrm{Y} & \mathrm{R} & \mathrm{V} & \mathrm{L}\end{array}$ & 174 \\
\hline \multirow[t]{2}{*}{721} & TGCACTGGGAGAACCCCGTCGTGTCCTCACAGTTCTATGGGGCTCTTCTGGGCACAGTCT & \\
\hline & $\begin{array}{lllllllllllllllllll} & W & E & N & P & V & V & S & S & Q & F & Y & G & A & L & L & G & T & V\end{array}$ & 194 \\
\hline \multirow[t]{2}{*}{781} & GCATGCTGTATTTGCTGCCACTCTGCTGGGTTCTCACCCTTTTAAACAGCACGCTCTTTC & \\
\hline & $\begin{array}{llllllllllllllllllll}M & \mathrm{~L} & \mathrm{Y} & \mathrm{L} & \mathrm{L} & \mathrm{P} & \mathrm{L} & \mathrm{C} & \mathrm{W} & \mathrm{V} & \mathrm{L} & \mathrm{T} & \mathrm{L} & \mathrm{L} & \mathrm{N} & \mathrm{S} & \mathrm{T} & \mathrm{L} & \mathrm{F} & \mathrm{L}\end{array}$ & 214 \\
\hline \multirow[t]{2}{*}{841} & TGGGGAATGTGGAGTTCTTCCGAGTTGTGTCTGAGTACAGGGCATCTCTGCAGCAGAGGA & \\
\hline & $\begin{array}{llllllllllllllllllll}G & N & V & E & F & F & R & V & V & S & E & Y & R & A & S & L & Q & Q & R & M\end{array}$ & 234 \\
\hline \multirow[t]{2}{*}{901} & TGAACCCAAAGCAGGAAGAGCATGCCTTTGAGAGTCCTCCACCACCAGATGTTGGGGGGA & \\
\hline & $\begin{array}{lllllllllllllllllll}P & K & Q & E & E & H & A & F & E & S & P & P & P & P & D & V & G & G & K\end{array}$ & 254 \\
\hline \multirow[t]{2}{*}{961} & AGGATGGTCTGATGGACAGCACGCCTGCCCTCACACCCACGGAGAGTCTCTCTTCCCAGG & \\
\hline & $\begin{array}{llllllllllllllllllll}\mathrm{D} & \mathrm{G} & \mathrm{L} & \mathrm{M} & \mathrm{D} & \mathrm{S} & \mathrm{T} & \mathrm{P} & \mathrm{A} & \mathrm{L} & \mathrm{T} & \mathrm{P} & \mathrm{T} & \mathrm{E} & \mathrm{S} & \mathrm{L} & \mathrm{S} & \mathrm{S} & \mathrm{Q} & \mathrm{D}\end{array}$ & 274 \\
\hline \multirow[t]{2}{*}{1021} & ACCTCACACCGGGCAGCGTGGAGGAGGCTGAGGAGGCTGAGCCAGATGAAGAGTTTAAAG & \\
\hline & $\begin{array}{llllllllllllllllllll}\mathrm{L} & \mathrm{T} & \mathrm{P} & \mathrm{G} & \mathrm{S} & \mathrm{V} & \mathrm{E} & \mathrm{E} & \mathrm{A} & \mathrm{E} & \mathrm{E} & \mathrm{A} & \mathrm{E} & \mathrm{P} & \mathrm{D} & \mathrm{E} & \mathrm{E} & \mathrm{F} & \mathrm{K} & \mathrm{D}\end{array}$ & 294 \\
\hline
\end{tabular}




\begin{tabular}{|c|c|c|}
\hline 1081 & TGCGATTGAGGAGACCCACTTGGTGGTGCTGGAGGATGATGAGGGCGCCCCGTGCCCAG & \\
\hline & $\begin{array}{llll}E & G & A & P\end{array}$ & 314 \\
\hline 1141 & CAGAGGATGAGCTGGCCCTGCAGGACAACGGGTTCCTGAGCAAGAATGAGGTGCTGCGCA & \\
\hline & $\begin{array}{llllllllllll}N & G & F & L & S & K & N & E & V & L & R & S\end{array}$ & 334 \\
\hline 1201 & GCAAGGTGTCTCGGCTCACGGAGCGGCTCCGCAAGCGCTACCCCACCAACAACTTCGGGA & \\
\hline & $\begin{array}{llllllllllllllllllll}K & \mathrm{~V} & \mathrm{~S} & \mathrm{R} & \mathrm{L} & \mathrm{T} & \mathrm{E} & \mathrm{R} & \mathrm{L} & \mathrm{R} & \mathrm{K} & \mathrm{R} & \mathrm{Y} & \mathrm{P} & \mathrm{T} & \mathrm{N} & \mathrm{N} & \mathrm{F} & \mathrm{G} & \mathrm{N}\end{array}$ & 354 \\
\hline 1261 & ACTGCACGGGCTGCTCGGCCACCTTCTCAGTGCTGAAGAAGAGGCGGAGCTGCAGTAATT & \\
\hline & $\begin{array}{llllllllllllllllll}G & C & S & A & T & F & S & V & L & K & K & R & R & S & C & S & N & C\end{array}$ & 374 \\
\hline 1321 & GTGGAAACAGCTTCTGCTCTCGATGCTGCTCCTTCAAGGTGCCCAAGTCCTCCATGGGGG & \\
\hline & $\begin{array}{llllllllllllllllllll}G & N & S & F & C & S & R & C & C & S & F & K & V & P & K & S & S & M & G & A\end{array}$ & 394 \\
\hline 1381 & CCACAGCCCCTGAAGCCCAGAGGGAGACTGTGTTTGTGTGTGCCTCGTGTAACCAGACCT & \\
\hline & $\begin{array}{lllllllllllllllllll}T & A & P & E & A & Q & R & E & T & V & F & V & C & A & S & C & N & Q & T\end{array}$ & 414 \\
\hline 1441 & TGAGCAAGTGAGAAGAGAGGCCAGGGTCCAACCAGGCACCCGTCCTTGGGACCAGCAGTA & \\
\hline & $\mathrm{K}$ & 416 \\
\hline 1501 & GACCCCCCACTCTCCCCACCCCTGGCCCACTGTGGTGTGTGCTGGGCAAATGTGGCCTGA & \\
\hline 1561 & ATGCTAGGTAGGCTTCCCCTTCCTTCCTCACTCTCTCCAGCTGGATTCTGGAGCTGTTCT & \\
\hline 1621 & CCATCCATGAGAGTGGCTGGCAATGGCTGCTCTCAATCCCTTGAGGGAGAAGAGCCCCTG & \\
\hline 1681 & GAGGGCCTGGCATGTTTGTCCTGCTCTGCCTGGGACTGAGCGAGTGGACTTAGGGCTGGG & \\
\hline 1741 & CAGGCAGTAGCCACCAGAGGGCAGCAGCGAACTAGGCCAGGCCTGACTGGGGTCTGAAGA & \\
\hline 1801 & TCAGGGTCAGTGTGGCTGTGCCTGGGAATTCCAGACCTGAGGTTGGGAAAAGAGGTTTTT & \\
\hline 1861 & CTCCTGCAGGGTACTGGGCCAGGCCCTCAGCCTCAGAGAGCCTGCAGAAGGGCTTGGGAG & \\
\hline 1921 & TGCCACACCCCATCTCTGCTGATTGAATGTCCCTCCAGGCACCAGGATCTCATCATTTCC & \\
\hline 1981 & CCATCAGAGGGTGTGGCCAGGCCTAACAAGACCATGGGTGCTTCTAGAAACAGGGTTGAA & \\
\hline 2041 & GTTCCCAGATTCCCTGAGAGGAGAATGTGTATAGGAGGGTTTGGCTGAGTCCTTCAGCGT & \\
\hline 2101 & TAAGTGGAGGAAAGCTTGGGGAAGCCCCAATAGCTGGACAGACCTCGGCCTCCCCTCGAA & \\
\hline 2161 & GACACCTCAATTCACAGACTCTCAGCCCACACAATGCCCCAGTGTCCCCAGCTCCGCTGG & \\
\hline 2221 & AGCAGCTGCAGGGCACTTGGATCACAACTTCTGCACCCTCTGTCCAGAGTCTAGGGCAGT & \\
\hline 2281 & CCTCCACTGGCCCAGCACTCCAGTTTCCTTTCCCTGCCTCTTGTCCAATGGAGTGGGAGG & \\
\hline 2341 & CCAGGTGAGTGGAGCAGAGGTCCTGAAGCCCTTGACCCCTGGGGGCCTGGGTAGTGTAGG & \\
\hline 2401 & ATCTCGCTGGGCTGGGTCCTGGATTCCAGGGCTATTCCCTGGAGGACAGTCTCAGTTATG & \\
\hline 2461 & GGATAAGGCCCCCTGGGGGTCTCCATTTCTTTCCAACAGTTTCATGTTCACTACTGGACT & \\
\hline 2521 & CTTACGGGCTCAGTATCTCTCCCTTAGCCATGAGCTGGCTCAGGCATCCCTTCCCTTCCC & \\
\hline 2581 & TGGAGCTGCCCTGCCTTTCTCAAGTATTTATTTATTTATTGCATGGTTCCTGGGAACATG & \\
\hline 2641 & TGGCACAAGTAATGGGATGAGGAGGAATTGGGGGTGGGGGTCTTCTACCTAGGACTCTTC & \\
\hline 2700 & CCTGGAGTCATGGGCTGCCTGGGACCCAGGACCCATGAGGGGGCTGAGAGGTTTCTACAC & \\
\hline 2761 & TCGAGGAGCAGGGGTCCAGAGAGGCAGGCTGGGGAGGCAAGGGACCCATCCTAGGCCCGC & \\
\hline 2821 & TTTCTTGCCGAGCCAAGCAGCTTAGCTGGGGCTGTGCAGCCAGGGGCTTACCCAGGCCAG & \\
\hline 2881 & TGGAGGTGCCACAGCCCTGGGGAGCCAGACAGGCTTTGGTATCGTATCGCCTCTGTGTCC & \\
\hline 2941 & TTTTAAGAGAGGAGAGTTCAGTACCCCGTGCTTTCTTTACACTGGAGAGGAACTAAAAGG & \\
\hline 3001 & ATCTCTGTGTCTATGGAGAATTGTCAATAAAAAGGCCTCAAGCTTC & \\
\hline
\end{tabular}




\section{2 cDNA, kodierende Sequenz und Aminosäuresequenz von zfyve27 (Genbanknummer NM_177319.2)}

cDNA: $5581 \mathrm{bp}$

CDS: 1043 bp

AS: 347

\begin{tabular}{|c|c|c|}
\hline & GGCAGACGGTTCCCGGGTGGACCTGCGACTTCGGAGCGTCGGTGGGAGGTGGCGTGGCGT & \\
\hline 61 & GGCGTGGGGTGGGGCGGGCCTGGCCTGAGGGACCGCTCCGGGGCTTGGTGGCССTTCTGT & \\
\hline 121 & ССCCCTGGCCGTTCCTGTCTCTTCCTTTCCTGGGACAGCGTCCGGAATGCAGACTTCGGA & \\
\hline 181 & TCGGGACCTGAGTGGGCCGGAGGCGAGCCCCAGCGGGATGCCTGAGGTTCTCTCTGAGTG & \\
\hline 241 & TCCACCTGCCCCTACCAAGTCAGCAGCGTTTGATCTCTTCAACCTGGTCCTGTCCTACAA & \\
\hline 301 & GAGGCTGGAGATCTACCTGGAACCCCTGAAGGATGCAGGGGACGGTGTTCGATACTTGCT & \\
\hline \multirow[t]{2}{*}{361} & AAGGTGGCAGATGCCTTTGTGTTCCTTGCTGACTTGCCTGGGCCTCAACATCTTGTTCCT & \\
\hline & $\begin{array}{lllllllllllllllll}\text { M } & \mathrm{P} & \mathrm{L} & \mathrm{C} & \mathrm{S} & \mathrm{L} & \mathrm{L} & \mathrm{T} & \mathrm{C} & \mathrm{L} & \mathrm{G} & \mathrm{L} & \mathrm{N} & \mathrm{I} & \mathrm{L} & \mathrm{F} & \mathrm{L} \\
\end{array}$ & 17 \\
\hline \multirow[t]{2}{*}{421} & CACTTTGAACGAGGGTGCGTGGTACTCCATGGGTGCCTTGATGATCTCGGTGCCTGCCCT & \\
\hline & $\begin{array}{llllllllllllllllllll}T & L & N & E & G & A & W & Y & S & M & G & A & L & M & I & S & V & P & A & L\end{array}$ & 37 \\
\hline \multirow[t]{2}{*}{481} & ACTGGGCTACCTTCAGGAGGTGTGCCGGGGACAGCTGCCAGAGTCGGAGCTGATGCGGAG & \\
\hline & $\begin{array}{llllllllll}Q & L & P & E & S & E & L & M & R & R\end{array}$ & 57 \\
\hline \multirow[t]{2}{*}{541} & GAAGTACCACAGCATAAGGCAGGAAGACCTGCAGAGAGTTCGCCTTTCCCGAGTGCACCT & \\
\hline & $\begin{array}{llllllllllllllllllll}K & \mathrm{Y} & \mathrm{H} & \mathrm{S} & \mathrm{I} & \mathrm{R} & \mathrm{Q} & \mathrm{E} & \mathrm{D} & \mathrm{L} & \mathrm{Q} & \mathrm{R} & \mathrm{V} & \mathrm{R} & \mathrm{L} & \mathrm{S} & \mathrm{R} & \mathrm{V} & \mathrm{H} & \mathrm{L}\end{array}$ & 77 \\
\hline \multirow[t]{2}{*}{601} & TTCCCGCCCTGAGGCTGTTGCTGAGGTGAAGAGCTTCTTGATCCAACTGGAAGCCTTCTT & \\
\hline & $\begin{array}{llllllllllllllllllll}S & R & P & E & A & V & A & E & V & K & S & F & L & I & Q & L & E & A & F & L\end{array}$ & 97 \\
\hline \multirow[t]{2}{*}{661} & GGCCCGCCTGTGCTATACCTGCGAGTCAGCCTACCGTGTACTTCACTGGGAGAACCCCGT & \\
\hline & $\begin{array}{lllllllllllllll}T & \mathrm{C} & \mathrm{E} & \mathrm{S} & \mathrm{A} & \mathrm{Y} & \mathrm{R} & \mathrm{V} & \mathrm{L} & \mathrm{H} & \mathrm{W} & \mathrm{E} & \mathrm{N} & \mathrm{P} & \mathrm{V}\end{array}$ & 117 \\
\hline \multirow[t]{2}{*}{721} & GGTGTCCTCACAGTTCTATGGCGCTCTTCTGGGCATGGTGTGCATGCTCTACCTGCTACC & \\
\hline & $\begin{array}{llllllllllllllllllll}V & S & S & Q & F & Y & G & A & L & L & G & M & V & C & M & L & Y & L & L & P\end{array}$ & 137 \\
\hline \multirow[t]{2}{*}{781} & GCTCTGCTGGGTCCTCGCCCTGTTAAATAGCACACTCTTCCTGGGAAATGGGGACTTCTT & \\
\hline & $\begin{array}{llllllllllllllllllll}\mathrm{L} & \mathrm{C} & \mathrm{W} & \mathrm{V} & \mathrm{L} & \mathrm{A} & \mathrm{L} & \mathrm{L} & \mathrm{N} & \mathrm{S} & \mathrm{T} & \mathrm{L} & \mathrm{F} & \mathrm{L} & \mathrm{G} & \mathrm{N} & \mathrm{G} & \mathrm{D} & \mathrm{F} & \mathrm{F}\end{array}$ & 157 \\
\hline \multirow[t]{2}{*}{841} & CCGAGTGGTGTGTGAGTACAGGGCCTGCCTGCAGCGGAGGATGAACCCCCGGCAGGAAGA & \\
\hline & $\begin{array}{llllllllllllllllllll}\mathrm{R} & \mathrm{V} & \mathrm{V} & \mathrm{C} & \mathrm{E} & \mathrm{Y} & \mathrm{R} & \mathrm{A} & \mathrm{C} & \mathrm{L} & \mathrm{Q} & \mathrm{R} & \mathrm{R} & \mathrm{M} & \mathrm{N} & \mathrm{P} & \mathrm{R} & \mathrm{Q} & \mathrm{E} & \mathrm{E}\end{array}$ & 177 \\
\hline \multirow[t]{2}{*}{901} & GTGTGCCTGTGAGAGCTCAGCACTGCAGGGGGCCGGAGGGAGGGGCCTGCTGGACAGCTC & \\
\hline & $\begin{array}{llllllllllllllllllll}C & A & C & E & S & S & A & L & Q & G & A & G & G & R & G & L & L & D & S & S\end{array}$ & 197 \\
\hline \multirow[t]{2}{*}{961} & GCCTGCCCCCACACCCACCGAGGACCTCACGCCAGGCAGTGTGGAGGAAGCTGAGGAGGC & \\
\hline & $\begin{array}{llllllllllllllllllll}\mathrm{P} & \mathrm{A} & \mathrm{P} & \mathrm{T} & \mathrm{P} & \mathrm{T} & \mathrm{E} & \mathrm{D} & \mathrm{L} & \mathrm{T} & \mathrm{P} & \mathrm{G} & \mathrm{S} & \mathrm{V} & \mathrm{E} & \mathrm{E} & \mathrm{A} & \mathrm{E} & \mathrm{E} & \mathrm{A}\end{array}$ & 217 \\
\hline \multirow[t]{2}{*}{1021} & TGAGCCAGATGAGGAGTTCAAAGATGCAATTGAGGAGACCCACCTGGTGGTGCTGGAGGA & \\
\hline & $\begin{array}{llllllllllllllllllll}\mathrm{E} & \mathrm{P} & \mathrm{D} & \mathrm{E} & \mathrm{E} & \mathrm{F} & \mathrm{K} & \mathrm{D} & \mathrm{A} & \mathrm{I} & \mathrm{E} & \mathrm{E} & \mathrm{T} & \mathrm{H} & \mathrm{L} & \mathrm{V} & \mathrm{V} & \mathrm{L} & \mathrm{E} & \mathrm{D}\end{array}$ & 237 \\
\hline \multirow[t]{2}{*}{1081} & TGAAGAGGGCACCCCGTGCCCAGCAGAGGATGAGCTGACCCTGCAGGACAATGGATTCCT & \\
\hline & $\begin{array}{llllllllllllllllllll} & E & G & T & P & C & P & A & E & D & E & L & T & L & Q & D & N & G & F & L\end{array}$ & 257 \\
\hline
\end{tabular}




\begin{tabular}{|c|c|c|}
\hline 1141 & CAGCAAGAATGAGGTGCTGCGCAGCAAGGTGTCCCGGCTTACAGAGCGGCTTCGCAAGCG & \\
\hline & $\begin{array}{llllllllllll}K & \mathrm{~V} & \mathrm{~S} & \mathrm{R} & \mathrm{L} & \mathrm{T} & \mathrm{E} & \mathrm{R} & \mathrm{L} & \mathrm{R} & \mathrm{K} & \mathrm{R} \\
\end{array}$ & 277 \\
\hline \multirow[t]{2}{*}{1201} & TTACCCAACCAATAACTTCGGGAATTGTGCAGGCTGTGCCGCTACGTTCTCCGTGCTGAA & \\
\hline & $\begin{array}{llllllllllllll}N & N & F & G & N & C & A & G & C & A & A & T & F & S\end{array}$ & 297 \\
\hline \multirow[t]{2}{*}{1261} & GAAGAGGCGGAGCTGCAGCAACTGTGGGAACAGCTTCTGCTCGCGGTGTTGCTCCTTCAA & \\
\hline & $\begin{array}{llllllllllllllllllll} & K & R & R & S & C & S & N & C & G & N & S & F & C & S & R & C & C & S & F\end{array}$ & 317 \\
\hline \multirow[t]{2}{*}{1321} & GGTGCCCAGGTCCTCTATGGGAGCCACAGCTCCTGAAGCCCAGAGAGAGACTGTGTGTGT & \\
\hline & $\begin{array}{lllllllllllllllllll}V & P & R & S & S & M & G & A & T & A & P & E & A & Q & R & E & T & V & C\end{array}$ & 337 \\
\hline \multirow[t]{2}{*}{1381} & GTGCGCCTCCTGCAATCAGACCCTGAGCAAATGAGAAGAGAAGCCAGGCTCCAACTGTCC & \\
\hline & $\begin{array}{llllllll}S & C & N & Q & T & L & S & K\end{array}$ & 347 \\
\hline 1441 & TGGGGCCAGCAGTGACCCTACTGTCCCAACTCTGGGCCTCTGAGGCCTGTGCTGGGCAAA & \\
\hline 1501 & CGTAGCCTGACAGCTAGGTCCTTCCTGCCCTTCCCCTGCTGCCTCCAGCTGGGCTGGTGT & \\
\hline 1561 & GCTCTAAGGCCCAGGGGGAGAGGAGCCCCTGGGGTCCCGGCTCTTGGTTCTGCTCTATCC & \\
\hline 1621 & TATACCCTGTTAACTCAGGGCTAGCGAGGGAGTGTCCACCAGAGGGCAGAATTGAGCACA & \\
\hline 1681 & GCCTGCTCTCATCTGGGCTCTGGTCGTCAAGGTCAGGCTGGCTAGACCTTAGGATCCAAG & \\
\hline 1741 & AGACTTGAGGTTGGAAAAGAGGTTCTTCCCTGTTGGGTACTTGTCAGTCTCTCAGCCCCA & \\
\hline 1801 & GAGAGCCTGCGAGGGGACTTAGAGCTCCATGGCCTGCCTTTGCCTTTTGAATAGCCTCAG & \\
\hline 1861 & GACTGGCGTTCCCAGGTGTCCCAAGGAGAGGGAAGGTGAGGGTGCTGCTCAAGTCCTTCA & \\
\hline 1921 & GTGTCAAGTGGATGGCAGGATGGGGAAGCTCTGCTTACAGAATCTTAACTCCCATGGTTC & \\
\hline 1981 & TCTGGTGTCCTCAGCCCTGCTGGGGTGGCTACAGGACCCTCACATCACTCTTCCATCCTG & \\
\hline 2041 & CTCTGAGTCTAGGGCACCCCACCTTTCTCCCACTGCCACATATCTCTAGCCCTTATCTCA & \\
\hline 2101 & TGGAACATGCGGCCAGGTGAGTGGAGCAGAGAGACTGCAAGCCTTTGAGGTCCAGGGACG & \\
\hline 2161 & TGTAGGACTGCCCGGATTTCAGGGCTGTTCCTGGAGTAGAGATAGCATTGTAGGATAGGG & \\
\hline 2221 & TCAGTCACATGGCCAGTTTTATGTTCCCTCTGACCTGCCAAGGGTGCTGTGCCTCTTCTT & \\
\hline 2281 & AAGCCATGAGCTGGCTCAGGCCCCTTCCCCTGGAGCTTTTTTCAGAGTATTTATTTATTTA & \\
\hline 2341 & TTTCATGGTTCCTGAGAGCACGCAGCACAGGGTAGGATGAAGAAGACAAGGGGCTTCTGC & \\
\hline 2401 & CTGAGACCCTTCTGCAGTCATGGACTGCCCTTGGAGCTGATCTTCAGGAACTGTTTCTGC & \\
\hline 2461 & TGCCCAGTCATGGGTGTGGTGCCCACACCTGAACCATTTGAGGTCCTCCTTGCTGATAGG & \\
\hline 2521 & CCACACACACACAGCAGTAGAGCACTGAGGGTTTGGCAGTGGGGACCAAGCAGGTGAGGT & \\
\hline 2581 & GTACTCCTTTGTCCTGGTGAGAGATGCTCACCTCTGCGTATTTATACTGTAGAGCAGTAG & \\
\hline 2641 & ACAGGAACGCTGTGGAGAATTGTCAATAAAAGGCCCCATGCTTATGGTTTTGTCAGGTCT & \\
\hline 2700 & CCTAGTGCTGTTCAGGTCTTTCATGTTGCCCAGGGTGGGCTGTAGGTGGGCTTTGCACAC & \\
\hline 2761 & CTCCTGTGGCAATTCGTGAGCCAGCCAGGCCCAGTGGAAAGCTGTGCCTTATCAACAGGA & \\
\hline 2821 & GGGGTGGGCTTTATCTTGTGACCAGACCCACGGTCTTGGATTGAGGTTGGGACCAGAACT & \\
\hline 2881 & TAACTATAAATAATGCAGGCTTCAGAATGGAAAGGTTTTAGCTAATCCTCTGGGAAAGAC & \\
\hline 2941 & AGAAAGGCCAGCGCTGCAGGAGGCTGAGAGCTGGTAAGCAGGTTTCTGGTGGGGTGAGGT & \\
\hline \multirow[t]{4}{*}{3001} & GCAAGTTGGCCCTGTGATCAGGCTAGGCTGGAGCTGGGCACTGCACACATTATGTTAGCG & \\
\hline & CTGGCACCAAGCTCATGAGGTAGGCTCTGTTTTCCACATGGTAAGGCCGGCAGTGCACAG & \\
\hline & CAGCAGCACTGTGAGCCAGCTCTGAGCTCAGCCCCACCTACCAAGGACCCATGTGCTATC & \\
\hline & ATCCTGTAGCCTTTAGAAAGAATGCACATCTGTCCTGTGTCCTTATAGCAAAAGCCACTG & \\
\hline
\end{tabular}




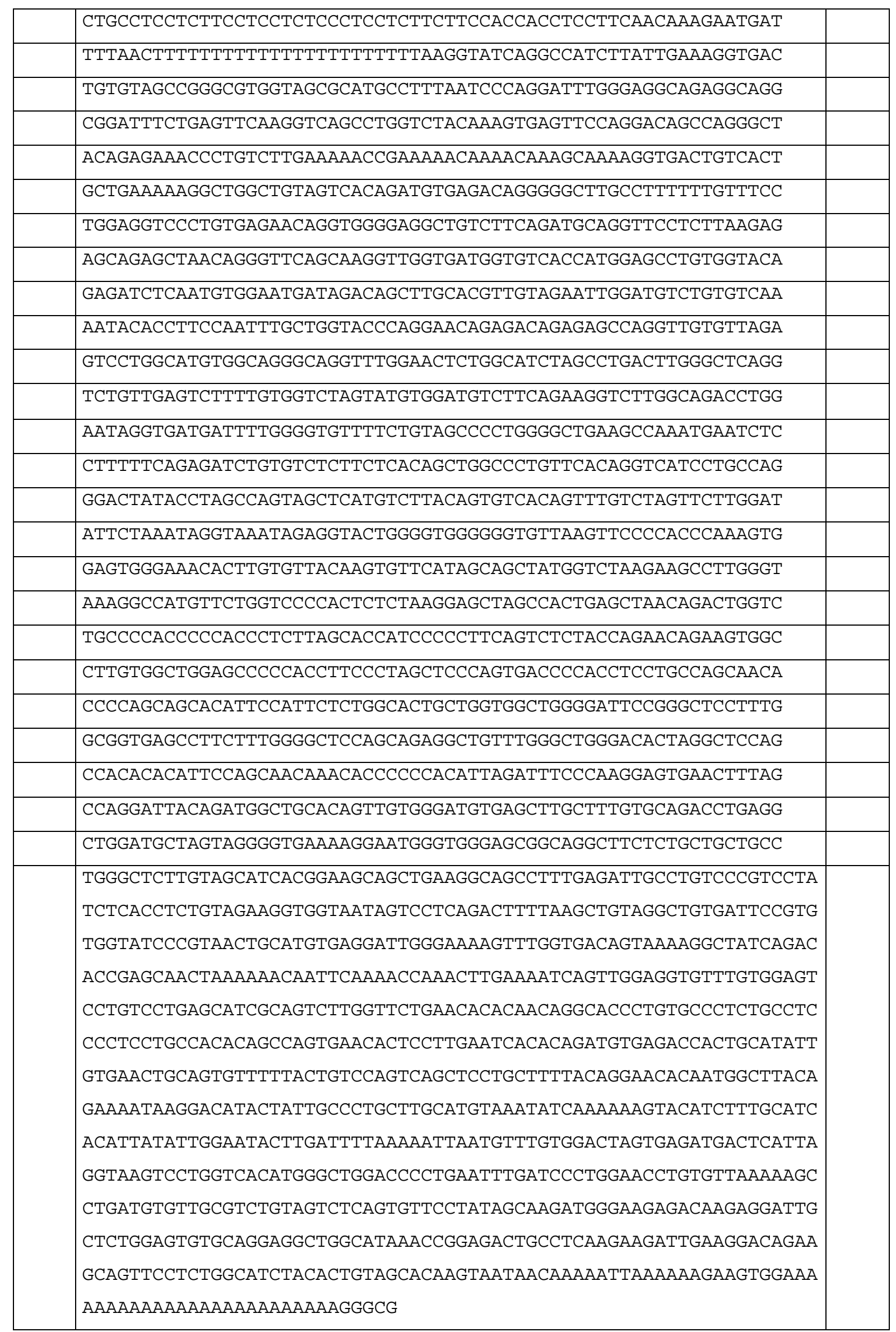


7.3 Ergebnisse der Real-Time-PCR-Messungen

\begin{tabular}{|c|c|c|c|c|c|c|}
\hline Exon & 13 & 14 & 15 & 16 & 17 & $17-x$ \\
\hline WT-1 A & 1,18 & 1,10 & 0,86 & 1,35 & 0,85 & 1,28 \\
\hline WT-1 B & 1,03 & 0,97 & 0,76 & 1,15 & 0,92 & 0,97 \\
\hline Mittelwert & 1,10 & 1,03 & 0,81 & 1,24 & 0,98 & 1,18 \\
\hline Abweichung & 0,07 & 0,06 & 0,04 & 0,10 & 0,06 & 0,10 \\
\hline WT-2 A & 0,93 & 0,88 & 0,93 & 0,95 & 0,90 & 0,90 \\
\hline WT-2 B & 0,98 & 0,95 & 1,02 & 1,04 & 0,95 & 0,95 \\
\hline Mittelwert & 0,95 & 0,91 & 0,97 & 0,99 & 0,92 & 0,92 \\
\hline Abweichung & 0,02 & 0,03 & 0,04 & 0,04 & 0,02 & 0,02 \\
\hline 19544 A & 2,10 & 2,37 & 1,00 & 0,54 & 1,41 & 1,25 \\
\hline 19544 B & 1,39 & 1,52 & 1,11 & 0,51 & 1,17 & 1,12 \\
\hline Mittelwert & 1,74 & 1,94 & 1,05 & 0,52 & 1,28 & 1,18 \\
\hline Abweichung & 0,35 & 0,42 & 0,05 & 0,01 & 0,11 & 0,06 \\
\hline 19545 A & 1,08 & 1,11 & 1,06 & 0,62 & 0,99 & 0,90 \\
\hline 19545 B & 0,94 & 1,22 & 1,14 & 0,59 & 1,05 & 0,95 \\
\hline Mittelwert & 1,01 & 1,16 & 1,09 & 0,60 & 1,01 & 0,92 \\
\hline Abweichung & 0,07 & 0,05 & 0,03 & 0,01 & 0,02 & 0,02 \\
\hline 19549 A & 0,76 & 0,94 & 1,18 & 0,52 & 1,11 & 1,01 \\
\hline 19549 B & 0,64 & 0,98 & 1,34 & 0,50 & 1,22 & 1,01 \\
\hline Mittelwert & 0,69 & 0,95 & 1,26 & 0,50 & 1,16 & 1,01 \\
\hline Abweichung & 0,06 & 0,02 & 0,07 & 0,01 & 0,05 & 0,01 \\
\hline 21962 A & 0,91 & 0,92 & 1,04 & 0,49 & 0,78 & 1,23 \\
\hline 21962 B & 1,43 & 1,02 & 1,01 & 0,46 & 0,98 & 0,91 \\
\hline Mittelwert & 1,16 & 0,97 & 1,02 & 0,47 & 0,88 & 1,07 \\
\hline Abweichung & 0,26 & 0,05 & 0,01 & 0,01 & 0,09 & 0,16 \\
\hline 21969 A & 0,92 & 1,47 & 1,10 & 0,39 & 0,75 & 1,16 \\
\hline 21969 B & 0,87 & 1,77 & 1,15 & 0,33 & 0,85 & 1,08 \\
\hline Mittelwert & 0,89 & 1,62 & 1,12 & 0,36 & 0,79 & 1,12 \\
\hline Abweichung & 0,02 & 0,14 & 0,02 & 0,03 & 0,05 & 0,04 \\
\hline 21940 A & 0,89 & 0,51 & 0,42 & 0,64 & 0,64 & 0,90 \\
\hline 21940 B & 1,08 & 0,60 & 0,51 & 0,51 & 0,76 & 1,22 \\
\hline Mittelwert & 0,98 & 0,55 & 0,46 & 0,572 & 0,70 & 1,05 \\
\hline Abweichung & 0,09 & 0,04 & 0,04 & 0,06 & 0,06 & 0,16 \\
\hline
\end{tabular}

